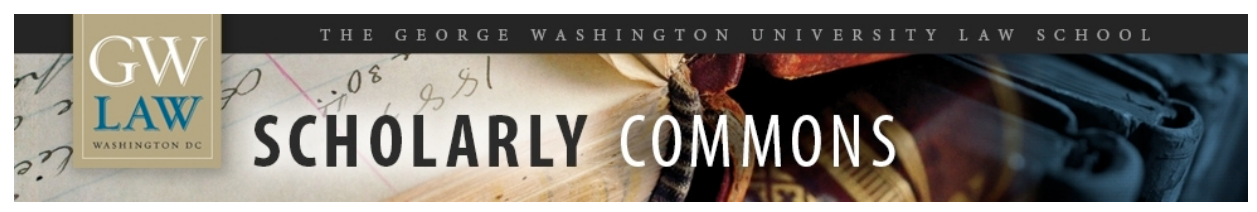

\title{
Transforming Document Recordation at the United States Copyright Office
}

\author{
Robert Brauneis \\ The George Washington University Law School, rbraun@law.gwu.edu
}

Follow this and additional works at: https://scholarship.law.gwu.edu/faculty_publications

Part of the Law Commons

\section{Recommended Citation}

Brauneis, Robert, Transforming Document Recordation at the United States Copyright Office (December 31, 2014). Available at SSRN: https://ssrn.com/abstract=2611481 or http://dx.doi.org/10.2139/ ssrn.2611481

This Article is brought to you for free and open access by the Faculty Scholarship at Scholarly Commons. It has been accepted for inclusion in GW Law Faculty Publications \& Other Works by an authorized administrator of Scholarly Commons. For more information, please contact spagel@law.gwu.edu. 
UNITED STATES COPYRIGHT OFFICE

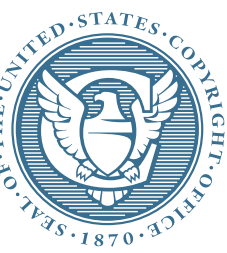

\section{TRANSFORMING DOCUMENT RECORDATION AT ThE UNITED States Copyright Office}


UNITED STATES COPYRIGHT OFFICE

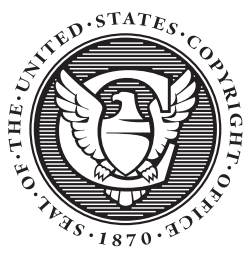

\section{TRANSFORMING DOCUMENT RECORDATION AT the United States Copyright Office}

A REPORT OF THE ABRAHAM L. KAMINSTEIN SCHOLAR IN RESIDENCE DECEMBER 2014 
December 31, 2014

Dear Register Pallante:

I am pleased to deliver a report on the recordation of documents pertaining to copyright, one of the crucial functions that the Copyright Office has performed for over a century. I prepared this report while serving as the Abraham L. Kaminstein Scholar in Residence at the Copyright Office, a position that I was honored and grateful to hold.

The report first presents information about the history and current state of copyright recordation, including the statutory framework; the recordation process; the document repository and catalog; fees, staffing, and processing times; and recordation statistics and case law under the Copyright Act of 1976. The report then recommends implementing an electronic recordation system. Based on comments to a Notice of Inquiry, three stakeholder roundtables, and additional research, the report makes nine specific recommendations about features and functions of such a system. It covers issues such as electronic signatures, certifications, remitter provision of and responsibility for cataloging information, the scope of Copyright Office screening of documents, the form of a digital document repository, redaction of documents, and additional legal incentives to record. The report also makes several additional recommendations about matters such as information gathering and handling in an electronic recordation system, interoperability and third-party enhanced services, Section 508 litigation notifications, and updating contact and "rights and permissions" information.

While the report contains many recommendations, its limitations should also be acknowledged. Implementing an electronic recordation system will require developing and satisfying business and technology requirements at an organizational level, and procuring necessary funding and human resources. Those are complicated and difficult tasks that the report does not aim to perform. In addition, specific resolutions of issues such as acceptable electronic signatures, certifications, and redaction of documents will be best accomplished through targeted rulemaking proceedings. Lastly, although the report concludes that its recommendations regarding an electronic recording system can be implemented under current statutory provisions, the report also recommends that the Copyright Act be amended to clear up possible confusion and fully empower the Copyright Office to create a 21 stCentury recording system.

Yours sincerely,

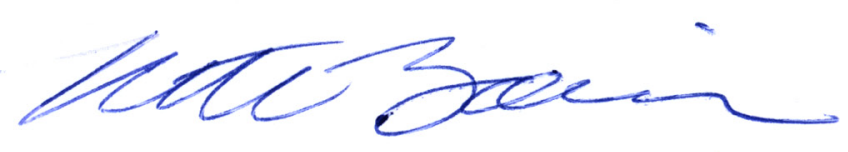

Robert Brauneis

Abraham L. Kaminstein Scholar in Residence 


\section{Transforming Document Recordation at the United States Copyright Office: \\ A Report to the Register of Copyrights}

\section{Robert Brauneis}

Abraham L. Kaminstein Scholar in Residence, U.S. Copyright Office Professor of Law, The George Washington University Law School

December 31, 2014 


\section{About the Abraham L. Kaminstein Scholar in Residence Program}

Through its Abraham L. Kaminstein Scholar in Residence Program, the Copyright Office brings leading academics with a demonstrated commitment to the study of copyright law and policy to the Copyright Office, at the invitation of the Register, to conduct research and/or work on mutually beneficial projects for a sustained period of time.

Abe Kaminstein served as the sixth Register of Copyrights, from 1960 to 1971. He was a leading force in adapting the copyright registration system to the public interest, and in laying the groundwork for the general revision of copyright law. 


\section{Table of Contents}

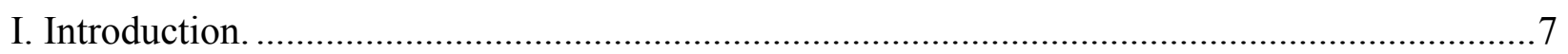

A. Process.

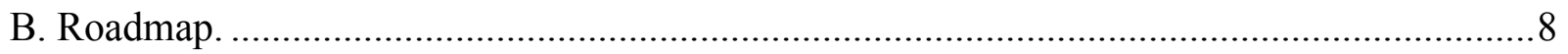

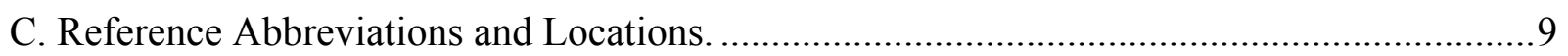

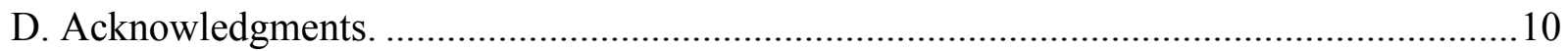

II. The Recording of Documents Pertaining to Copyright: History and Current State. .................11

A. The Statutory Framework: A Brief History and Outline...................................................11

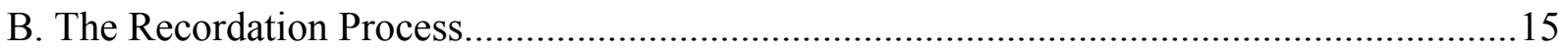

1. Receipt and Initial Processing: the In-Processing Section, Copyright Information

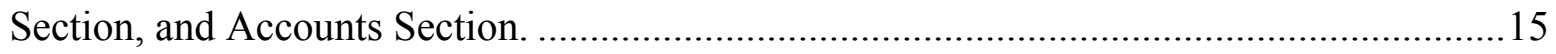

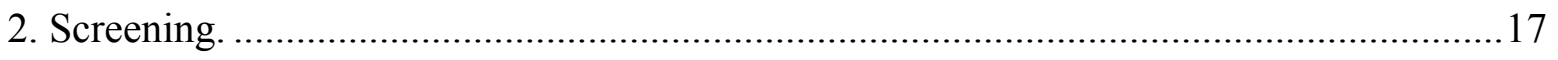

a. The Requirements for which Documents are Screened...............................................17

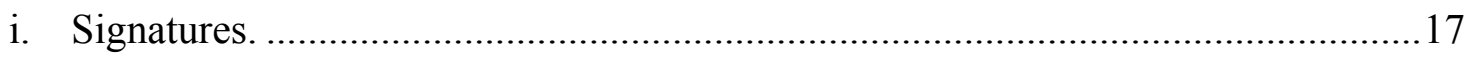

ii. "Pertaining to Copyright." ............................................................................. 18

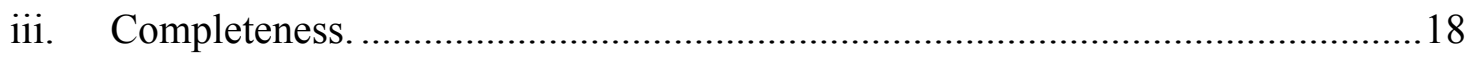

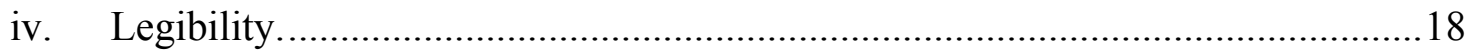

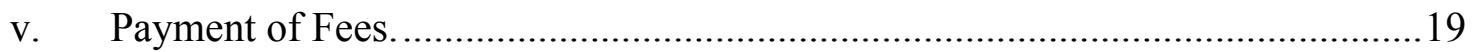

vi. Documents That Purport to Accomplish "Transfers of Copyright Ownership.".19

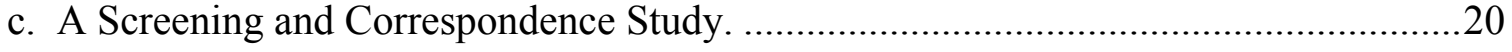

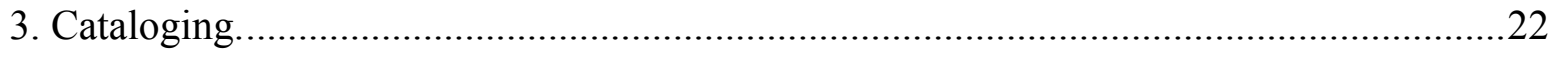

a. The Cataloging Process: Transcription, Description, Creation. ……………………....22

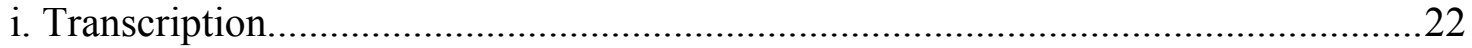

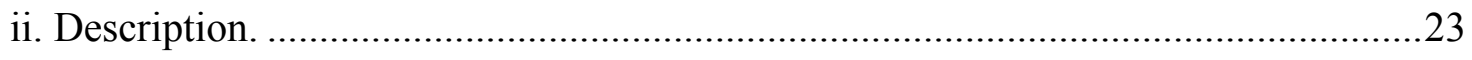

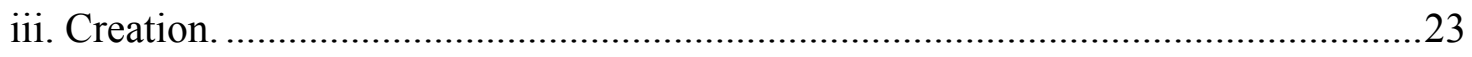

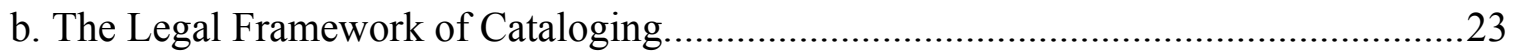

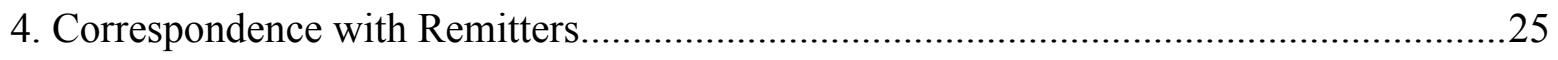

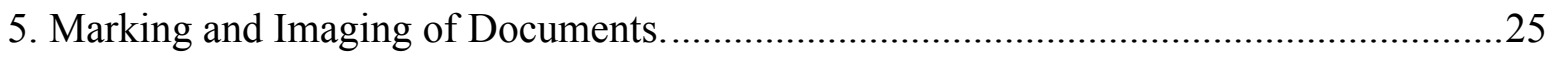

6. Creation of Recordation Certificate, and Sending of Certificate and Document. .............25

C. Recordation from a Searcher's Perspective: The Document Repository and Catalog. ........26

1. An Historical Review of Recorded Document Repositories and Finding Aids................26 


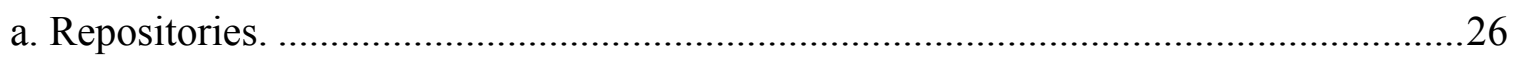

b. Finding Aids.

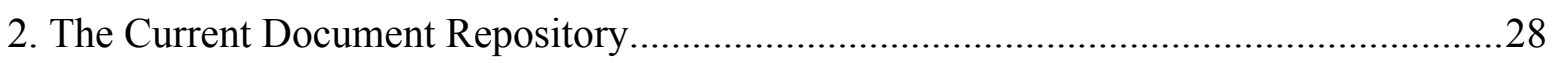

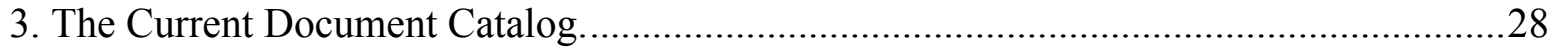

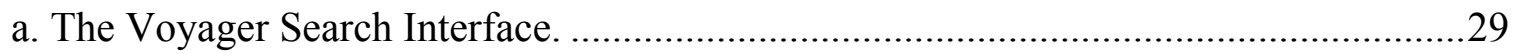

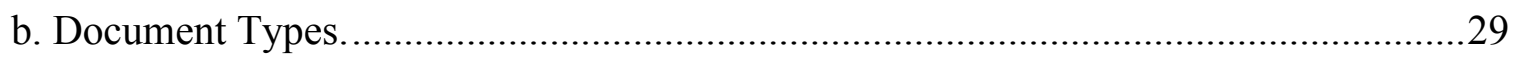

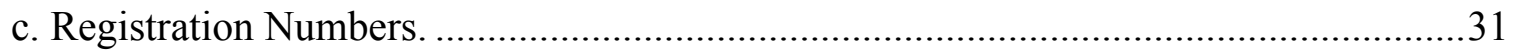

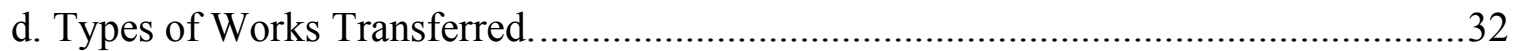

D. Recordation Fees, Staffing, and Processing Times. …………….........................................

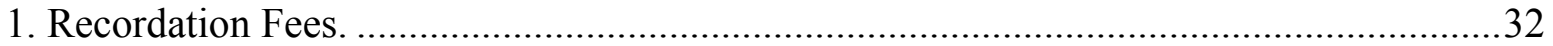

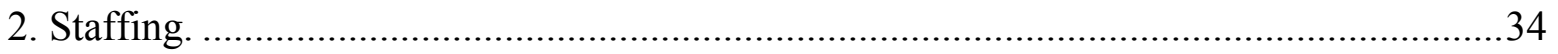

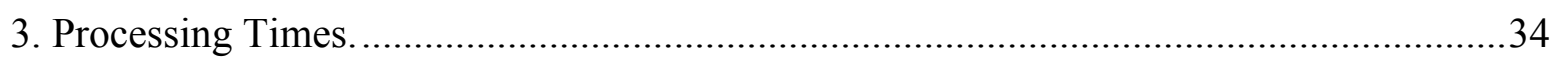

III. The Big Picture: Trends in Document Recordation and Case Law Since 1978 .......................36

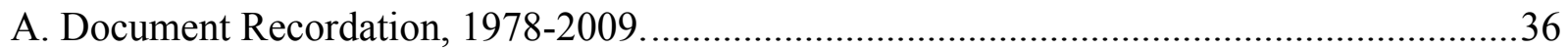

B. Case Law Regarding Recordation under the 1976 Act........................................................49

1. Straightforward Applications of Priority Rules. .............................................................50

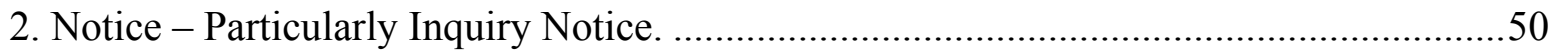

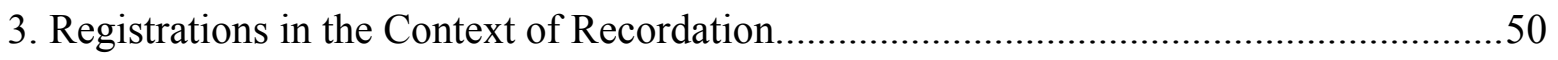

4. Bankruptcy and the Perfection of Secured Interests......................................................52

5. The Former $\S 205(\mathrm{~d})$ Requirement of Recording Before Filing a Lawsuit........................53

IV. An Electronic Recordation System: Detailed Evaluation and Recommendations....................54

A. Shortcomings of the Current Recordation System. ............................................................54

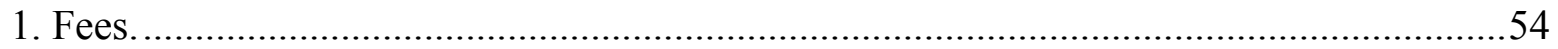

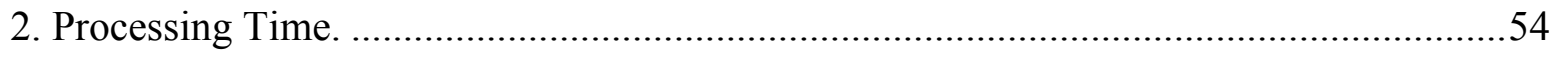

3. Difficulties and Mismatches with Business Practices in the Recording Process. ..............55

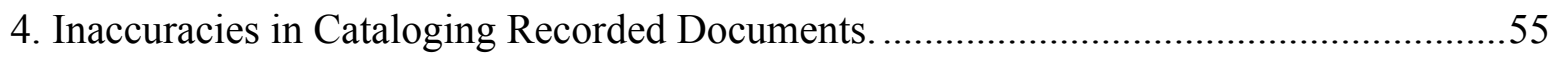

B. The Principal Features of an Electronic Recordation System. .............................................57

1. Optional Electronic Submission of Documents...........................................................59

2. Allowing Identifiable, Discrete Electronic Signatures on Recorded Documents. ............60

a. The Statutory Interpretation Issue: Can Electronic Signatures be "Actual Signatures"

Within the Meaning of $\$ 205(a)$ ? . 
b. Copyright Office Electronic Signature Regulations for Remitted Documents: "Discrete and Identifiable" Signatures. .65

3. Requiring Remitters to Submit Sworn, Electronically-Signed Certifications. .67

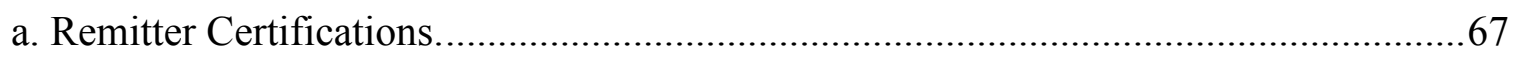

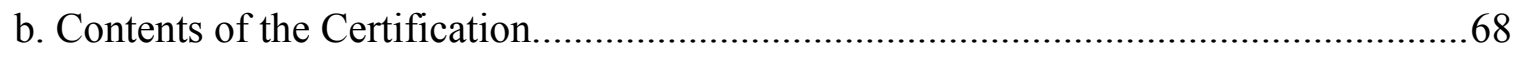

c. User Account Creation and Electronic Signatures on Certifications............................. 71

4. A Public Digital Document Repository: Preserving Documents in Portable Document Format and Making Them Available on the Internet. .....................................................72

a. The Advantages of a Digital Document Repository............................................. 73

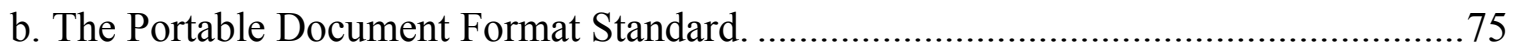

c. Making Documents Available on the Internet. .......................................................... 76

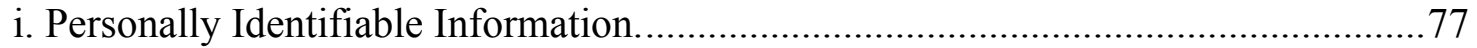

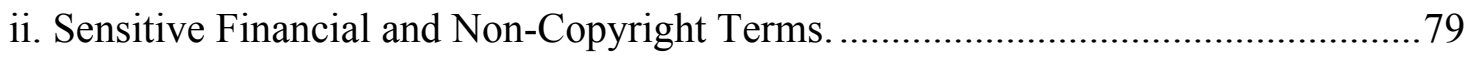

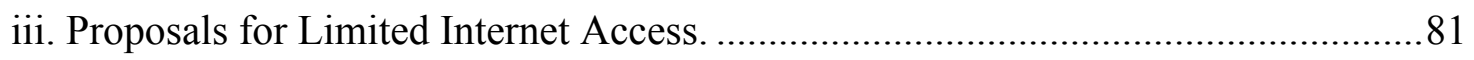

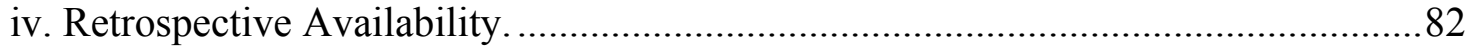

5. Copyright Office Screening of Documents and Remitter Certification of Document

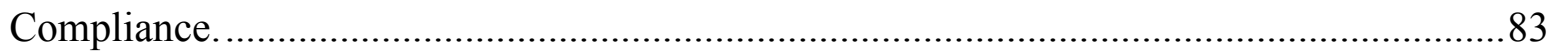

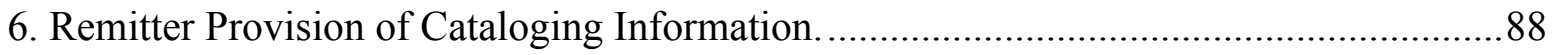

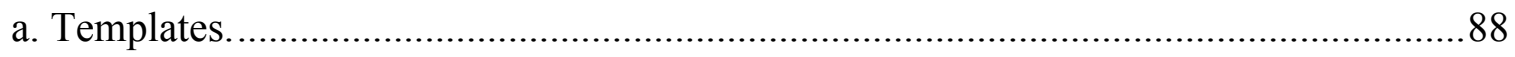

b. Bulk Submission of Titles, Registration Numbers and other Work Identifiers.............88

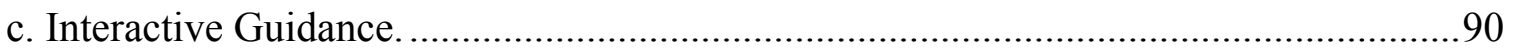

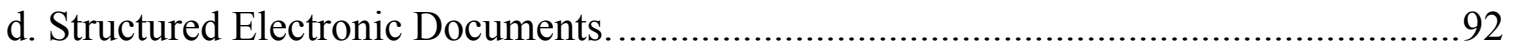

e. Legal Authority for Requiring Remitters to Provide Cataloging Information. ...........93

7. Remitter Responsibility for Constructive Notice that Requires Both Satisfactory

Documents and Accurate Cataloging.

a. The Legal Framework for Remitter Responsibility for Accurate Catalog Information

b. Copyright Office Regulations Regarding Recordation. .......................................... 108

8. Remitter Receipt of Recordation Certificate and Labeled Document in Electronic Form

a. The Statutory Framework. 109

9. New Legal Incentives to Record. 
C. Amending the Copyright Act....................................................................................112

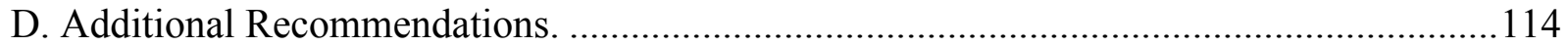

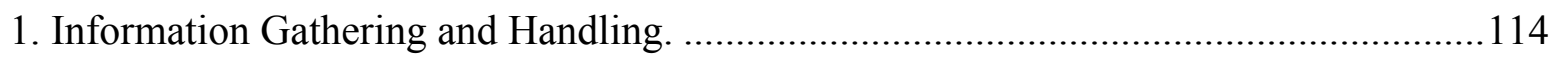

a. Data Collection in an Electronic Recordation System...............................................114

b. Data Format Consistency and Parsing.......................................................................115

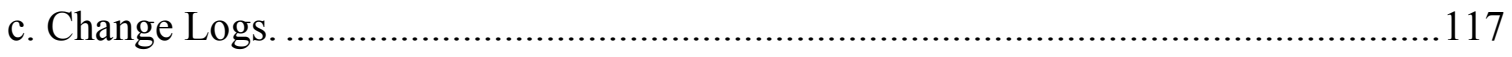

2. Registration Numbers in Recorded Document Records................................................117

3. Interoperability and Third-Party Enhanced Services.....................................................119

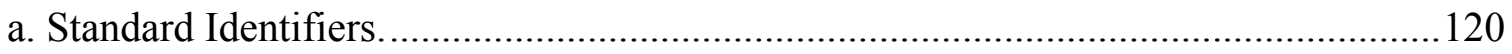

b. Application Programming Interfaces.........................................................................121

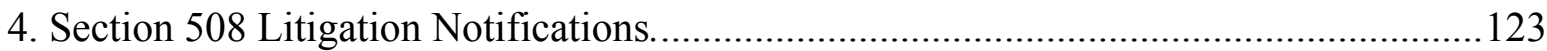

5. Updating Contact and "Rights and Permissions" Information: A New Model................127

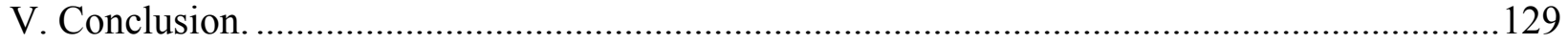

Appendix: An Overview of the Proposed Recordation Process .................................................130 


\section{Introduction.}

For over 140 years, federal law has provided for recording of documents pertaining to copyright in one central location, at the Copyright Office and, before the Copyright Office was created as a separate unit, at the Library of Congress. Over that time, the copyright recordation system has supported a market for interests in and use of works of authorship by lowering the cost of obtaining information about ownership and by reducing unavoidable risks that threaten ownership. It has done so in two related ways. First, it has created a central registry where documents that may or do affect ownership of interests in works under copyright can be placed on public record, and has indexed those documents so that they are easy to locate. Second, it has changed legal rules about notice and priority between conflicting transfers.

As technologies have changed over the past 140 years, so have the forms of the Copyright Office's recorded document repository, the indexes and finding aids to that repository, and the methods of accepting and processing documents for recordation. In 1870, the full texts of documents submitted for recordation were transcribed in handwriting into bound volumes, and index entries were made in handwriting in the front of each of the volumes. In 2014, digital images are made of remitted documents, and the document index is maintained in a computer database available on the Internet. In other respects, however, document recordation at the Copyright Office has changed little since 1870. As they were in 1870, documents are still only accepted on paper, and Copyright Office recordation specialists create the index of recorded documents by reading each document and manually transcribing selected information from it.

For some time, it has been generally accepted that the Copyright Office needs to further modernize its document recordation function by enabling electronic submission of documents for recordation and by taking advantage of other opportunities created by the Internet and other technological advances. However, the devil is in the details, and figuring out how to implement an electronic recordation system is a difficult project. This report attempts to make a contribution to that project. In doing so, it makes a number of assumptions.

First, the copyright recording system must generally cover its own costs. A recording system might well better achieve the goal of enhancing certainty in title to copyrights if the Copyright Office reduced the recording fee to zero, while at the same time spending large sums to catalog documents and make them available to the public. However, it is unlikely that copyright recordation will consistently receive large subsidies. Thus, it is assumed that recordation costs must generally be recovered through fees.

Second, generally speaking, the more documented copyright transactions that are recorded, the better. The great virtue of a central repository of transaction documents is that it lowers costs of obtaining ownership information by giving interested parties one place to search for many documents, and the more comprehensive that search can be, the better. However, there will almost certainly be some trade-off between the number of documents recorded and the quality of the repository. As recordation fees are lowered, the number of documents recorded 
will likely increase, but if fees must generally recover the costs of the recording process, then lower fees will result in fewer resources available to examine, catalog, and make available remitted documents. The key is to try to build a system that uses resources efficiently to produce a document repository and catalog that meets high standards of accuracy, convenience and currency, recognizing that perfection is not possible and that the pursuit of perfection could result in a less complete public record as high fees deter some recordation.

Third, the best use of new technologies may not be to preserve old processes while trying to make them less expensive or faster; rather, it may be to change processes substantially. For example, the interactive character of web-based entry forms - their ability to validate entries, present information back for review, and so on - may mean that entirely new forms of producing index entries are the most efficient.

\section{A. Process.}

With those principles in mind, production of this report began by presenting a series of proposals, and asking a series of questions, to the public generally and in particular to a diverse set of users of the recordation system. On January 15, 2014, the Register of Copyrights issued a Notice of Inquiry covering many of the topics in this report, ${ }^{1}$ which specified that comments were due by March 15, 2014. Twenty-four organizations and individuals submitted comments in response to the Notice of Inquiry. ${ }^{2}$ On February 4, 2014, the Register issued a Notice of Public Meetings, announcing meetings to be held at University of California, Los Angeles School of Law on March 25, 2014; at Stanford Law School on March 26, 2014; and at Columbia Law School on March 28, 2014. Forty-eight individuals participated in those roundtables, most of them as representatives of a variety of organizations. Transcripts of the roundtable proceedings were prepared and are available on the Copyright Office website. ${ }^{3}$ Through the Copyright Office's academic partnerships program, the Stanford Law and Policy Lab produced a lengthy, informative report on copyright recordation. ${ }^{4}$ As scores of citations below will demonstrate, the submitted comments, roundtable participants, and Stanford report provided many valuable insights that informed the analysis and recommendations in this report.

\section{B. Roadmap.}

Part II of this Report provides a detailed description of the current state of copyright recordation and the current recordation process, in order to help readers understand exactly

\footnotetext{
${ }^{1}$ See Library of Congress, Copyright Office, Notice of Inquiry: Strategic Plan for Recordation of Documents, 79 Fed. Reg. 2696 (Jan. 15, 2014).

${ }^{2}$ These comments are available at http://www.copyright.gov/docs/recordation/comments/79fr2696/.

${ }^{3}$ See Roundtables on Reengineering of Recordation of Documents, http://www.copyright.gov/docs/recordation/transcripts/.

${ }^{4}$ See Ariel Green, Sean Harb, Peter Holm, Kingdar Prussien, Kasonni Scales, Juliana Yee, Paul Goldstein, Luciana Herman, and Lisa Valenti-Jordan, Improving Copyright Information Management: An Investigation of Options and Areas for Further Research (2014) (hereinafter "Stanford Report"), available as an appendix to NOI Comments of Stanford Law School.
} 
where there may be opportunities for improvement. Part III continues with an overview of document recordation since 1978, the effective date of the Copyright Act of 1976. It includes a statistical review of recordation, and a review of published decisions in litigation over recordation disputes. Part IV begins by detailing the shortcomings of the current recordation system. It then moves to the heart of this report, which is a series of nine recommendations about the principal features of a proposed electronic recordation system, and analysis to back those recommendations. Although this report concludes that the recommendations it makes can be implemented under the current Copyright Act, Part IV also recommends that the Act be amended to clarify certain matters and provide broad support for a $21^{\text {st }}$-Century recordation system. Part IV concludes with a series of additional recommendations that are focused on information gathering, handling, and sharing in a database-focused world. Part V presents a very brief conclusion. An appendix provides a convenient look at the steps in the proposed electronic recordation process.

\section{Reference Abbreviations and Locations.}

Most sources cited in this document are given complete citations, but the documents that are available on the Recordation Reengineering web page on the U.S. Copyright Office web site, http://www.copyright.gov/docs/recordation/, are hereinafter cited in abbreviated form:

- The Notice of Inquiry issued on January 15, 2014, and available at http://www.copyright.gov/fedreg/2014/79fr2696.pdf, is cited as "Notice of Inquiry of Recordation Reengineering." Its full citation is "Library of Congress, Copyright Office, Notice of Inquiry: Strategic Plan for Recordation of Documents, 79 Fed. Reg. 2696 (Jan. 15, 2014)."

- Comments submitted in response to the Notice of Inquiry are cited as "NOI Comments of ," where "__ " is the name of the organization or person commenting. Those comments are all available on this page: http://www.copyright.gov/docs/recordation/comments/79fr2696/

- Transcripts of roundtable discussions on March 25, 26, and 28, 2014 are cited as "UCLA Roundtable Transcript," "Stanford Roundtable Transcript," and "Columbia Roundtable Transcript," respectively. They are available at http://www.copyright.gov/docs/recordation/transcripts/

The author of this report also constructed a database of all recorded documents represented in the electronic Copyright Office Catalog as of March 26, 2013. The database was constructed by extracting data from approximately 8.5 million document records in their native MARC (Machine Readable Access Catalog) format and importing that data into a FileMaker Pro database with a number of related tables. Some of the data from the database was exported into Microsoft Excel spreadsheets and PowerPivot workbooks for analysis. That analysis forms the basis of the charts presented in Part III.A. of this Report, and for all other statistics about recorded documents that are not supported by references to other specific sources. That database 
will be referred to as the Research Database. The Research Database, accompanying spreadsheets, and all e-mails referenced in this report are on file at the Copyright Office.

\section{Acknowledgments.}

This project could not have been completed without the generous assistance of many people. Joanna Corwin, Project Manager, Copyright Technology Office, scheduled the entire project, organized and participated in the roundtables, corresponded with commenters and roundtable participants, arranged for posting of the Notice of Inquiry comments, created an analytical index to the comments and the roundtable transcripts, read and commented on drafts of this report, and made many other contributions. Zarifa Madyun, Head of the Recordation Section, provided invaluable insights into recordation on many occasions, participated in the roundtables, co-drafted several memos, and read and commented on drafts of portions of this report. Alison Storella, my intern for summer 2014, provided in-depth research on many of the issues discussed in the report, and read and commented on drafts of the report. John Grbic and Christopher Ohslund, my interns for spring 2014, also provided important research on a number of issues discussed in the report, and provided invaluable assistance in building a database of recorded documents and undertaking the statistical analysis that is presented in Part III of the report. Jackie Cohen of the University of Michigan School of Information produced important analyses during a one-week "alternative spring break" that she spent at the Copyright Office.

Gail Sonnemann in the Copyright Technology Office answered dozens of questions about the Copyright Office Catalog in great detail, and provided documentation of Catalog structure and practices. Jacqueline Charlesworth, General Counsel, provided important legal insights about the Copyright Act and Copyright Office regulations; she and Sarang Damle, Special Advisor to the General Counsel, read a draft of this report and provided very thorough comments. Robert Kasunic, Associate Register of Copyright and Director of Registration Policy and Practice, and Elizabeth Scheffler, Director of Public Records and Repositories, also read a draft of this report and provided detailed comments. David Christopher, Chief Operating Officer, undertook the herculean task of obtaining complete Copyright Office Catalog data, and provided additional logistical support. Douglas Ament, Chief Information Officer, provided important information generated by the Copyright Technology Office during its technical upgrades project. William Roberts, Associate Register of Copyrights and Director of Public Information and Education, commented on memos and provided drafts of the Compendium of Copyright Office Practices section on recordation. Karyn Temple Claggett, Associate Register of Copyrights and Director of Policy and International Affairs, and Maria Strong and Catherine Rowland, Senior Counsels in the Office of Policy and International Affairs, provided me with a briefing on international issues. Chih-Lan Olson led sessions on transitioning to Siebel for back-end processing of recorded documents that led to important insights, and provided perceptive comments. Bill Collins provided important information about recordation workloads, and documentation of cataloging practices. Megan Rivet explained the mechanics of fee studies. John Riley helped with hiring and interviewing of interns. McKenna Rain helped locate books 
and other reference materials. Terri Vincent made all travel arrangements for the roundtables, and also organized all intern hiring. Renee Coe shared her knowledge of Section 508 notifications. Many others at the Copyright Office generously gave their time and insights.

Mark Polutta at the U.S. Patent and Trademark Office answered many questions about PTO recordation practice, and organized a meeting with several staff members. Neil Netanel and David Nimmer at UCLA, Paul Goldstein at Stanford, and June Besek and Jane Ginsburg at Columbia arranged to host and participated in roundtables. Paul Goldstein, Luciana Herman, and Lisa Valenti-Jordan at Stanford led a team of students - Ariel Green, Sean Harb, Peter Holm, Kingdar Prussien, Kasonni Scales, and Juliana Yee - at the Stanford Law and Policy Lab, which produced the very helpful report on copyright recordation mentioned above. ${ }^{5}$ All of those who provided comments to the Notice of Inquiry, and who participated in the roundtables at UCLA, Columbia, and Stanford, provided invaluable insights, as reflected in dozens of footnotes in this report. And just as the director traditionally gets the last of the opening credits in a motion picture, Maria A. Pallante, Register of Copyrights, was the ultimate driving force behind this entire project and has supported it in innumerable ways over the past year.

\section{The Recording of Documents Pertaining to Copyright: History and Current State.}

As a baseline against which to describe and assess potential changes in document recordation at the Copyright Office, it is helpful to review the current recordation system, as well as certain historical practices. This Part of this report reviews the recordation system from four perspectives. First, it briefly considers the history of the statutory framework, and provides an outline of the current framework. Second, it reviews the current process of recording, including screening and cataloging documents, correspondence with remitters, document marking and imaging, and sending the recordation certificates and document originals to remitters. Third, it reviews the repository of recorded documents, and the catalog of those documents, from the perspective of searchers. Fourth, it reviews the staffing of the Recordation Section, and changes in fees charged for recordation from 1978 to present.

\section{A. The Statutory Framework: A Brief History and Outline.}

A provision for recording assignments of copyright was first introduced into federal law on July 8, 1870, as part of the Act that consolidated responsibilities for administration of copyright, including registration and deposit, in the Library of Congress. Section 85 of that Act provided:

That copyrights shall be assignable in law, by any instrument of writing, and such assignment shall be recorded in the office of the Librarian of Congress within sixty

\footnotetext{
${ }^{5}$ See n. 4, supra.
} 
days after its execution, in default of which it shall be void as against any subsequent purchaser or mortgagee for a valuable consideration, without notice. ${ }^{6}$

Thus, the first recording provision was integrated with a statute of frauds provision requiring assignment in writing. It was what is known as a "notice" recording statute - it obligated a prior purchaser to record a document in order to prevail against a subsequent purchaser of a conflicting interest who did not have actual notice of the prior transaction, but it did not require the subsequent purchaser to take any action. Finally, it provided a 60 -day grace period; the prior purchaser would prevail so long as he or she recorded within 60 days of the document's execution.

Recording of documents next received attention in Section 44 of the Copyright Act of 1909, which provided:

That every assignment of copyright shall be recorded in the copyright office within three calendar months after its execution in the United States or within six calendar months after its execution without the limits of the United States, in default of which it shall be void as against any subsequent purchaser or mortgagee for a valuable consideration, without notice, whose assignment has been duly recorded. ${ }^{7}$

That language changed the recording regime in two respects. First, the last clause of $\S 44$ placed an obligation on the subsequent purchaser to record in order to prevail. Unlike the recording provision under the Copyright Act of 1976, the 1909 Act's provision does not specify that the subsequent purchaser's assignment must be first duly recorded, and thus does not cleanly add a "race" requirement and create a "race-notice" recording regime. ${ }^{8}$ The Nimmer treatise, followed by one District Court in dictum, suggests that the 1909 Act requires the subsequent purchaser to record its assignment within the provided grace period, as well as take without notice of the prior conveyance, to prevail over the prior purchaser. ${ }^{9}$ Second, the 1909 Act lengthened and split the grace period, to three months for documents executed in the United States and to six months for documents executed outside the United States. The 1909 Act provision was recodified in 1947 as $\S 30$ of the Copyright Act, ${ }^{10}$ but otherwise remained unchanged until the Copyright Act of 1976 became effective on January 1, 1978.

\footnotetext{
${ }^{6}$ An act to revise, consolidate, and amend the statutes relating to patents and copyrights, $41^{\text {st }}$ Cong., $2^{\text {nd }}$ Sess., Chap. 230, sec. 85, 16 Stat. 212 (July 8, 1870).

${ }^{7}$ Copyright Act of March 4, 1909, 35 Stat. 1075, § 44.

${ }^{8}$ See JOYCE PALOMAR, PATTON AND PALOMAR ON LAND TITLES $\S 8$ (3d ed. 2013) ("The distinction in the language of most 'race-notice' statutes compared to 'notice' statutes is that the latter speak of one recording - the first grantee must record to give constructive notice and preserve her right against subsequent grantees' claims, while 'race-notice' statutes speak of two recordings - the first grantee must record to give constructive notice and, if she does not, her right will not be preserved against a subsequent grantee who records his instrument before the first grantee records.").

${ }^{9}$ Melville B. Nimmer \& David Nimmer, Nimmer on Copyright § 10.07[A][1][b]; Peer Int'l Corp. v. Latin Am. Music Corp., 161 F. Supp. 2d 38, 48 (D.P.R. 2001).

${ }^{10}$ See Act of July 30, 1947, c. 391, 61 Stat. 660.
} 
The recording provisions of the Copyright Act of 1976, as amended, are somewhat more complicated. The principal section governing recording is $\S 205$. Its basic rule to resolve conflicts between grants of exclusive rights requires the subsequent purchaser both to purchase without actual or constructive notice of the prior transfer, and also to record before the prior purchaser records. ${ }^{11}$ Thus the 1976 Act, unlike the 1909 Act, creates a clear "race-notice" regime for conflicting grants of exclusive rights. The 1976 Act also maintains different grace periods for documents executed within and outside of the United States, while shortening those periods to one month and two months, respectively. ${ }^{12}$

However, § 205 also explicitly provides a special rule for resolving conflicts between grants of exclusive rights and grants of non-exclusive rights, ${ }^{13}$ and it sets out in some detail the conditions under which recording a document will provide constructive notice. ${ }^{14}$ Those conditions are prerequisites for gaining priority in case of a conflict between two transfers; ${ }^{15}$ by judicial interpretation, they are also conditions for perfecting a security interest in a registered work. ${ }^{16}$ Before 1989, $§ 205$ required that all who owned copyright in a work by virtue of a transfer needed to record that transfer before suing for infringement of that work. ${ }^{17}$ That requirement was abolished by the Berne Convention Implementation Act, ${ }^{18}$ although scholars have questioned whether such a requirement would actually have violated the Berne Convention. $^{19}$

Section 205 permits recording of "[a]ny transfer of ownership or other document pertaining to a copyright," and hence is the principal, broad provision concerning recording of documents in the Copyright Act; the vast majority of documents recorded at the Copyright Office are recorded under this provision. However, there are a number of other more specific provisions in Title 17 concerning the recording or filing of documents at the Copyright Office. Those which concern documents that are cataloged in the electronic Copyright Office Catalog ${ }^{20}$ and that fall within the scope of this report ${ }^{21}$ include:

\footnotetext{
${ }^{11}$ See 17 U.S.C. $\S 205(\mathrm{~d})$.

${ }^{12}$ See id.

${ }^{13}$ See 17 U.S.C. $\S 205($ e).

${ }^{14}$ See 17 U.S.C. $\$ 205($ c). This section is further discussed below on p. 96.

${ }^{15}$ See 17 U.S.C. $\$ 205(\mathrm{~d})$.

${ }^{16}$ See, e.g., In re World Auxiliary Power Co., 303 F.3d 1120 (9th Cir. 2002).

${ }^{17}$ See 17 U.S.C. $\$ 205(d)$ (1978).

${ }^{18}$ See P.L. 100-568, 102 Stat. 2853, § 5 (Oct. 31, 1988).

${ }^{19}$ See, e.g., Jane C. Ginsburg, "With Untired Spirits and Formal Constancy" Berne Compatibility of Formal Declaratory Measures to Enhance Copyright Title-Searching, 28 Berkeley Tech L.J. 1583, 1611-1612 (2013). For further discussion of incentives to record, see infra p. 109.

${ }^{20}$ The Copyright Office Catalog, which catalogs copyright registrations as well as recorded documents, is available online at cocatalog.loc.gov. Although the Copyright Office maintained a catalog of registrations and recorded documents in paper form before 1978, which is of course still available, most references in this report to the Copyright Office Catalog will be to the catalog maintained in electronic form since 1978.

${ }^{21}$ Documents that are to be filed or recorded at the Copyright Office but are not cataloged in the Copyright Office Catalog and do not fall within the scope of this report include designations of agents of online service providers to receive notifications of claimed infringement, see 17 U.S.C. $\S 512(\mathrm{c})(2)$; and various documents that are handled by
} 
- $\S 104 \mathrm{~A}(\mathrm{e})(1)$, which provides for the filing of notices of intent to enforce a restored copyright; ${ }^{22}$

- $\S 108(\mathrm{~h})(2)(\mathrm{C})$, which provides for the filing of notices of normal commercial exploitation or activity at a reasonable price, ${ }^{23}$ although it appears that none of these has ever been filed;

- $\S 113(\mathrm{~d})(3)$, which provides for the filing of artist's statements and building owner's statements relating to qualifying "works of visual art," and none of the latter can be found in a search of the Copyright Office Catalog; ${ }^{25}$

- $\S 302(\mathrm{c})$, which provides for the recording of statements concerning the identity of the author of an anonymous or pseudonymous work ${ }^{26}$

- $\S 302(d)$, which provides for the recording of statements that the author of a work died on a particular date, or was still alive on a particular date, ${ }^{27}$

- $\S \S 203(a)(4)(A), 304(c)(4)(a)$, and 304(d)(1), which provide for the recording of copies of notices of terminations of transfer, ${ }^{28}$

- $\S 508$, which requires clerks of federal courts to send to the Copyright Office notifications of filing and determination of legal actions taken under title $17 ;^{29}$

- $\S 903(\mathrm{c})$, which provides for the recording of documents pertaining to mask works; ${ }^{30}$

- $\S 1320(\mathrm{~d})$, which provides for the recording of assignments, grants, conveyances, and mortgages of hull designs; ${ }^{31}$ and

- $\S 805$ of the Computer Software Rental Amendments Act of $1990,{ }^{32}$ which provides for the recording of documents pertaining to licensing terms of computer shareware, although a search of the Copyright Office Catalog located at most one of these. ${ }^{33}$

\footnotetext{
the Licensing Division, including contracts entered into by cable systems located outside of the 48 contiguous states, see 17 U.S.C. § 111(e); statements of account for cable systems, see 17 U.S.C. § 111(d), satellite carriers, see 17 U.S.C. § 119(b), and digital audio recording devices and media, see 17 U.S.C. § 1003(c); notices of intention to obtain a compulsory mechanical license, see 17 U.S.C. § 115(b); and certain agreements between public broadcasting entities and copyright owners, see 17 U.S.C. $\S 113$.

${ }^{22}$ See 17 U.S.C. $\$ 104 \mathrm{~A}(\mathrm{e})(1)$. This provision resulted in many documents being filed at the Copyright Office in 1996 and 1997, but currently is dormant, because no foreign country has recently become a country newly eligible for restoration. Another provision that is now inactive is Section 334 of the North American Free Trade Agreement Implementation Act of December 8, 1993, P.L. 103-182, which provided that copyright would be restored in any Mexican and Canadian motion picture that lost protection because it was published in the U.S. without notice between January 1, 1978 and March 1, 1989, on the condition that the owner of copyright in that motion picture file a notice of intent to restore within one year after the effective date of the Act, which was January 1, 1994.

${ }^{23}$ See 17 U.S.C. $\S 108(\mathrm{~h})(2)(\mathrm{C})$.

${ }^{24}$ See 17 U.S.C. $\$ 113(\mathrm{~d})(3)$.

${ }^{25}$ The artist's statements located in a search of the Catalog bear the document numbers of V3508D499, V3609D703, V3490D631, and V3490D632.

${ }^{26}$ See 17 U.S.C. $\$ 302(\mathrm{c})$.

${ }^{27}$ See 17 U.S.C. $\$ 302(\mathrm{~d})$.

${ }^{28}$ See 17 U.S.C. $\S 203(a)(4)(A) ; 17$ U.S.C. $\S 304(c)(4)(a) ; 17$ U.S.C. $\S 304(d)(1)$.

${ }^{29}$ See 17 U.S.C. $\$ 508$.

${ }^{30}$ See 17 U.S.C. $\$ 903(c)$.

${ }^{31}$ See 17 U.S.C. $\$ 1320(\mathrm{~d})$.

${ }^{32}$ P.L. 101-650, 104 Stat. 5089 (1990).
} 
Some of these more specific statutory provisions are implemented by regulations that merely incorporate by reference the regulations promulgated under $\S 205,{ }^{34}$ and thus an amendment to the $\S 205$ regulations would effectively change recording procedures under those provisions as well. That is true of the regulations implementing $\S 903(\mathrm{c})$, concerning mask works, ${ }^{35}$ and $\S$ 1320(d), concerning hull designs. ${ }^{36}$ For other provisions, such as $\S \S 302(\mathrm{c})$ and $302(\mathrm{~d})$, the Office has never promulgated regulations. ${ }^{37}$ However, some of these provisions are implemented through their own promulgated regulations, separate from the regulations promulgated under $\S 205$. This is true most prominently of the provisions respecting notices of terminations of transfer, the regulations for which contain their own formal requirements, including signature requirements. ${ }^{38}$ Thus, if an electronic recordation system were to be designed to accommodate a wide variety of documents, necessitating changes in signature requirements, care would need to be taken to amend all of the relevant regulatory provisions concerning signatures.

\section{B. The Recordation Process.}

For purposes of this description, the process of recording a document has been divided into six stages: receipt and initial processing; screening; cataloging; correspondence with remitters; marking and imaging of documents; and creation of the recordation certificate and sending of the certificate and document. All but the first stage of processing are performed by the Recordation Section.

\section{Receipt and Initial Processing: the In-Processing Section, Copyright Information Section, and Accounts Section.}

Documents can currently be remitted for recordation in two ways. Most documents are sent in the mail, and are received by the In-Processing Section. That Section opens and sorts all incoming mail. The Copyright Office has issued a form cover sheet for recorded documents. It is not required, and no preferential treatment is given when remitters complete it and send it in with

\footnotetext{
${ }^{33}$ That one document was accepted as a copyright registration, TXu000693445, but the Catalog record states that the "claim is limited to text of shareware statement."

${ }^{34}$ The regulations implementing $\S 205$ are to be found at 37 C.F.R. $\S 201.4$.

${ }^{35}$ See 37 C.F.R. § 211.2 .

${ }^{36}$ See 37 C.F.R. $\S 212.6$.

${ }^{37}$ In August 1979, the Copyright Office published in the Federal Register a Proposed Rule under $\S 302(\mathrm{c})$ and $\S 302(d)$, both of which state that documents recorded under those provisions should comply with form and content regulations promulgated by the Copyright Office. See 44 Fed. Reg. 47550 (Aug. 14, 1979). The proposed regulation defined in more detail those persons who "have an interest in a copyright" sufficient to allow them to record 302(c) and 302(d) statements; provides requirements for the contents of such statements and the Office's procedure in examining submitted statements, and creates a "Registry of Vital Information Concerning Authors" that would contain, not only recorded 302(c) and 302(d) statements, but also information about the lives and deaths of authors compiled by the Copyright Office from various sources. The regulation, however, was never promulgated.

${ }^{38}$ See 37 C.F.R. $\S 201.10($ c).
} 
a document, ${ }^{39}$ but in practice remitters submit a cover sheet with $80 \%-90 \%$ of documents. Those documents that are accompanied by recordation cover sheets are quickly identified as documents remitted for recordation, and routed to the Accounts Section, often referred to as the Maintain Accounts section. Some documents are not accompanied by a cover sheet, or are remitted with cover letters or notes that are confusing because the sender is mistaken or unsure about what he or she should be doing with the document. Those documents are set aside for review and may reach the Accounts Section only after some delay.

Documents can also be hand-delivered to the Public Information Office (PIO), operated by the Copyright Information Section. Copyright Information Section staff members will assist people who walk into PIO, and will perform an initial review of the document and may identify problems that the remitter needs to correct. Documents that are delivered through PIO will be forwarded to the Accounts Section.

The Accounts Section checks that payment has been submitted for at least the current basic recordation fee. It does not, however, count the titles in a multi-title document to see whether the correct additional payment has been made for the additional titles; that is left for Recordation Specialists during the screening process, described below.

The Accounts Section also processes payments. Remitters can submit payment by credit card, check, cash (which is rarely used) and through the use of deposit accounts maintained by the Copyright Office, into which remitters make deposits from time to time to cover recordation and registration fees as they are incurred. Deposit accounts are popular in part because in large corporations, the department that disburses payments is often not the same department that records documents, and those who record documents do not want to have to submit an internal request that payment be made every time they remit a document for recordation. ${ }^{40}$ From Fiscal Year 2009 through Fiscal Year 2013, deposit accounts were used to pay for between 41\% and $57 \%$ of recordation fees. ${ }^{41}$ Though frequent remitters often pay fees for small- to medium-sized documents through deposit accounts, fees for very large documents are usually paid by check, presumably because deposit account balances are not sufficient to cover those fees. Table 1 on the following page shows the payments made for recorded documents from October 1, 2013 through June 30, 2014 by payment type. It reveals, among other things, that although during that period only about $42 \%$ of recordation fees were paid by means of deposit accounts, those fees covered over $66 \%$ of the documents recorded.

\footnotetext{
${ }^{39}$ See Compendium II of Copyright Office Practices $\S 1605$ ("Cases submitted with a document cover sheet will be processed and verified in the same manner as a document submitted without a cover sheet. Neither category of document will receive priority processing."); Compendium III of Copyright Office Practices (Public Draft - Not Final August 19, 2014) § 2309.12(A) Note ("A document submitted with a document cover sheet will be processed in the same manner as a document submitted without a cover sheet.").

${ }^{40}$ For more information on Deposit Accounts, see Circular 5, How to Open and Maintain a Deposit Account, available at http://copyright.gov/circs/circ05.pdf (last visited August 21, 2014).

${ }^{41}$ E-Mail from Jerry Tobin, Copyright Technology Office, to Robert Brauneis, August 14, 2014.
} 


\begin{tabular}{|r|rr|r|r|r|}
\hline \multicolumn{7}{|c|}{ Table 1 } \\
\hline Recordation Payments by Type, 10/1/2013 - 6/30/2014 \\
\hline Payment Type & \multicolumn{2}{|c|}{ Amount } & $\begin{array}{c}\text { \% of Total } \\
\text { Amount }\end{array}$ & $\begin{array}{r}\text { Number of } \\
\text { Documents }\end{array}$ & $\begin{array}{r}\text { \% of Total } \\
\text { Documents }\end{array}$ \\
\hline Check & $\$ 1,234,337.50$ & $52.59 \%$ & 2,749 & $31.47 \%$ \\
\hline Credit Card & $\$$ & $127,205.00$ & $5.42 \%$ & 182 & $2.08 \%$ \\
\hline Cash & $\$$ & 655.00 & $0.03 \%$ & 2 & $0.02 \%$ \\
\hline Deposit Account & $\$$ & $984,810.00$ & $41.96 \%$ & 5,803 & $66.43 \%$ \\
\hline Total & $\$ 2,347,007.50$ & $100.00 \%$ & 8,736 & $100.00 \%$ \\
\hline
\end{tabular}

The Accounts Section then creates an initial record for the document in the internal electronic processing system - which is now run on a Siebel platform similar to that used for registration processing - and forwards the document to the Recordation Section. If payment processing fails - if, for example, a check bounces - then the Accounts Section corresponds with the remitter about the failure of payment.

\section{Screening.}

Screening, or examination, involves review of each remitted document by Recordation Section staff to ensure that it meets certain standards established by statute, by regulation, or in the Compendium of Copyright Office Practices, before being accepted for recordation and becoming part of the Copyright Office public record. The screening process also occasionally involves correspondence with remitters about potential document defects that may not violate recording requirements, but that may defeat the intent of the parties with regard to the document. $^{42}$

a. The Requirements for which Documents are Screened. Copyright Office practice is to screen each remitted document for compliance with the following requirements:

i. Signatures. One of the two explicit statutory requirements for recording a document concerns signatures. The Copyright Act requires every document filed for recordation either "to bear the actual signature of the person who executed it," or to be "accompanied by a sworn or official certification that it is a true copy of the original, signed document." ${ }^{\text {43 }}$ In 2010, the Copyright Act was amended to provide that "[a] sworn or official certification may be submitted to the Copyright Office electronically, pursuant to regulations established by the Register of Copyrights." "As of this writing, however, the Copyright Office has not yet promulgated such regulations.

Under Copyright Office practice, an "actual signature" is an "actual handwritten signature of an individual person." 45 Thus, to be recorded, a document must be submitted

\footnotetext{
${ }^{42}$ See infra p. 18.

4317 U.S.C. $\S 205(a)$; see 37 CFR $\S 201.4(c)(1)$; Compendium II $\S 1602.01$.

${ }^{44}$ Copyright Cleanup, Clarification and Corrections Act of 2010, Pub. L. No. 111-295, § 3, 124 Stat. 3180 (2010); 17 U.S.C. $\S 205(a)$.

${ }^{45}$ Compendium II $\S \S 1606.05(a), 1606.07$.
} 
on paper bearing one or more ink or pencil signatures; or alternatively, it must be accompanied by a sworn or official certification that it is a true copy of an original, signed document. A sworn certification is defined by Copyright Office regulations as "an affidavit under the official seal of any officer authorized to administer oaths within the United States"; ${ }^{46}$ however, under current practice, the requirement of the official seal is not enforced, and certifiers and just make a statement under penalty of perjury, as they do on the document cover sheet form. ${ }^{47} \mathrm{~A}$ sworn certification must itself be "signed by at least one of the persons who executed the document, or by an authorized representative of that person." 48 An official certification "is a certification, by the appropriate Government official, that the original of the document is on file in a public office and that the reproduction is a true copy or the original." 49 In practice, official certifications are rare, but they are received from time to time.

ii. "Pertaining to Copyright." The other statutory requirement is that a document must be a "transfer of copyright or other document pertaining to copyright." definition that includes, for example, wills of authors that do not explicitly mention particular works of authorship, but that may affect their ownership. Documents that on their face concern only the transfer of trademarks or tangible property, for example, will be refused. ${ }^{51}$

iii. Completeness. Copyright Office regulations require a remitted document to be "complete by its own terms." 52 The typical violation of this requirement involves documents that are missing appendices or attachments to which they refer. As a general matter, such documents will not be recorded unless the reference to the appendix is deleted and that deletion is signed or initialed by the parties to the document. ${ }^{53}$ The regulations and Compendium provide for one exception, which applies only if three conditions are met:

(A) the attachment is completely unavailable for recordation; (B) the attachment is not essential to the identification of the subject matter of the document; and (C) it would be impossible or wholly impracticable to have the parties to the document sign or initial a deletion of the reference. ${ }^{54}$

iv. Legibility. The document must be "legible and capable of being imaged or otherwise reproduced in legible copies by the technology employed by the Office at time of submission." 55

\footnotetext{
4637 C.F.R. § 201.4(a)(3)(i).

${ }^{47}$ See http://www.copyright.gov/forms/formdoc.pdf.

${ }^{48}$ Compendium II $\S 1606.03$.

4937 C.F.R. $\$ 201.4($ a)(3)(ii).

${ }^{50} 17$ U.S.C. $\S 205(a) ;$ see 37 CFR $\S \S 201.4(c), 201.4(a)(2)$; Compendium II $\S \S 1603.01,1603.02$.

${ }^{51}$ Compendium II $\S 1604$.

5237 CFR §201.4(c)(2); Compendium II $\S 1609$.

5337 CFR §201.4(c)(2)(i); Compendium II § 1609.01.

5437 CFR §201.4(c)(2)(i); see Compendium II $\S$ 1609.01(b).

5537 CFR §201.4(c)(3); see Compendium II $\S 1606.04$.
} 
v. Payment of Fees. The proper recordation fee must have been paid by the remitter, according to the schedule of fees adopted in 37 CFR $\S 201.3(\mathrm{c})$. Although the Maintain Accounts staff, not the Recordation Section staff, initially checks for sufficiency of fee payment, it is the Recordation Section staff that counts titles of works in multititle documents to check whether the fee paid has been properly calculated to take account of the number of titles to which the recorded document refers.

vi. Documents That Purport to Accomplish "Transfers of Copyright Ownership." Section 204 of the Copyright Act is a writing-and-signature requirement that applies to any "transfer of copyright ownership," which is defined in $\S 101$ as "an assignment, mortgage, exclusive license, or any other conveyance, alienation, or hypothecation of a copyright or of any of the exclusive rights comprised in a copyright, whether or not it is limited in time or place of effect, but not including a nonexclusive license." ${ }^{, 56}$ Section 204 provides that such a transfer, "other than by operation of law, is not valid unless an instrument of conveyance, or a note or memorandum of the transfer, is in writing and signed by the owner of the rights conveyed or such owner's duly authorized agent."57 The Compendium II of Copyright Office Practices establishes three additional screening requirements for documents that purport to accomplish "transfers of copyright ownership" Such documents must:

a. Be "instruments in writing." This requirement is established by 17 U.S.C. $\S$ 204, which provides that "[a] transfer of copyright ownership . . . is not valid unless an instrument of conveyance . . . is in writing . ..., 58

b. Identify the transferor and transferee. ${ }^{59}$

c. Contain words of conveyance. ${ }^{60}$

b. Other Issues that May Prompt Correspondence. Recordation specialists may also contact remitters if they see issues with documents that do not implicate the requirements listed above, but may cause the document to fail to implement the parties' intent. A number of these issues are mentioned in the Compendium II of Copyright Office Practices. For example, "[i]f a number of transferors are identified in the body of the document, and spaces have been provided for the signatures of all of them, the document will be questioned if any of the signatures is missing." ${ }^{61}$ Similarly, "[d]ocuments which do not identify the necessary parties will be questioned, but recordation will not be refused if, following correspondence, the sender continues to request recordation." 62

\footnotetext{
${ }^{56} 17$ U.S.C. $\S 101$ (“transfer of copyright ownership"); see 17 U.S.C. $§ 204$.

${ }^{57}$ Id.

5817 U.S.C. $\S 204$; see Compendium II $\S \S 1606.01(1), 1606.02$.

${ }^{59}$ See Compendium II $\S 1606.01(3)$.

${ }^{60}$ See Compendium II $§$ 1606.01(4).

${ }^{61}$ Compendium II of Copyright Office Practices, $\S 1606.05(b)$.

${ }^{62}$ Compendium II $\S 1607.01$.
} 
c. A Screening and Correspondence Study. To better understand the frequency with which the Recordation Section staff encounters various problems during screening of documents, a study of Recordation Section document processing was conducted over a six-week period in April and May of 2014. Recordation Section staff kept track of each instance in which a problem concerning a remitted document required correspondence with the remitter. The results of that study are summarized in the table displayed below:

\begin{tabular}{|c|c|c|c|}
\hline \multicolumn{4}{|c|}{$\begin{array}{c}\text { Table 2: } \\
\text { PROBLEMS REQUIRING CORRESPONDENCE } \\
\text { DURING DOCUMENT SCREENING }\end{array}$} \\
\hline & Number & $\begin{array}{c}\text { Percentage of } \\
\text { Total }\end{array}$ & $\begin{array}{l}\text { Percentage of } \\
\text { Problems }\end{array}$ \\
\hline Documents Screened & 292 & $100 \%$ & \\
\hline $\begin{array}{l}\text { Documents with problems requiring correspondence } \\
\text { (types of problems listed below) }\end{array}$ & 71 & $24.32 \%$ & $100 \%$ \\
\hline Fee Issues & 48 & $16.44 \%$ & $67.60 \%$ \\
\hline $\begin{array}{l}\text { - Multiple documents submitted under single } \\
\text { cover sheet with single fee payment }\end{array}$ & 27 & $9.25 \%$ & $38.03 \%$ \\
\hline $\begin{array}{l}\text { - Discrepancy between fee paid and number of } \\
\text { titles }\end{array}$ & 21 & $7.20 \%$ & $29.58 \%$ \\
\hline Completeness & 8 & $2.74 \%$ & $11.27 \%$ \\
\hline Signature & 6 & $2.05 \%$ & $8.45 \%$ \\
\hline Legibility & 4 & $1.37 \%$ & $5.63 \%$ \\
\hline Certification date missing on document cover sheet & 2 & $0.69 \%$ & $2.82 \%$ \\
\hline $\begin{array}{l}\text { Certificate of merger filed with unconnected list of } \\
\text { titles }\end{array}$ & 2 & $0.69 \%$ & $2.82 \%$ \\
\hline Parties reversed on signature line & 1 & $0.34 \%$ & $1.41 \%$ \\
\hline
\end{tabular}


As Table 2 shows, a total of 292 documents were tracked during the six-week study for problems requiring correspondence with the remitter. Of those 292 documents, 71 documents, or $24.32 \%$, had problems that required correspondence. This is a substantial percentage that contributes significantly to the labor needed to process documents for recordation.

The detailed breakdown of types of problems provides somewhat more encouraging news about the prospects for automation of document recordation. Of the 71 documents that required correspondence, 48 of them - about two-thirds - had problems relating to the calculation of proper fees payable for recordation. ${ }^{63}$ For 21 documents, the remitter had made an error in counting the number of titles in the remitted document that affected the fee calculation. For 27 documents, the remitter prepared a single cover sheet for multiple documents, causing the Maintain Accounts Section to withdraw a fee from a deposit account that covered only one document. $^{64}$ It is very likely that in an electronic recording system, the frequency of these problems would be drastically reduced. In such a system, the remitter would likely submit the titles of the works covered by a document before the fee was calculated, and a computer program would calculate the fee based on the number of titles submitted. While it would still be possible for a remitter to neglect to submit some of the titles covered by a document, such an omission would limit the legal benefits of recording the document, ${ }^{65}$ and the prospect of losing such benefits would act as a strong incentive to submit complete information.

Eight documents in the study, or $2.74 \%$, required correspondence due to lack of completeness. In these cases, the remitter did not submit attachments that were not relevant to the copyright transaction memorialized in the document. For example, a transaction may have concerned the transfer of both trademarks and copyrights, and the missing attachment was a schedule of trademarks conveyed. The remitter was notified of the deficiency and submitted the missing attachments.

Six documents, or $2.05 \%$ of all documents in the study, were submitted as photocopies that did not have handwritten signatures and were not accompanied by sworn or official certifications. Four documents, or $1.37 \%$, had some portion that was illegible.

Two documents, $0.69 \%$ of the total, were copies of the originals and thus required certifications. ${ }^{66}$ They were submitted with cover sheets that included certifications, but the dates on which the certifications were signed were missing. Another two documents were certificates of merger, indicating that one company had merged into another company. A list of titles of works that were affected by the merger - that had been owned by the company now merged into the other company - was attached to the certificate, but the certificate had been issued without

\footnotetext{
${ }^{63}$ All explanations of problems were provided by Zarifa Madyun, Head of the Recordation Section, who coordinated the study.

${ }^{64}$ For more on deposit accounts, see supra p. 16.

${ }^{65}$ For a discussion of the issue of remitters omitting information or submitting mistaken information, and the effects of such acts on constructive notice and priority, see infra p. 96.

${ }^{66}$ For an explanation of certifications, see supra p. 17.
} 
such a list and the remitter simply attached it. The Recordation Section required the remitter to execute an affidavit that the titles in question were in fact affected by the merger, and then to record the affidavit with the certificate of merger and list of titles. Lastly, one document required correspondence because the signature line switched the identities of the parties as had been established in the document's text - that is, the transferor became the transferee, and vice versa.

These last three categories of problems are interesting because they do not neatly fit the requirements identified above for which recordation specialists should be screening. Neither the Copyright Office regulations nor the Compendium explicitly require a date on a certification, but the cover sheet that includes a certification form does include a space for a date, and so perhaps the implicit requirement is that the document should be fully completed. The attachment of the list of titles to the certificate of merger could perhaps be characterized as a purported memorandum of transfer that lacked a signature. The switching of the signature lines might be characterized as a failure of the document to identify unambiguously the transferor and transferee.

\section{Cataloging.}

The second principal part of the recordation process involves preparation of the Copyright Office Catalog record of the recorded document. Information that becomes part of the Catalog entry for a recorded document is either transcribed from the document, created as a description of some characteristic of the document, or created independently of the document.

\section{a. The Cataloging Process: Transcription, Description, Creation.}

i. Transcription. Under current practice, Recordation Section staff members must manually transcribe many elements of the remitted document into data fields that eventually become part of the Catalog record for that document. Because remitted documents themselves do not arrive in any standard format, transcription requires interpretation: Recordation Section staff must identify, through interpretation of varying language, a number of elements in the document. The principal elements that must be identified and transcribed are the following:

- Grantor(s)/Assignor(s)/Licensor(s) or other party whose copyright interests the document concerns (known in Copyright Office parlance as "Party One")

- Grantee(s)/Assignee(s)/Licensee(s) (known in Copyright Office parlance as "Party Two")

- Title of the document ("Assignment," "Grant of Security Interest," etc.)

- Title(s) of Work(s) involved

- Credited Author(s) of Work(s) involved (transcribed as part of the title statement)

- Associated Registration number(s) (if available)

- Date(s) of execution

- Date(s) of certification 
Transcription of Titles and Registration Numbers. Although most recorded documents concern a single identified work, ${ }^{67}$ some documents concern hundreds or thousands of works. When a document concerns a very large number of works, manual transcription of the titles of those works, and their registration numbers when they are provided (which they have been, on average, for about $45 \%$ of identified works) can be a very time-consuming effort, requiring, in some cases, days to complete. The Copyright Office has been running an informal pilot project under which it accepts electronic lists of titles submitted on tangible media such as USB thumb drives. This has led to some reduction of time needed to enter titles, but in the legacy internal document processing system - CORDOCS - titles still must be copied and pasted one at a time. The document recording process has very recently been moved onto a new internal system (a new application of the Siebel software used to process registrations), and that system allows for copying and pasting of multiple titles at a time, which will substantially further reduce time needed to enter titles. The Copyright Office recently published a Final Rule more generally allowing for electronic submission of titles when a document contains 100 or more titles. ${ }^{68}$

ii. Description. In addition to transcribing elements of the document, personnel also engage in limited description of the document. They classify the document into one of several categories, including security interest, termination of transfer, and general assignment or license. They may also enter notes about the document into the Copyright Office Catalog record.

iii. Creation. Lastly, cataloging involves some data that is generated by the Copyright Office itself, such as the date of recordation; $;{ }^{69}$ the date of creation of the catalog record; the document number, known colloquially as the "VDOC" number; catalog record locator numbers; and other internal processing information such as the "DPUL" number - the date on which the record was uploaded from the internal processing software into the public catalog database.

\section{b. The Legal Framework of Cataloging.}

Cataloging also stems from a legal mandate. Section 705(a) of Title 17 provides that "[t]he Register of Copyrights shall ensure that records of deposits, registrations, and other actions taken under this title are maintained, and that indexes of such records are prepared." ${ }^{, 70}$ Assuming that placing a remitted document on public record qualifies as "[an]other action taken under this title," which it should, \$705(a) requires the Register to ensure that records of recorded documents are maintained and that indexes of such records are prepared.

The mandate to "ensure that" records are maintained and indexes are prepared, however, means that the Copyright Office need not maintain records and prepare indexes itself. That

\footnotetext{
${ }^{67}$ See infra n. 97.

${ }^{68}$ Changes to Recordation Practices, 79 Fed. Reg. 55633 (September 17, 2014).

${ }^{69}$ See Compendium of Copyright Office Practices, Third Edition, Chapter 2100, "Recordation" (public draft August 19, 2014) (defining "date of recordation" as "the date when the last necessary element (document and filing fee) was received"). The term "date of recordation" was chosen to avoid confusion with the term "effective date of registration," which is used in the context of registration of copyright claims.

${ }^{70} 17$ U.S.C. $\$ 705(a)$.
} 
language stems from a 2000 amendment that replaced the version original to the Copyright Act of 1976, which had provided that "[t]he Register of Copyrights shall provide and keep in the Copyright Office records of all deposits, registrations, recordations, and other actions taken under this title, and shall prepare indexes of all such records." ${ }^{71}$ The legislative history of the amendment makes clear that its purpose was to allow the Register to enter into agreements to have some of the recordkeeping and indexing done outside of the Copyright Office. ${ }^{72}$ It should be noted that $\S 205$ (a) of the Copyright Act still arguably assumes that the Copyright Office itself is preparing the index to documents; it provides that recording a document "will give all persons constructive notice of the facts stated in the recorded document, but only if . . the document ... specifically identifies the work to which it pertains so that, after the document is indexed by the Register of Copyrights, it would be revealed by a reasonable search under the title of registration number of the work." ${ }^{, 73}$ It seems likely that this reference in passing, however, would not alter the more specific, direct, and later-imposed mandate under $\S 705(\mathrm{a})$. If the Register has "ensured that" a document was indexed under $\S 705(\mathrm{a})$, then she almost certainly has "indexed" that document within the meaning of $\S 205(a)$.

Under a proposed electronic recordation system, remitters might themselves provide information that would form a key part of the index or Catalog entry for a remitted document. It seems likely that requiring remitters to provide Catalog information would not even violate the Register's previous duty to "prepare indexes," since that language need not mandate transcription of information from documents by Copyright Office staff. By creating and maintaining a searchable catalog of recorded documents; determining what information needs to be in a catalog entry for each document; and asking the remitter to provide some or all of such information, the Register can still be said to be "preparing an index." However, the mandate in place since 2000 to "ensure that . . . indexes . . . are prepared" makes clear that tasks involved with index preparation can be delegated outside of the Copyright Office.

Two issues remain and will be discussed below. The first is whether making remitters legally responsible for any errors in index information they provide is compatible with the Copyright Office's statutory mandate to "ensure that . . . indexes . . . are prepared." "74 The second is whether full-text searching might make "indexing," in the narrow sense of preparing an independent alphabetical reference list by work titles or party names that appear in documents, less important and possibly obsolete. ${ }^{75}$

\footnotetext{
${ }^{71} 17$ U.S.C. § 705(a) (1982); see Work Made for Hire and Copyright Corrections Act of 2000, Pub. L. No 111-295, 124 Stat. 3180, 3181 (substituting the current language).

${ }^{72}$ See H.R. Rep. No. 106-861, at 5-6 (2000) (noting that the amendment would allow the function of maintaining records of deposits of serials to be performed by the Serials Records Division of the Library of Congress rather than the Copyright Office).

${ }^{73} 17$ U.S.C. \$205(a) (emphasis added).

${ }^{74}$ See infra p. 100.

${ }^{75}$ See infra p. 73.
} 


\section{Correspondence with Remitters.}

As noted above, Recordation Section staff members correspond with remitters when they discover problems with remitted documents. As will be noted below, when the recordation process for a document is successfully completed, the document is returned to the remitter together with a certification of recordation.

Traditionally, the Copyright Office has not separately notified the remitter of the receipt of a document for recordation. Remitters, however, have expressed a desire for such notification, especially as backlogs have grown and the delay between remitting a document and having it returned with a certificate has increased by many months. A recently finalized rule allows remitters who submit cover sheets and stamped, self-addressed envelopes with their documents to request return receipts. ${ }^{76}$

\section{Marking and Imaging of Documents.}

Until this year - 2014 - recordation specialists affixed a label to each page of each document remitted for recordation. The label included the recordation number of the document, and the page number for each page. An image of each page was then captured; the images were retained by the Copyright Office, while the labeled original documents were returned to the remitter. Since 1997, the document images have been stored in the digital Copyright Imaging System (CIS), which is described in more detail below.

The internal processing of recorded documents has recently been moved onto a Siebel platform similar to that used for processing registrations. The Siebel system has the capability of marking or stamping each image of a recorded document page electronically, by modifying the image file to include the recorded document number and the page number. This electronic marking avoids the need to place labels on each paper document page. It also, however, raises the question of what to return to the remitter, since the original paper document will no longer have labels on it - a question that will be discussed in the next section below.

\section{Creation of Recordation Certificate, and Sending of Certificate and Document.}

In the last stage of the recording process, a recordation certificate is printed, and the certificate is mailed to the remitter. The original document remitted for recordation is returned to the remitter with the certificate. As mentioned above, the remitter used to receive the original with labels attached to each page. These labels contained the recorded document number and the number of each page. The marking is now done electronically after scanning, so the original document is no longer labeled. The current practice is to print out a copy of the scanned, labeled document, and send it in the mail to the remitter together with the original document and recordation certificate.

\footnotetext{
${ }^{76}$ See Changes to Recordation Practices, 79 Fed. Reg. 55633, 55636 (September 17, 2014) (regulation regarding return receipt to be codified at 37 C.F.R. § 201.4(f)).
} 


\section{Recordation from a Searcher's Perspective: The Document Repository and Catalog.}

While the previous section described how the Copyright Office processes a document remitted for recordation, this section describes the document recordation system from the perspective of someone searching the recorded document records: How have those documents been preserved and indexed or cataloged, and how are they currently cataloged and preserved?

\section{An Historical Review of Recorded Document Repositories and Finding Aids.}

The Copyright Office maintains a repository of recorded documents, and finding aids for that repository, that date back to 1870 , but the form that the repository and finding aids have taken has changed a number of times in the last 145 years.

a. Repositories. The first document pertaining to copyright was accepted for recordation on July 25,1870 . The original documents remitted have apparently always been returned to the remitter. For the first several decades of recordation, the repository was created by transcribing the documents in full, in handwriting, in bound and numbered volumes. Over time, the method of making repository copies of remitted documents began to include typewriters, and then photocopies on paper, ${ }^{77}$ but the method of handwritten transcription was not immediately discarded. For example, Volume 147, which contains documents recorded in portions of 1926 and 1927, contains side by side examples of handwritten transcription, typewritten transcription, and photocopies.

However, beginning with Volume $181^{78}$ - the first document in which was recorded on April 27, 1927 - copies of documents were made by photocopy only. The method of preserving photocopies of documents in bound volumes persisted through Volume 890, in which the last document was recorded on July 29, 1953. Beginning with Volume 891, documents were preserved on microfilm. (A retrospective microfilm set of Volumes $1-890$ was also made, and is available in the Copyright Public Reading Room.) Microfilm remained the medium of recorded document preservation until 1997. In 1997, the Copyright Office began using the current digital Copyright Imaging System (CIS) for recorded documents; it had been using that system for registrations since 1993. Volume 3400 is the first volume of documents the images of which are stored in CIS; the first document in that volume, numbered V3400D001, bears a recordation date of April 4, 1997, although some documents with recordation dates later in 1997 have numbers in Volume 3399 and are preserved on microfilm.

b. Finding Aids. Each bound volume from Volume 1 through Volume 153 contains an alphabetical index to the documents transcribed in that volume. Each document was indexed at

\footnotetext{
${ }^{77}$ The photocopies were called "photostats," after the brand name of an early photocopy machine that became generic. See "Photostat Machine," http://en.wikipedia.org/wiki/Photostat (last visited July 28, 2014).

${ }_{78}$ Volumes 154 through 180, though in existence and shelved with the other volumes in the Copyright Card Catalog Room, are blank.
} 
least by the names of the assignor and assignee, and sometimes by the title of the work transferred in the document as well. The volumes after Volume 153 no longer include indexes in the volumes themselves.

An assignor/assignee index to recorded documents is available on index cards as part of the Copyright Card Catalog. That index is split into two time periods: 1870 to 1940 and 1941 to 1977. A title index is also available on cards in the Copyright Card Catalog, and covers the period from 1928 to 1977 . The cards in the assignor/assignee and title indexes contain several types of information other than, respectively, names of assignors and assignees and titles, and volume and page numbers of documents. The Assignor/Assignee cards almost always include the title(s) of the work(s) transferred; they often include the author(s) of the work(s) and sometimes the registration number(s) of the work(s). The Assignor/Assignee cards in the 1870 to 1940 index also contain the "date of receipt" of the document, which is presumably the date of recordation, and the initials of the Copyright Office staff members by whom the document was "recorded," "revised," and "indexed." The Assignor/Assignee cards in the 1941 to 1977 index drop the initials of Copyright Office staff members, and add the date of execution of the document. The Title index cards invariably include the Assignor and Assignee names, often include the name of the author of the work, and sometimes include the work's registration number.

The information on the index cards in excess of the bare minimum index items of assignor/assignee or title and corresponding volume and page number can be seen to serve two possible functions. First, it can aid the search by further confirming or disconfirming that the assignor/assignee or title listed on the card is really the one for which the searcher is looking. Titles, for example, are not necessarily unique to particular works, and the combination of a title with an author's name and/or a registration number will more likely point uniquely to the correct document. Second, however, the information can in some circumstances obviate the need to look at the document itself, because the information in the document that is crucial to the searcher's purpose may also be contained in the index card. If one is looking to see whether Alpha transferred an interest in "Summer Breeze" to Beta on July 1, 1968, that information can be found on the card itself. (The 1870-1977 cards do not specify the nature of the interest granted, but law under the 1909 Act and previous acts make it almost certain that the transaction represented by each document was an assignment, will, or mortgage.)

From 1978 onwards, recorded documents have been cataloged in the Copyright Office Electronic Catalog. The electronic catalog was apparently made available on terminals in the Library of Congress beginning in 1978. On April 30, 1993, it was made available remotely through a command-line Telnet interface as part of LOCIS, the Library of Congress Information System. ${ }^{79}$ A web-based search was made available on the Copyright Office website in $2001 .^{80}$

\footnotetext{
${ }^{79}$ See "Remote Access to Library of Congress Computer Files Now Available," April 6, 1993, available at http://www.loc.gov/today/pr/1993/93-059.html (last visited July 28, 2014).
} 
That initial web search interface offered search only by title, assignor name, assignee name, or document number; ${ }^{81}$ additional search capabilities, including a "keyword search" that searches many fields at once, have been added more recently.

\section{The Current Document Repository.}

Copies of recorded documents are currently maintained in the digital Copyright Imaging System (CIS), as they have been since 1997. The CIS stores images of document pages in Tagged Image File Format ("TIFF"). Upon request, it creates a Portable Document Format ("PDF") file of all of the page images for one document, although in a small number of cases documents are too long for PDF assembly to take place. The image files are purely graphic in nature - they contain only grayscale graphic information, and have not been subject to any optical character recognition (OCR) process. Therefore, they do not include any associated text files or indexes, and the text of the imaged documents cannot be searched. Of course, these image files also do not preserve special features of electronic documents, such as digital signatures or internal indexes. The CIS system is currently accessible only within the Copyright Office, both to staff members and at public terminals in the Copyright Public Reading Room. It is not available remotely, on the Internet or otherwise; hence copies of documents can only be retrieved on site at the Copyright Office.

\section{The Current Document Catalog.}

Catalog entries for recorded documents are currently maintained on electronic records in MARC (Machine Readable Cataloging) format. A single MARC record is generated for a document that concerns only one title. Documents that contain more than one title are cataloged in at least one "parent" record for the document, and "child" records for each of the titles mentioned in the document. Limitations in older internal processing software capped the number of titles that could be referenced in one electronic record at 200, so that any document that contained more than 200 titles had to be split up into multiple parts and each part had to be assigned a separate document number and "parent" record. Even after that limitation was lifted, Recordation Section practice was to split up documents with more than 1000 titles. The largest number of MARC parent records into which a document is split is $258, ;^{82}$ of the approximately 479,000 recorded documents in the Research Database, covering the period from January 1978 to March 2013, 51 of them were split into 50 or more parent records, 537 were split into 10 or more parent records, and 5198 were split into two or more parent records.

\footnotetext{
${ }^{80}$ See "Copyright Office Announces New Search System," August 17, 2001, available at http://www.loc.gov/today/pr/2001/01-114.html (last visited July 28, 2014).

${ }^{81}$ See "Copyright Search" (Copyright Office website search page, captured by the Internet Archive on February 4, 2002), https://web.archive.org/web/20020204132315/http://www.loc.gov/copyright/search/cohd.html (last visited July 28,2014$)$.

${ }_{82}$ That document is titled ".44 and 50,924 other titles; musical compositions," and is recorded at Volume 1977, pages 1-703 and Volume 1978, pages 1-333.
} 
a. The Voyager Search Interface. While the card catalog indexes and bound volume indexes could be "browsed" alphabetically - one could flip back and forth through adjacent cards or pages - browsing is not made available as a primary type of online access to electronic records of recorded documents, and it would not be obvious to most people how one might use the current web interface to approximate the experience of browsing ${ }^{83}$ Rather, the primary access to the electronic records is through a web search interface, which since 2007 has connected to a Voyager ${ }^{84}$ platform that is used both for copyright records and Library of Congress bibliographic records. Simple searches can be performed for titles, names of assignors, assignees, and authors, and for document numbers, but a variety of more sophisticated and inclusive searches are also possible. "Keyword" searches look for specified words anywhere in the document record, and can include operators for truncation, omission, conjunction, and exact phrases; "Command Keyword" searches also can include index codes which map to one or more MARC record fields, as well as Boolean operators. An "Other Search Options" page includes a dropdown box for specifying particular index codes, as well as dropdown boxes for conjunction, omission, and phrases and radio buttons for Boolean operators. The documentation on index codes and how they relate to fields in the MARC records is far from complete.

The Voyager system has a number of serious limitations, including a limit on the number of records retrieved by any one search or any one part of a Boolean search $(10,000)$, and an apparent limitation on the number of characters in a search string. These limitations are imposed across the board, both on public access and on access inside the Copyright Office.

Labeled excerpts from records are displayed as search results in the public search interface. The search interface available inside the Copyright Office (the "Copyright Staff Catalog") also includes a tab that displays the full MARC listing with the complete contents of the MARC record for the document or work in question.

b. Document Types. Of the kinds of information available in the Catalog about a recorded document beyond title, assignor/assignee name, and document number, probably the most important are:

- the transcribed heading of the document;

- the date of recordation;

- the date or dates of execution; and

- the registration numbers, if available, of the works that the document concerns.

The transcribed heading of the document often gives a very good clue about the type of copyright interest that is transferred by the document. For example, the document may be titled

\footnotetext{
${ }^{83}$ One could always truncate the title or the assignor's or assignee's name to locate records that would be adjacent to a particular record in an alphabetically ordered group of records. In many cases, however, even modest truncation would run up against Voyager's current limitation of 10,000 records returned for each search, discussed below.

84 "Voyager" is the brand name of integrated library management system software produced by Ex Libris, Ltd. See Voyager Integrated Library System, http://www.exlibrisgroup.com/category/Voyager (last visited July 28, 2014).
} 
"Grant of Security Interest"; "Short Form Option"; "Termination of Transfer"; or "Assignment." However, there are no standards in place to ensure consistency in naming of documents. In the MARC record specifications for recorded document records, one subfield, 917f, has been set aside to classify the type of document recorded, and the numbers $1,2,4,6,7$, and 8 have been defined to represent certain document types. Table 3 shows the numbers used, their definitions, the number of documents marked with each number, and the recordation dates of the earliest and latest documents so marked. It reveals that both in theory and in practice, the classification system has severe limitations.

First, many well-recognized types of documents have no assigned number; the classification system was not designed to be comprehensive. Second, partly as a result of the lack of comprehensiveness of the classification system, of the 478,825 documents in the Research Database, only 81,263 of them, or $16.97 \%$, have been classified under this system. The $917 \mathrm{f}$ field in the records for the other 397,562 documents is blank. Third, by far the largest number of documents in a single classification are the 57,610 documents classified as "6," grants of security interests. However, it is clear that coverage within that classification is incomplete, both over time - the first document so classified was recorded in 1988 - and within the covered time period, as other searchers have revealed many grants of security interests between 1988 and 2013 that are not marked. $917 \mathrm{f}$ coverage appears to be more comprehensive with respect to three specialized types of documents: notices of intent to enforce under the Uruguay Round Agreement Act, notices of terminations of transfer, and statements of intent to restore under the North American Free Trade Act. ${ }^{85}$

\footnotetext{
${ }^{85}$ In addition, in 1978 and 1979, the Copyright Office cataloged notifications of litigation filed under $\S 508$ of the Copyright Act. See 17 U.S.C. § 508 (requiring clerks of court to file notifications with the Copyright Office regarding litigation involving works of authorship). These catalog records are marked with an entry of " 2 " in the $917 \mathrm{f}$ field. While $\S 508$ remains in force today, and clerks of court continue to file $\S 508$ notifications, the Office decided to stop cataloging those notifications in 1980. See p. 122, infra.
} 
Table 3: Entries in MARC field $917 f$

\begin{tabular}{|c|c|c|c|c|}
\hline Entry & Definition & $\begin{array}{l}\text { Number of } \\
\text { Records } \\
\text { Containing this } \\
\text { Entry }\end{array}$ & $\begin{array}{l}\text { Recordation } \\
\text { Date of First } \\
\text { Record } \\
\text { Containing this } \\
\text { Entry }\end{array}$ & $\begin{array}{l}\text { Recordation } \\
\text { Date of Last } \\
\text { Record } \\
\text { Containing this } \\
\text { Entry }\end{array}$ \\
\hline 1 & $\begin{array}{l}\text { Statement of Death, } \\
\text { Identity, or Life Under } \S \\
\text { 302(d) }\end{array}$ & 31 & $7 / 28 / 1978$ & $2 / 25 / 2011$ \\
\hline 2 & $\begin{array}{lll}\S & 508 & \text { Litigation } \\
\text { Notifications } & \end{array}$ & 3016 & $1 / 17 / 1978$ & $5 / 6 / 1980^{1}$ \\
\hline 3 & $\begin{array}{l}\text { (no apparent clear } \\
\text { definition) }\end{array}$ & 7 & $8 / 20 / 1978$ & $3 / 7 / 2003$ \\
\hline 4 & $\begin{array}{l}\text { Notice of Termination of } \\
\text { Transfer under } \S 304(c) \\
\text { or } \S 304(d)\end{array}$ & 9276 & $1 / 21 / 1977$ & $1 / 14 / 2013$ \\
\hline 5 & $\begin{array}{l}\text { (no apparent clear } \\
\text { definition) }\end{array}$ & 3 & 9/3/1991 & $1 / 23 / 2004$ \\
\hline 6 & $\begin{array}{lr}\text { Grant or } & \text { Release of } \\
\text { Security } & \text { Interest } \\
\text { (Mortgage) } & \\
\end{array}$ & 57610 & 3/7/1988 & $1 / 31 / 2013$ \\
\hline 7 & $\begin{array}{l}\text { NAFTA Statement of } \\
\text { Intent to Restore }\end{array}$ & $345^{2}$ & $6 / 15 / 1994$ & $1 / 3 / 1995$ \\
\hline 8 & $\begin{array}{lll}\text { Notice of Intent } & \text { to } \\
\text { Enforce under URAA } & \\
\end{array}$ & 10973 & $1 / 3 / 1996$ & $3 / 21 / 2000^{3}$ \\
\hline $\begin{array}{l}{ }^{1} \text { One ou } \\
{ }^{2} \text { Does } n \\
{ }^{3} \text { All but }\end{array}$ & $\begin{array}{l}\text { with a recording date of } \\
\text { aclude } 2 \text { documents that at } \\
\text { ef these documents wer }\end{array}$ & $\begin{array}{l}/ 03 / 1981 \\
\text { clearly not NAF } \\
\text { recorded by } 12 / 3\end{array}$ & $\begin{array}{l}\text { Statements of I } \\
997\end{array}$ & t to Restore \\
\hline
\end{tabular}

c. Registration Numbers. Of the approximately 8.3 million works specifically identified in recorded documents in the Catalog, about 3.7 million of them, or $45 \%$, are identified by registration number as well as title. These registration numbers are all entered into a defined MARC record subfield, $017 \mathrm{n}$. However, the registration numbers entered into $017 \mathrm{n}$ have not been validated either as to format or as to association with a valid registration record. In fact, few (if any) registration numbers in $017 \mathrm{n}$ are entered in the format used for registration numbers in corresponding registration records (in subfields $017 \mathrm{a}, 027 \mathrm{a}, 035 \mathrm{a}$, or 917a). Thus, records for recorded documents that contain registration numbers are not linked to corresponding registration records, and could not be so linked without modifying the format of the registration 
numbers as they appear in the recorded document records. ${ }^{86}$ Moreover, although a "keyword search" for a registration number in exactly the format that it is entered on a recorded document will retrieve that record, a keyword search for that registration number in any other format, including the format used in registration records, will not retrieve the recorded document record.

For example, recorded document number V3568D013 (which is actually one part of a document that has been divided into six parts) includes the conveyance of a registered work titled "King: style no. 31000." The registration number of that work is entered into the document record as "VA 1-134-876." A keyword search for the exact string "VA 1-134-876" will retrieve the document record for V3568D013. It will not retrieve the registration record for that work, because the format now used in registration records for that registration number is "VA0001134876." Conversely, a search for "VA0001134876" will retrieve the registration record, but not the record for document V3568D013. ${ }^{87}$

d. Types of Works Transferred. Although records for recorded documents sometimes contain information about the type of work being transferred - such as a literary work, motion picture, musical work, or graphic work - there is no standard list of terms used to provide that information, nor is the information always contained in a particular field. Thus, information about the types of works that particular documents concern is inconsistent and spotty.

\section{Recordation Fees, Staffing, and Processing Times.}

\section{Recordation Fees.}

From 1870 through 1997, Congress set the fees for recordation of documents (and for registration of claims to copyright) by legislation. As a result, fees were adjusted infrequently, and usually lagged behind the costs incurred by the Copyright Office. ${ }^{88}$ Congress initially set the basic fee for recordation under the Copyright Act of 1976 at \$10, which was not sufficient to cover the costs of recordation at that time. ${ }^{89}$ It raised the fee to $\$ 20$ in 1990 , but as Table 4 shows, that increase was just enough to keep pace with inflation, which had been particularly high in the late 1970s and early 1980s: under the CPI-U index of inflation, \$20 in 1990 was equal to only $\$ 10.52$ in 1978 dollars.

\footnotetext{
${ }^{86}$ Such modification could probably be accomplished for most records through the use of some cleverly formulated global search-and-replace functions, without having to manually modify the formats on a case-by-case basis.

${ }^{87}$ For policy implications of the decision not to standardize the format of registration numbers, see p. 116, infra.

${ }^{88}$ For a history of Copyright Office fees in relation to the cost of providing services, see Library of Congress Copyright Office, Fees, 63 Fed. Reg. 43426, 43427 (August 13, 1998), available at http://www.copyright.gov/fedreg/1998/63fr43426.pdf (last visited August 24, 2014).

${ }^{89}$ See id.
} 


\begin{tabular}{|l|l|l|l|}
\hline \multicolumn{4}{|c|}{$\begin{array}{c}\text { Table 4 } \\
\text { Recordation Fees, 1978-2014 } \\
\text { Basic Recordation Fee }\end{array}$} \\
\cline { 2 - 4 } $\begin{array}{l}\text { Effective Date } \\
\text { of Change }\end{array}$ & $\begin{array}{l}\text { Per 10 } \\
\text { (in Dollars) }\end{array}$ & $\begin{array}{l}\text { Additional Titles } \\
\text { Dollars, CPI-U) }\end{array}$ \\
\hline 1978 & 10 & 10 & $5^{*}$ \\
\hline January 1, 1990 & 20 & 10.52 & 10 \\
\hline July 1, 1999 & 50 & 19.57 & 20 \\
\hline July 1, 2002 & 80 & 28.99 & 20 \\
\hline July 1, 2006 & 95 & 30.72 & 25 \\
\hline August 1, 2008 & 105 & 31.91 & 30 \\
\hline May 1, 2014 & 105 & 28.84 & 35 \\
\hline *50 cents per additional title, or per page beyond six pages \\
\hline
\end{tabular}

In 1997, Congress granted the Copyright Office authority to set its own fees. ${ }^{90}$ The authorizing legislation provides that the fees have to be set on the basis of cost studies, though they also have to be "fair and equitable and give due consideration to the objectives of the copyright system." ${ }^{.91}$ Once the Copyright Office began to set fees on the basis of the actual costs of the labor-intensive process of recordation, recordation fees increased dramatically, both in nominal and real terms. The Copyright Office first increased the basic recordation fee from $\$ 20$ to $\$ 50$ on July 1, 1999, which represented a doubling of the 1978 fee in 1978 dollars, from $\$ 10$ to $\$ 19.57$. It again increased the basic recordation fee from $\$ 50$ to $\$ 80$ in 2002, which represented a near-tripling of the 1978 fee in 1978 dollars, from $\$ 10$ to $\$ 28.99$. After 2002, further fee increases did little more than keep up with inflation. The 2014 basic recordation fee, $\$ 105$, is $\$ 28.84$ in 1978 dollars, about the same as in 2002. Thus, over the last 36 years, it is the three years from 1999 to 2002 that is the crucial period from the perspective of constant-dollar pricing of recordation. That period saw first a doubling, and then a tripling, of the constant dollar fee. As will be further explored below, this price increase can likely be correlated with a significant drop in the number of documents submitted for recordation. ${ }^{92}$

Fees for recordation of documents, like all Copyright Office fees, are now based on "topdown" cost studies. Essentially, the total cost of running the Recordation Section, including a portion of indirect overhead costs, is divided by the total number of documents recorded, thus deriving a per-document cost of recordation, with an adjustment for number of titles per recorded document. The Copyright Act authorizes the Register to adjust fees "to not more than that necessary to cover the reasonable costs incurred by the Copyright Office" ${ }^{\prime 93}$ for the services

\footnotetext{
${ }^{90}$ See An Act to make technical amendments to certain provisions of title 17, United States Code, Public Law 10580, 111 Stat. 1529 (1997).

${ }^{91}$ Id. $\S 7$ (codified at 17 U.S.C. $\left.\S 708(\mathrm{~b})(4)\right)$.

${ }^{92}$ See infra pp. 44 - 48.

${ }^{93} 17$ U.S.C. $\S 708(b)(2)$.
} 
enumerated in the Act. It seems unlikely that these costs include long-term capital costs, because the Act does not seem to contemplate that the fees would be used to fund a multi-year capital improvement account. ${ }^{94}$ As for current costs, the mandate to adjust fees to no more than necessary to cover costs appears to be operative only at the aggregate level: fees for individual services might be set at below or above cost, an inference that is reinforced by the statutory mandate, mentioned above, that fees be "fair and equitable and give due consideration to the objectives of the copyright system." ${ }^{95}$ In practice, however, relatively little adjustment has been made for recordation fees.

\section{Staffing.}

The size and composition of the Recordation Section staff between 2005 and 2013 is detailed in Table 5 below. Due to budget constraints, the number of staff decreased greatly in 2010, from 15 to 9, with further decreases to 8 in 2011 and 7 in 2012. The reduced level of staffing was grossly inadequate to handle the number of documents remitted for recordation, which resulted in the increased processing times and backlog described below. In 2013, the Copyright Office hired five more document specialists, for a total of nine document specialists, two support specialists, and one section head.

\begin{tabular}{|l|c|c|c|c|c|c|c|}
\hline \multicolumn{7}{|c|}{ Table 5 } \\
\hline & $\begin{array}{c}\text { Full-Time } \\
\text { Contract } \\
\text { Employee }\end{array}$ & $\begin{array}{c}\text { Recordation } \\
\text { Specialist }\end{array}$ & $\begin{array}{c}\text { Senior } \\
\text { Recordation } \\
\text { Specialist }\end{array}$ & $\begin{array}{c}\text { Recordation } \\
\text { Support } \\
\text { Specialist }\end{array}$ & $\begin{array}{c}\text { Assistant } \\
\text { Section } \\
\text { Head }\end{array}$ & $\begin{array}{c}\text { Section } \\
\text { Head }\end{array}$ & TOTAL \\
\hline $\begin{array}{l}\mathbf{2 0 0 5 -} \\
\mathbf{2 0 0 9}\end{array}$ & $1 *$ & 8 & 2 & 2 & 1 & 1 & 15 \\
\hline $\mathbf{2 0 1 0}$ & 0 & 5 & 1 & 2 & 0 & 1 & 9 \\
\hline $\mathbf{2 0 1 1}$ & 0 & 5 & 0 & 2 & 0 & 1 & 8 \\
\hline $\mathbf{2 0 1 2}$ & 0 & 4 & 0 & 2 & 0 & 1 & 7 \\
\hline $\mathbf{2 0 1 3}$ & 0 & 9 & 0 & 2 & 0 & 1 & 12 \\
\hline $\begin{array}{l}* \\
\text { * In addition, between 2005 and 2009 an independent contractor handled some of the work of } \\
\text { entering titles in large documents into the database. }\end{array}$ \\
\hline
\end{tabular}

\section{Processing Times.}

Since mid-2007, each Catalog record of a recorded document has contained both information about the date of recordation of that document, and information about the dates that the record was uploaded from the internal processing system to the public Voyager catalog. (The former is in Subfield 017f; the latter is in Subfield 917n.) By subtracting the date of recordation

\footnotetext{
${ }^{94}$ The Act does provide that ' $[\mathrm{s}] \mathrm{uch}$ fees that are collected shall remain available until expended, 17 U.S.C. § 708(d)(1), but this likely contemplates occasional carryover from one fiscal year to the next rather than the funding of a capital improvement account.

${ }^{95} 17$ U.S.C. $\S 708(b)(4)$.
} 
from the date of entry in the public catalog, we can get a pretty good idea of how long processing of a document takes.

\begin{tabular}{|r|r|r|r|r|r|r|}
\hline \multicolumn{7}{|c|}{ Pable 6 } \\
\hline \multicolumn{7}{|c|}{ Processing Times for Document Recordation } \\
\hline \multicolumn{2}{|c|}{ (Number of Days Elapsed Between Date of Recordation and Date of Uploading to Public Catalog) } \\
\hline Year & Half & Average & \multicolumn{1}{|c|}{ First Quartile } & \multicolumn{1}{l|}{ Third Quartile } & 1 Work & $>99$ Works \\
\hline 2008 & 1 st Half & 118 & 88 & 133 & 115 & 253 \\
\hline & 2nd Half & 136 & 84 & 137 & 126 & 333 \\
\hline 2009 & 1st Half & 133 & 95 & 147 & 131 & 256 \\
\hline & 2nd Half & 151 & 105 & 159 & 153 & 398 \\
\hline 2010 & 1st Half & 173 & 150 & 185 & 170 & 348 \\
\hline & 2nd Half & 215 & 163 & 220 & 199 & 472 \\
\hline 2011 & 1st Half & 239 & 197 & 230 & 248 & 457 \\
\hline & 2nd Half & 271 & 228 & 258 & 257 & 596 \\
\hline 2012 & 1st Half & 356 & 293 & 332 & 340 & 677 \\
\hline & 2nd Half & 463 & 339 & 380 & 461 & 834 \\
\hline
\end{tabular}

Table 6 contains a variety of statistics about processing times of recorded documents, defined as number of days from date of recordation to date of uploading to the public catalog, from 2008 through 2012, by half-year, counting back from the uploading date. The "Average" column displays the average number of processing days for all recorded documents. The "first quartile" and "third quartile" columns display the number of processing days for the longest processing time of a document in the top $25 \%$ and top $75 \%$ of documents, respectively, as ranked by processing time. They are intended to give some idea of variation in processing times. The "1 Work" column displays the average processing time for all documents that concern a single work; the ">99 Works" column displays the average processing time for all documents that concern more than 99 works.

The table shows that processing of documents was relatively slow even in 2008, a year in which it took 118 days on average - almost four months - from the date on which the document was properly received with all fees paid to the date on which processing was complete and the document record entered the public catalog. However, between 2008 and 2012, the average processing time more than tripled, from 118 days to 463 days, and all other figures increased as well. In the first half of 2008, the average processing time for documents concerning more than 99 works was 138 days longer than the processing time for documents concerning one work; by the second half of 2012, that disparity had increased to 373 days. Processing time for the onequarter of documents that took the longest to process was so long in 2011 and 2012 that the average processing time sank below the third quartile figure. 


\section{The Big Picture: Trends in Document Recordation and Case Law Since 1978}

This part of this report surveys two aspects of document recordation under the Copyright Act of 1976. Part III.A. reviews statistical trends in recorded documents. Part III.B. reviews judicial decisions.

\section{A. Document Recordation, 1978-2009.}

To understand the importance of copyright recordation for various types of copyright transactions, the factors that may affect rates of recordation, and the challenges that recordation may face, it is useful to survey trends in copyright recordation since 1978, the year in which the Copyright Office began to keep electronic records of recorded documents. This survey will cover the 32 years from 1978 through $2009 .^{96}$

For those 32 years, the Research Database based on the Copyright Office Catalog as of March 2013 contains records of 454,974 recorded documents. Those documents reference approximately $8,000,000$ identified works. $^{97}$

\footnotetext{
${ }^{96}$ Due to the delays in recordation discussed above, electronic records for documents recorded after 2009 were significantly incomplete at the time this survey was conducted.

${ }^{97}$ Because the Copyright Office Catalog contains separate records for each work in a document that references more than one work, we can easily calculate that the multiwork documents recorded from 1978 through 2009 referenced 7,736,596 works. During that period, there were 339,343 documents that did not reference more than one work. The vast majority of those documents referenced one work, but some of them - such as statements of the death of an author or agreements concerning an unidentified number of works to be created in the future - referred to no identified works. Because of the way that documents are cataloged, it is a far more laborious task to separate out documents that reference one work from those that reference none, and that task has not yet been undertaken.
} 


\section{Figure 1:}

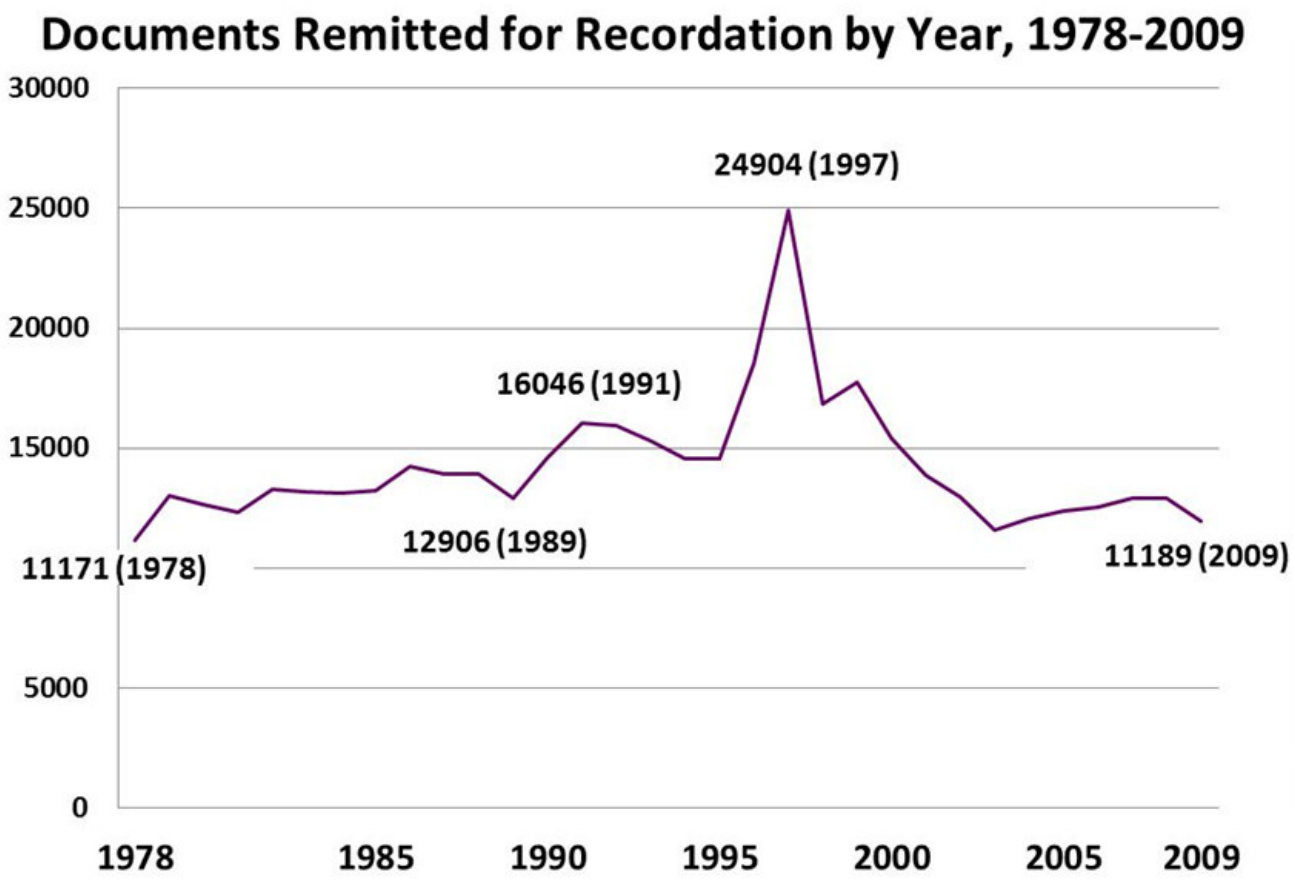

Figure 1 shows the number of documents remitted for recordation per year from 1987 through 2009. ${ }^{98}$ The number of documents for the first and last years in that range, 1987 and 2009, are remarkably similar: 11,171 and 11,189 . As we will see below, however, the types of documents recorded in those two years, and the number of works represented in those documents, is quite different.

The peak year in the range was 1997, a year in which 24,904 documents were recorded. As figure 2 shows, that remarkably high recording rate was due in large part to the recording of Notices of Intent to Enforce Restored Copyrights under the Uruguay Round Agreements Act. Under one provision of that Act, codified at 17 U.S.C. $\S 104 A(d)(2)(A)(i)$, an owner of a copyright that had been restored under the Act could bring an action against a "reliance party," if, among other things, that owner had filed a Notice of Intent to Enforce a Restored Copyright with the Copyright Office "during the 24-month period beginning on the date of restoration." 99 The "date of restoration" for all works the source countries of which were Berne Convention or WTO member countries on January 1, 1996 was that date: January 1, 1996. ${ }^{100}$ As a result, a

\footnotetext{
${ }^{98}$ The dates used for purposes of this figure are the dates of recordation - the dates on which each of the documents was properly remitted with the correct fee - not the dates that processing was completed or any other dates associated with the documents.

${ }^{99} 17$ U.S.C. $\S 104 \mathrm{~A}(\mathrm{~d})(2)(\mathrm{A})(\mathrm{i})$.

${ }^{100}$ See 17 U.S.C. $\$ 104 A(h)(2)(A)$.
} 
very large number of Notices of Intent to Enforce were filed in 1996 and 1997: 2713 in 1996, and 8256 in 1997.

One other type of document generally grouped with recorded documents is separated out in Figure 2. As noted above, ${ }^{101}$ notifications of litigation required to be filed under Section 508 were cataloged for only two-and-a-half years beginning in 1978. Figure 2 shows the number of recorded documents after subtracting out 728 Section 508 notifications filed in 1978, 1313 such notifications filed in 1979, and 568 filed in 1980. When the total number of recorded documents at the beginning and end of the range, 1978 and 2009, is now compared, 2009 is about seven percent higher.

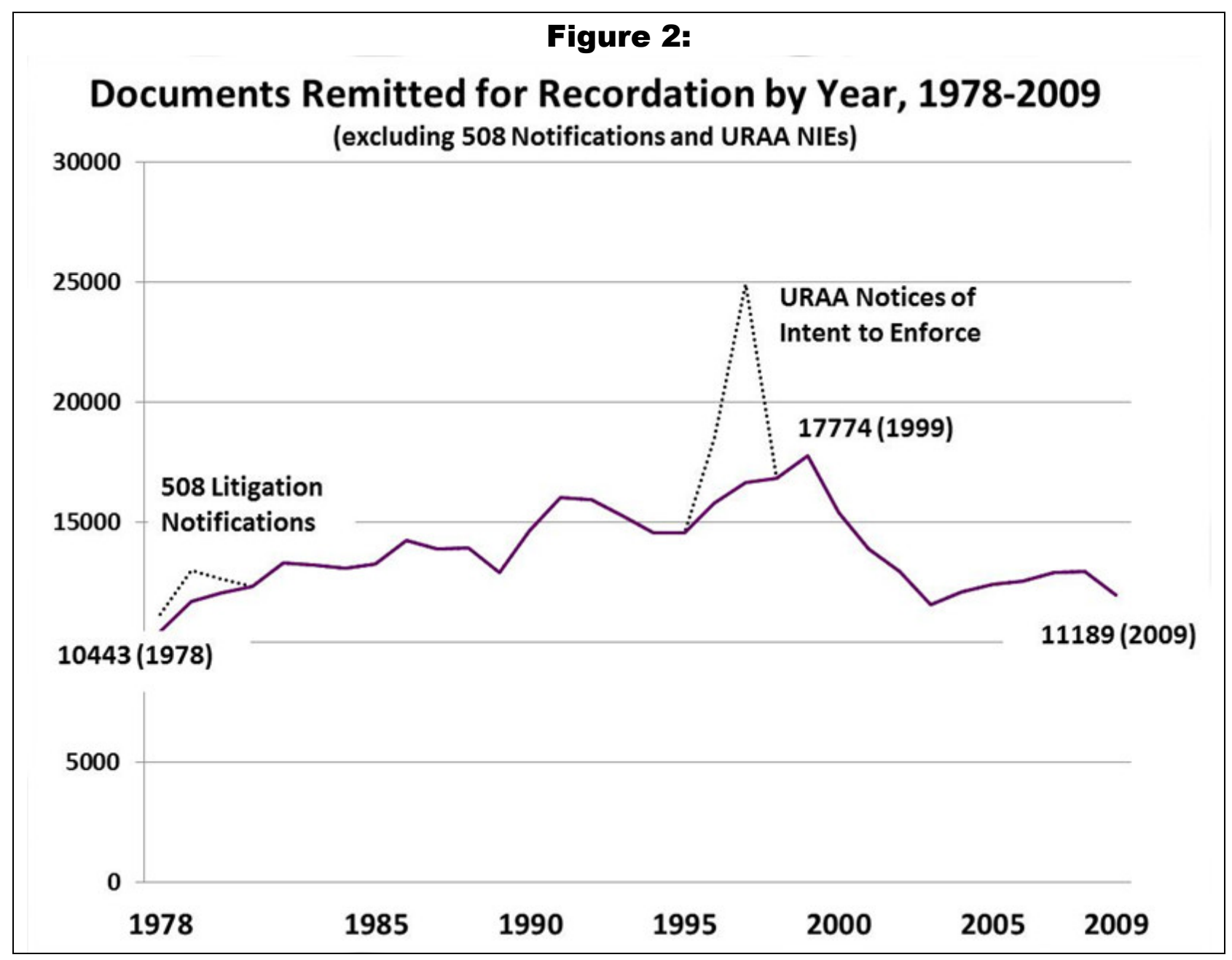

${ }^{101}$ See supra n. 85. 
When one further separates out types of documents recorded, perhaps the most dramatic phenomenon that emerges is the increase in importance of financing documents - documents connected with financing transactions involving works under copyright, and titled "Grant of Security Interest," "Mortgage," and the like - over the 1978-2009 period. Although many of these documents are connected with traditional loans, the category is broader. For example, the Screen Actors Guild - American Federation of Television and Radio Artists (SAG-AFTRA) stated in its comments to the recordation Notice of Inquiry that it "records hundreds of secured interests . . . relating to the copyright of Union-covered motion pictures in order to secure the payment obligations of producers who employ our members." ${ }^{102}$ Such documents would also fall into the category of "financing documents."

In 1978, only 74 recorded documents had titles transcribed into Catalog records by which they could be identified as financing documents. By 2000, there were 4484 such documents, and after a slight dip in the early- to mid-2000s, the number of financing documents recorded reached an all-time high of 4505 in 2008.

\section{Figure 3:}

\section{Assignments and Financing Documents (Adjusted)}

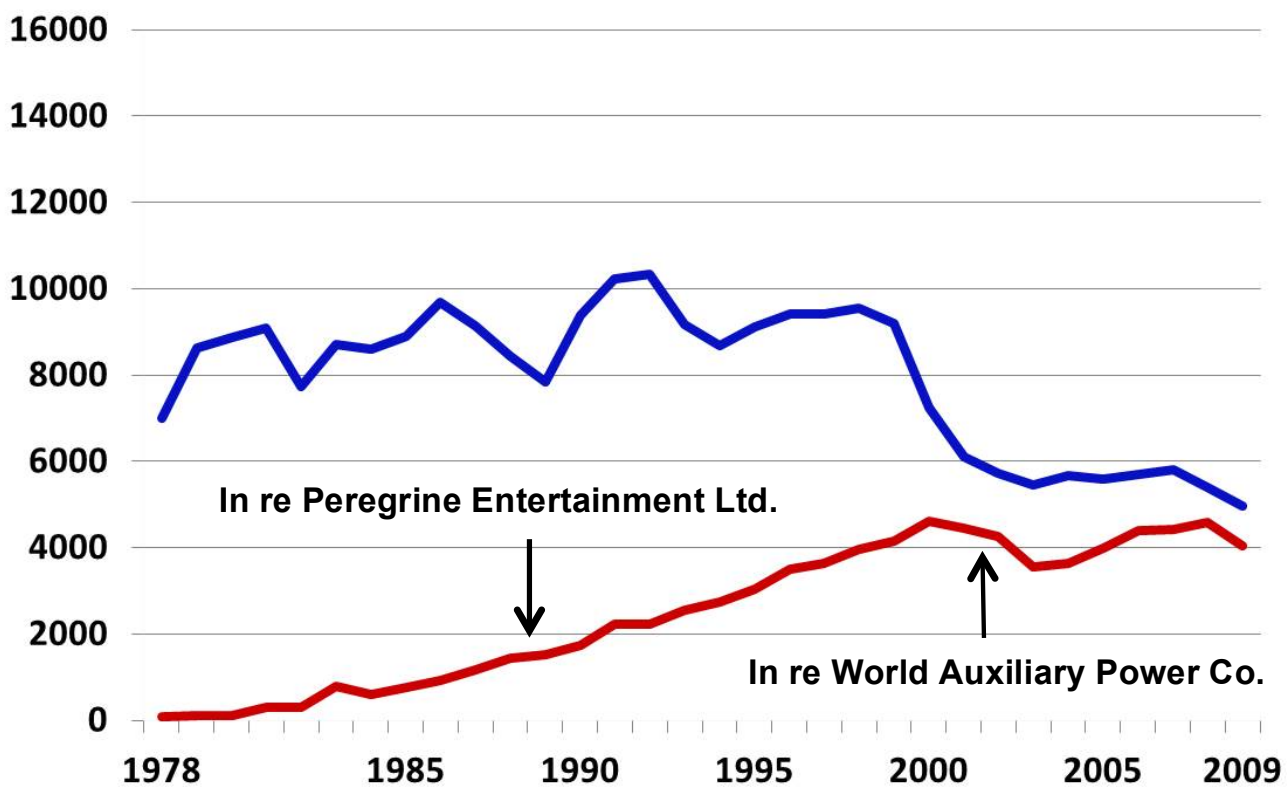

${ }^{102}$ NOI Comments of Screen Actors Guild - American Federation of Television and Radio Artists, p. 1. 
Figure 3 compares recording rates for financing documents and assignments. ${ }^{103}$ That Figure shows, first, the trend just described, namely that the number of recorded financing documents rose steadily from 1978 to 2000, dipped 2000-2003, and then rose again. It also shows the timing of two court decisions that likely had some influence on the financing document numbers. For some time, it was unclear whether perfection of security interests in works under copyright should be accomplished by recording the security interest grants at the Copyright Office, or by filing financing statements under the Uniform Commercial Code at relevant state offices. In 1990, the Central District of California (Kozinski, J., sitting by designation) held in In re Peregrine Entertainment, Ltd. ${ }^{104}$ that recording at the Copyright Office was the proper route to perfection of security interests. Twelve years later, in In re World Auxiliary Power Co., ${ }^{105}$ the Ninth Circuit Court of Appeals refined the ruling in Peregrine Entertainment. It held that while the Copyright Office recordation was the correct method for perfecting security interests in registered works, UCC financing statement filing was the correct method for perfecting security interests in unregistered works.

As for assignments, Figure 3 shows that while the number of recorded assignments remained mostly in the range of 8000 to 10,000 between 1978 and 1999, it then dramatically declined in 2000 and 2001, and since then has hovered below 6000 per year. Thus, at the same time that recording of financing documents is flattening out, in 2000, recording of assignments is dropping $25-40 \%$. As discussed above, this is exactly the period in which the most dramatic increases in recording fees occurred - a quadrupling in nominal fees, and a tripling in constant 1978 dollars, over the course of three years.

\footnotetext{
${ }^{103}$ The numbers in Figure 3 are adjusted to compensate for the varying number of Catalog records in which the field for transcription of the document title or heading is blank. Because the varying number of blank title fields very likely result from changes in cataloging practices, the Figure 3 numbers have been adjusted to allocate a proportional number of blanks to the categories of assignments and financing documents.

104 116 B.R. 194 (C.D. Cal. 1990).

${ }^{105} 303$ F.3d 1120 (9th Cir. 2002).
} 


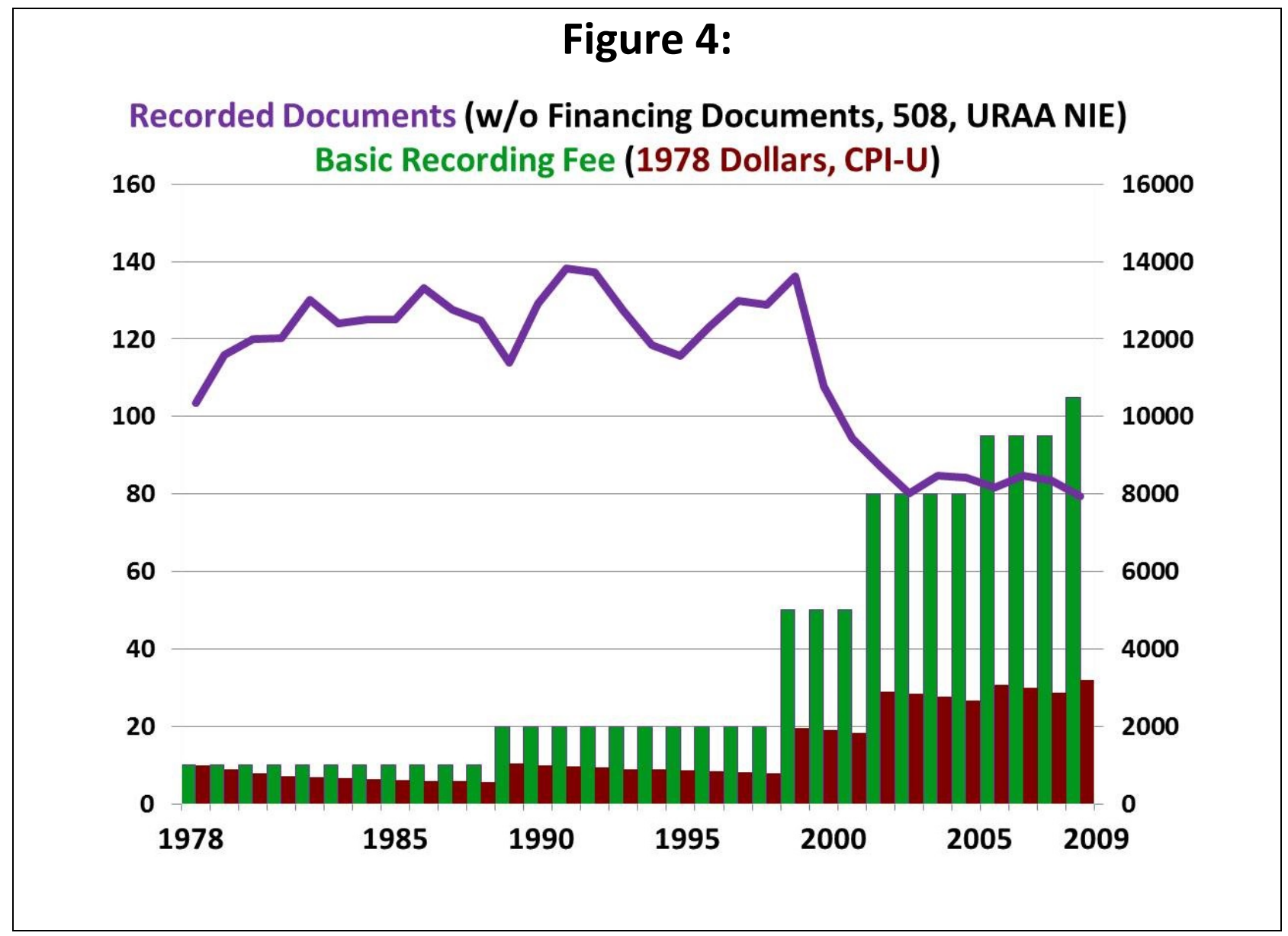

Figure 4 shows recording rates for all documents other than financing documents, URAA Notices of Intent to Enforce, and Section 508 notifications, juxtaposed against nominal basic recording fees (in green) and recording fees in constant 1978 dollars (in red).

With financing documents removed, ${ }^{106}$ the rate of document recording looks like it bears a substantial correlation to recording fees. Recording rates most substantially drop in 2000-2003, exactly the period in which recording fees most substantially increase. There may well be some causation behind that correlation, but a layer of complication is added by considering the number of works represented in the documents recorded.

\footnotetext{
${ }^{106}$ The theory on which financing documents are removed is that recording rates for financing documents are likely not to be sensitive to recording fees, because lenders will require a perfected security interest and the financing transactions are likely large enough that a recording fee in the range of $\$ 105$ or less will be an extremely small percentage of the transaction's value.
} 
Figure 5 shows the number of works represented in recorded documents by year. It reveals a more erratic trend, but with a decidedly upward slant that persists right through the end of the range under study. The peak year is 2008, a year in which documents representing 473,353 identified works were recorded, almost seven times the number of works represented in documents recorded in 1978.

\section{Figure 5:}

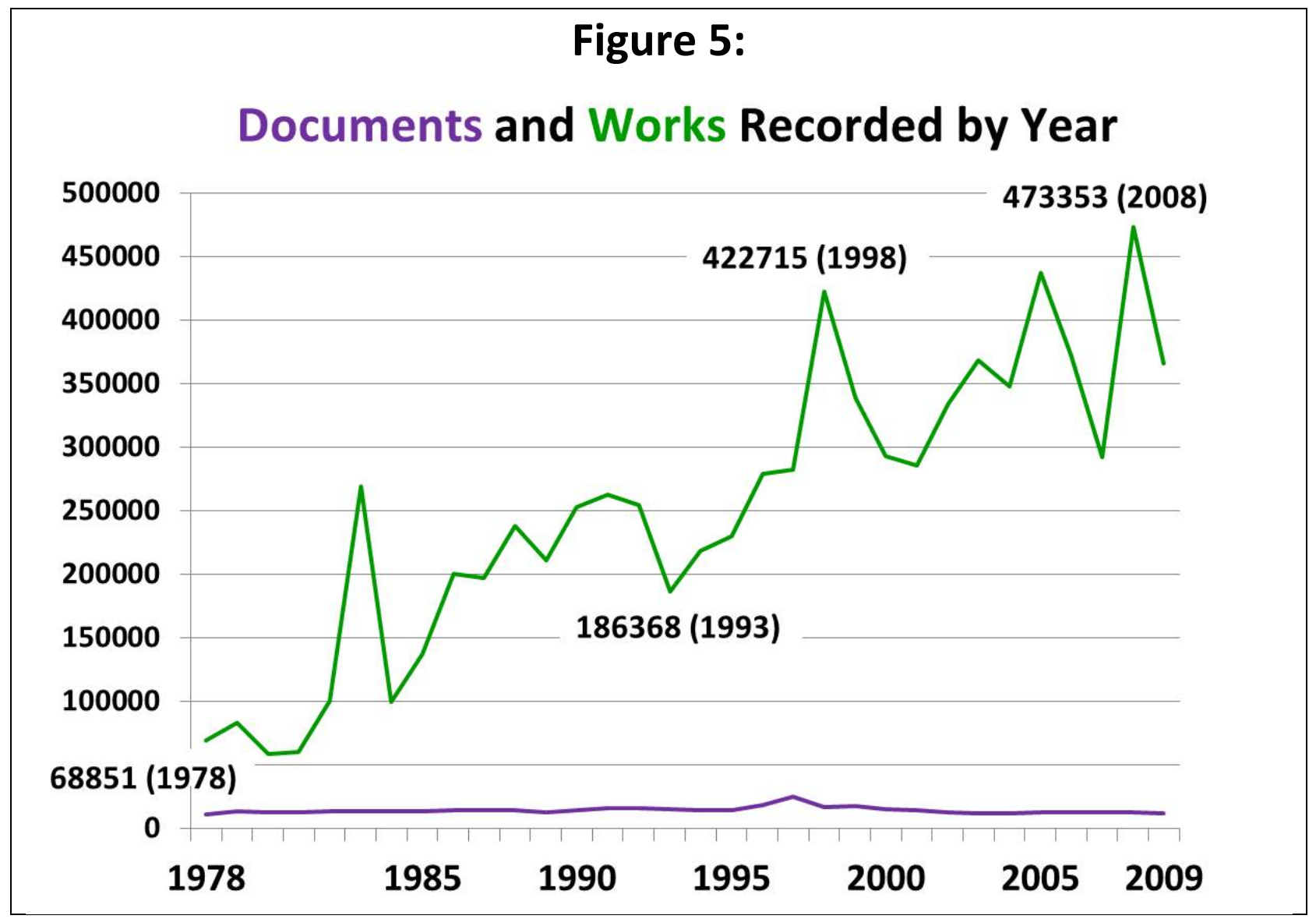


Figure 6 displays the same information about works per year as Figure 5, but it breaks each year down by document size ranges, showing, for each year, the number of works that appear in single-work documents; in documents with 2-99 works; in documents with 100-999 works; in documents with 1000-9999 works; and in documents with 10,000 or more works. Figure 6 makes clear that some of the bigger swings in numbers of works from year to year are due to a few very large transactions of 10,000 or more works. However, it also reveals that the number of transactions involving 100-999 works and 1000-9999 works have grown tremendously.

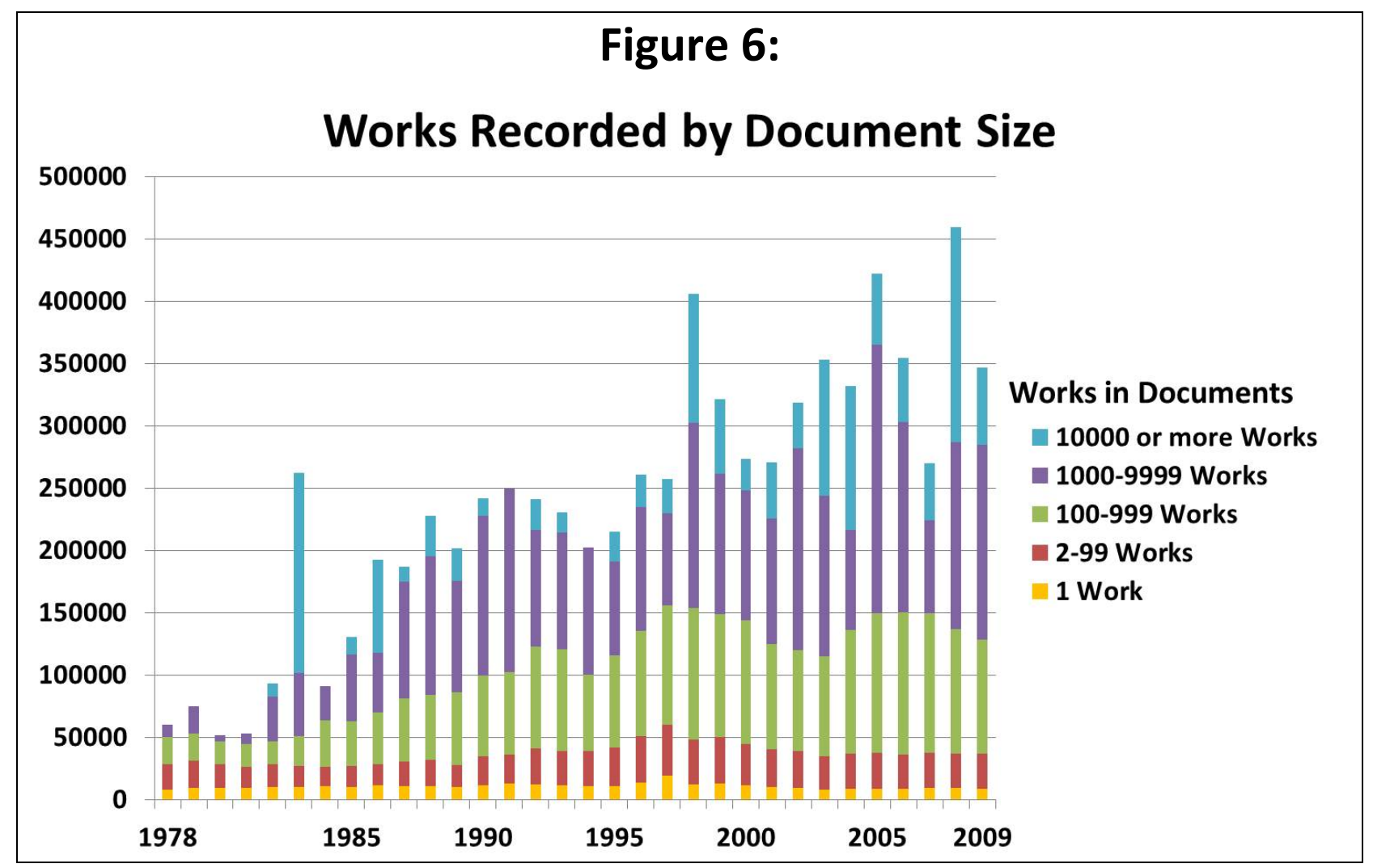


Figure 7 returns to a breakdown of document types, analyzing the number of works represented in assignments and financing documents. It reinforces the finding presented above about the increasing importance of financing transactions in recorded documents. It shows that the growth in number of works represented in recorded documents over the last decade has been due almost entirely to financing documents. The number of works represented in assignments reached a peak in 2003, and declined after that. By contrast, the number of works represented in financing documents increased substantially, and since 2005 financing documents have accounted for over twice as many works as assignments.

\section{Figure 7:}

\section{Works Represented in Assignments and Financing Documents}

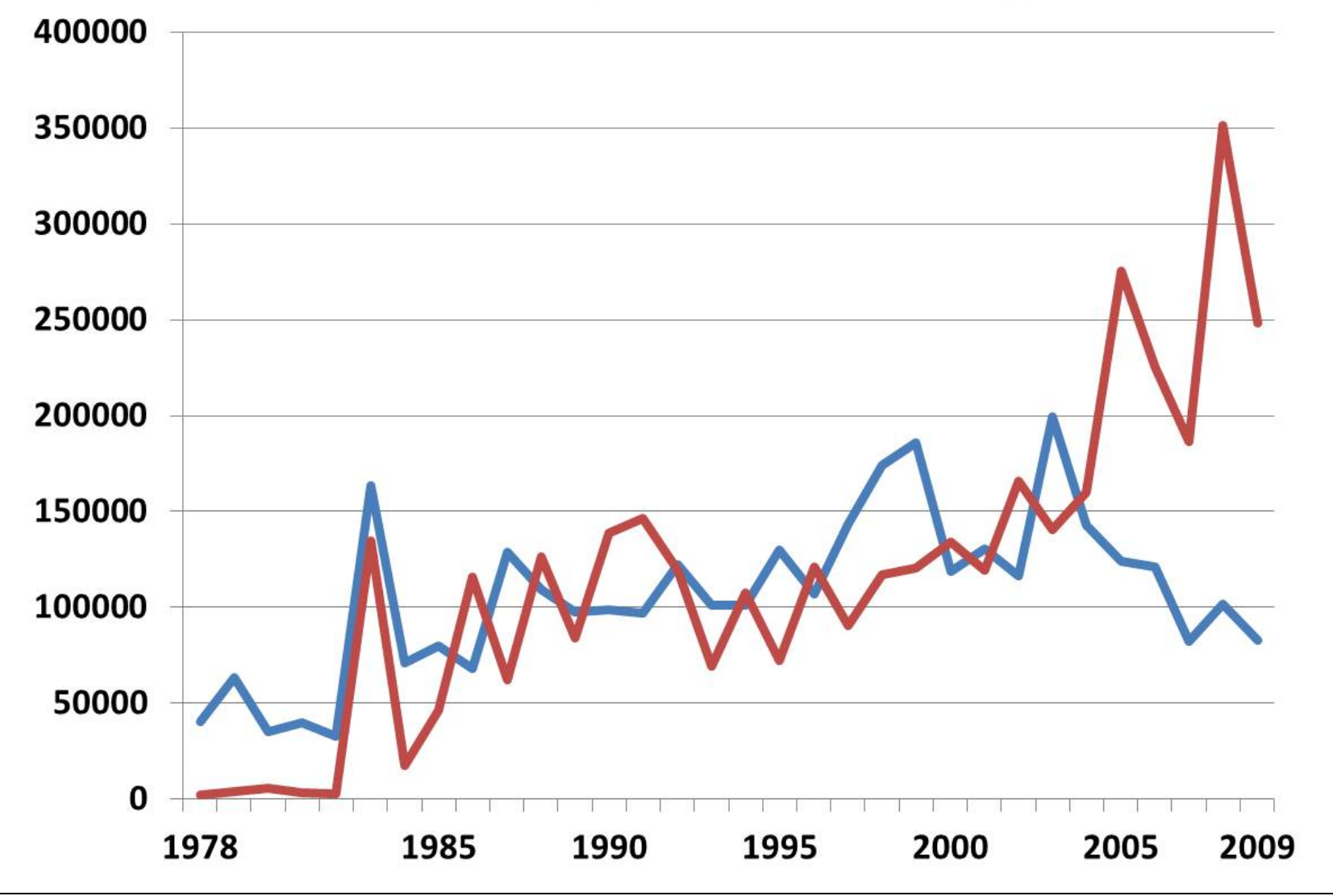

Finally, it is possible that the increase in the number of recorded financing documents, and the number of works represented in those documents, is due in part to the fact that a single financing transaction may generate two documents: a grant of an interest to secure a loan, and a release of that interest when the loan is repaid in full. To gauge the extent to which releases are influencing the financing document numbers, a search was performed to exclude financing documents the titles of which contained "release." Figure 8 shows that releases account for a substantial percentage of works in some years - notably 1983 and 1990 - but that they generally 
account for far less than $50 \%$ of works represented in financing documents. Even without releases, financing documents exhibit the same upward trend, and account for a majority of works represented in recorded documents in the last five years of the range studied, from 2005 to 2009.

\section{Figure 8:}

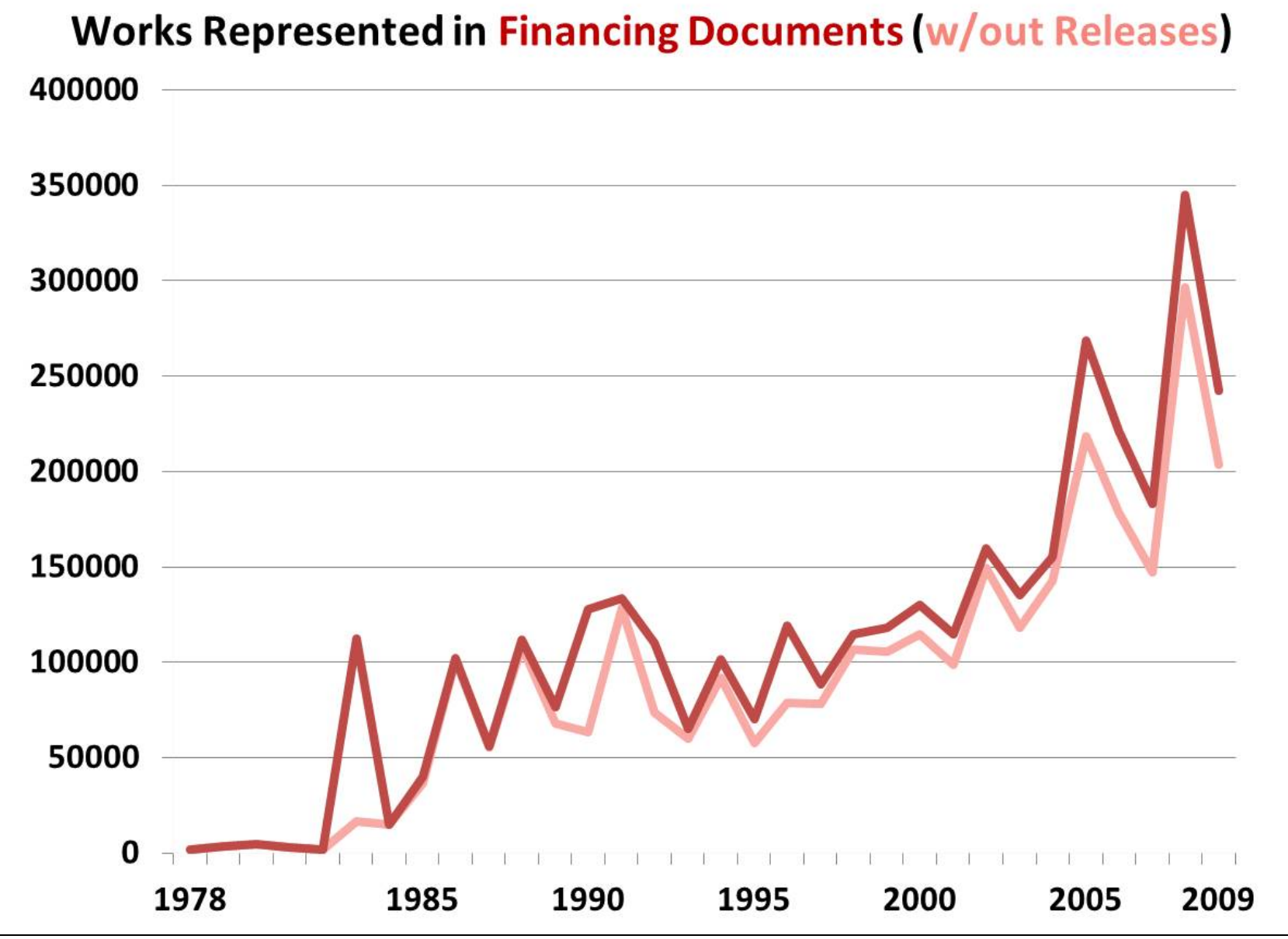

As might be imagined, nothing definitive can be said about the causes underlying all of these trends. However, some potential causes can be identified and partially assessed:

- Increase in Recording Fees. It seems likely that increases in recording fees have had some effect on recording rates. As Table 3 and Figure 4 above showed, the greatest increases in recording fees occurred in July 1999 and July 2002. Single-work documents effecting assignments, which one might expect to be the most price-sensitive, suffered the greatest decreases in recording rates from before those fee increases to after them: 6255 assignments were recorded in 1999, but an average of only 3751 for the years 2003-2009, a decline of $40 \%$. Single-work financing documents also faced a decrease, but a smaller one, from 3151 in 1999 to an average of 2552 in the years 2003-2009, a decline of 19\%. 
- Macroeconomic Trends. As Table 7 shows, from 1999-2012 the U.S. economy as a whole expanded in every year, except for contractions in 2008 and 2009; production did not exceed the 2007 level until 2011. Similarly, the core copyright industries grew in every year except for 2009; production did not exceed the 2008 level until 2011. Thus, if rates of recording copyright documents tracked either the US economy or production in the core copyright industries, we would expect to see a steady rise, interrupted only in the late 2000s.

\begin{tabular}{|c|c|c|}
\hline \multicolumn{3}{|c|}{$\begin{array}{c}\text { Table } 7 \\
\text { Production in the United States and in the U.S. Core Copyright Industries, } \\
1999-2012\end{array}$} \\
\hline Year & US GDP in trillions ${ }^{1}$ & $\begin{array}{l}\text { Core Copyright Industries in } \\
\text { Billions }\end{array}$ \\
\hline 1999 & 12.33 & 477.9 \\
\hline 2000 & 12.68 & 506.8 \\
\hline 2001 & 12.71 & $535.1^{2}$ \\
\hline 2002 & 12.96 & $626.2^{3}$ \\
\hline 2003 & 13.53 & 698.72 \\
\hline 2004 & 13.95 & 765.88 \\
\hline 2005 & 14.37 & 810.84 \\
\hline 2006 & 14.72 & $858.28^{4}$ \\
\hline 2007 & 15.00 & 898.58 \\
\hline 2008 & 14.57 & 925.96 \\
\hline 2009 & 14.54 & 864.05 \\
\hline 2010 & 14.94 & 900.04 \\
\hline 2011 & 15.24 & 955.10 \\
\hline 2012 & 14.94 & $992.46^{5}$ \\
\hline \multicolumn{3}{|c|}{$\begin{array}{l}2 \text { figures for } 1999-2001 \text { are in } 2001 \text { dollars. See Stephen E. Siwek, Copyright Industries in the U.S } \\
\text { Economy: The } 2002 \text { Report } 21 \text { (2002), available at } \\
\text { http://www.iipa.com/pdf/2002_SIWEK_FULL.pdf. }\end{array}$} \\
\hline \multicolumn{3}{|c|}{$\begin{array}{l}{ }^{3} \text { See Stephen E. Siwek, Copyright Industries in the U.S. Economy: The } 2004 \text { Report } 13 \text { (2004), } \\
\text { available at http://www.iipa.com/pdf/2004_SIWEK_FULL.pdf. }\end{array}$} \\
\hline \multicolumn{3}{|c|}{$\begin{array}{l}{ }^{4} \text { figures for the years } 2003-2006 \text { are in chained } 2000 \text { dollars. See Stephen E. Siwek, Copyright } \\
\text { Industries in the U.S. Economy: The 2003-2007 Report } 4 \text { n.5, } 18 \text { (2009), available at } \\
\text { http://www.iipa.com/pdf/IIPASiwekReport2003-07.pdf }\end{array}$} \\
\hline \multicolumn{3}{|c|}{$\begin{array}{l}{ }^{5} \text { figures for the years } 2007-2012 \text { are in } 2005 \text { dollars. See Stephen E. Siwek, Copyright Industries } \\
\text { in the U.S. Economy: The } 2011 \text { Report } 16 \text { (2013), available at } \\
\text { http://www.iipa.com/pdf/2011CopyrightIndustriesReport.PDF ; Stephen E. Siwek, Copyright } \\
\text { Industries in the U.S. Economy: The } 2013 \text { Report } 18 \text { (2013), available at } \\
\text { http://www.iipa.com/pdf/2013_Copyright_Industries_Full_Report.PDF }\end{array}$} \\
\hline
\end{tabular}


- Industry Concentration. Perhaps the number of transactions between firms, and hence the number of recorded documents, would decrease if the number of firms that dominated the market for creative works decreased (although there would still be assignments from authors to those firms, unless the authors were employees and the works were made for hire, a factor that will be considered below). As Table 8 shows, however, the U.S. Census Bureau has found only modest increases in concentration in many major copyright industries between 2002 and 2007, with the largest single increase being a $3.5 \%$ increase in the revenue share of the four largest companies in motion picture and video production. At the same time, the book publishing industry experienced a decrease in concentration on all levels - among the four, eight, and twenty largest firms, and all of the other industries for which statistics were gathered experienced decreases on at least one of those three levels. Thus industry concentration is unlikely to be a strong cause of changes in recording rates.

\begin{tabular}{|l|c|c|}
\hline \multicolumn{3}{|c|}{$\begin{array}{c}\text { Table 8 } \\
\text { Establishment and Firm Size: Concentration } \\
\text { by Largest Firms for the United States }\end{array}$} \\
\hline & Percentage of Industry Receipts \\
\hline Number of Firms & 2002 & 2007 \\
\hline Book Publishers & 40.7 & 33.4 \\
\hline 4 largest & 55.2 & 48.0 \\
\hline 8 largest & 72.7 & 68.3 \\
\hline 20 largest & & \\
\hline Software Publishers & 39.5 & 38.9 \\
\hline 4 largest & 45.6 & 46.6 \\
\hline 8 largest & 56.3 & 58.1 \\
\hline 20 largest & & \\
\hline Motion Picture and Video Production & 49.2 & 52.7 \\
\hline 4 largest & 67.6 & 66.4 \\
\hline 8 largest & 73.6 & 75.0 \\
\hline 20 largest & & \\
\hline Sound Recording Industries & 60.9 & 63.4 \\
\hline 4 largest & 78.4 & 76.9 \\
\hline 8 largest & 85.0 & 82.0 \\
\hline 20 largest & & \\
\hline Music Publishers & 55.4 & 57.1 \\
\hline 4 largest & 72.1 & 74.6 \\
\hline 8 largest & 88.4 & 85.8 \\
\hline 20 largest &
\end{tabular}

\footnotetext{
${ }^{107}$ This data is taken from U.S. Census Bureau, Establishment and Firm Size: Concentration by Largest Firms for the United States: 2007,

http://factfinder2.census.gov/faces/tableservices/jsf/pages/productview.xhtml?pid=ECN 2007 US 51SSSZ6\&prod Type=table (last visited July 28, 2014).
} 
- Works Made for Hire. As mentioned in the previous paragraph, a substantial change in the percentage of works that were created as works made for hire by employees might result in a change in the number of recorded documents, since in those cases no written transfers would be necessary to vest ownership of those works in the employers, which might be companies that owned and exploited the works for long periods of time.

Unfortunately, research done so far on the numbers of registration records per year in the Copyright Office Catalog that mention "work made for hire" or "employer for hire" suggests that very significant changes in those numbers are likely due to changes in cataloging practices rather than changes in the authorship of the registered works. Preliminary searching of the Catalog records reveals that the MARC field that contains work made for hire information has changed over time, from $249 \mathrm{c}$, to $279 \mathrm{c}$, to $279 \mathrm{~h}$. However, even searches that take all three of those fields into account generate suspicious results. Those searches reveal two dramatic changes in the numbers of works made for hire. From 1978 through 1991, between 60,000 and 80,000 records per year contain "for hire" language. There is then a dramatic drop in 1992 and 1993, and from 1993 through 2006 , only 20,000 to 30,000 records per year contain a "for hire" notation. That is followed by an even more dramatic increase in 2007 and 2008, and from 2008 through 2012, between 157,000 and 191,000 records per year contain a "for hire" notation. The latter increase coincides in time with the introduction of the electronic registration system. It is thus likely that the two large changes in yearly rates of "for hire" works resulted from changes in registration and cataloging practices, and that leaves us without a good idea of what the figures would be had there been a consistent and accurate method for noting whether a work was created as a work made for hire. More research would have to be done to see whether there was some alternative method of estimating consistent numbers.

- Processing times. Long delays between the time documents are remitted and the time they are placed on public record might also discourage recordation. Unfortunately, the Copyright Office Catalog began only in mid-2007 to contain information about the date that each document record was uploaded to the public catalog, and therefore before that time the precise delay between the date each document was remitted and the date the record for that document entered the public catalog cannot be calculated. ${ }^{108}$ Information about earlier processing times comes only from intermittent mentions in Copyright Office Annual Reports. The Annual Reports for Fiscal Years 1998 through 2002 do not mention processing times. The Annual Report for Fiscal Year 2003 states that the Document Recordation Section "cut its processing time by more than half"; ${ }^{109}$ the Annual Report for

\footnotetext{
${ }^{108}$ For a review of processing times since mid-2007, see supra p. 33.

${ }^{109}$ See United States Copyright Office, $106^{\text {th }}$ Annual Report of the Register of Copyrights for the Fiscal Year Ending September 30, 2003, at 11, available at http://copyright.gov/reports/annual/2003/Annual Report 2003 Full.pdf (last visited August 25, 2014).
} 
Fiscal Year 2004 states that "[a]s of the end of Fiscal Year 2004, the average processing time was down to 33 days, more than six times faster than the average of 210 days three years earlier." $" 110$ It may be that the very long processing time in Fiscal Year 2001 contributed to the drop in documents remitted between 2000 and 2003. However, most remitters are likely only generally aware of how long it takes to process documents, and that awareness probably lags changes in processing times by months or years. By contrast, changes in recording fees are noticed immediately and at the time that the of decision whether or not to remit a document.

It the end, it is only the increase in recording fees that correlates closely with the substantial drop in non-financing-related documents recorded in the early 2000s. While that does not "prove" causation, it lends the hypothesis that the fee increases were the cause of the substantial drop has some degree of persuasiveness.

\section{B. Case Law Regarding Recordation under the 1976 Act.}

The subject of recordation of documents pertaining to copyright has produced relatively few published judicial opinions, from which one should be able to infer that copyright recordation is litigated relatively infrequently. A search of the West key number for copyright recordation, for example, returns only 51 opinions from 1847 to the present. ${ }^{11}$ By contrast, searches of the West key numbers for recordation of deeds and of mortgages concerning real property return a total of 1998 opinions. ${ }^{112}$

A review of the judicial decisions concerning recordation of documents under the Copyright Act of 1976 reveals five major topics addressed: (1) straightforward applications of priority rules; (2) notice, and inquiry notice in particular; (3) the role of registrations in providing notice and establishing priority; (4) bankruptcy and the perfection of secured interests; and (5) the requirement to record before filing a lawsuit under the former $\S 205(\mathrm{~d}) .{ }^{113}$ This report will briefly consider each of those topics in turn.

\footnotetext{
${ }^{110}$ See United States Copyright Office, Annual Report of the Register of Copyrights, Fiscal Year Ending September 30, 2004, at 8, available at http://www.copyright.gov/reports/annual/2004/annual2004.pdf (last visited August 25, 2014).

${ }^{111}$ The West key number for copyright recordation, 99-46, returned 51 results (search performed on August 12, 2014).

${ }^{112}$ The West key number division for recordation of deeds, 120II, returned 1165 results (search performed on August 12, 2014); The West key number division for recordation of mortgages, 266II, returned 833 results (search performed on August 12, 2014).

${ }^{113}$ There are also a number of opinions that mention recordation of documents only in the course of rejecting obviously invalid arguments made by parties, such as an argument that recording a transfer in an unregistered work meets the Copyright Act's requirement of registering the work before filing an infringement suit. See Latin American Music Co. Inc. v. Media Power Group, Inc., 705 F.3d 34, 43 ( $1^{\text {st }}$ Cir. 2013).
} 


\section{Straightforward Applications of Priority Rules.}

In Mattel, Inc. v. MGA Entertainment, Inc., ${ }^{114}$ the court ruled that an earlier transfer of copyright that had been recorded prevailed over a later transfer that had never been recorded. In Quality Records, Inc. v. Coast to Coast Music, Inc., ${ }^{115}$ the court ruled that a later recorded transfer prevailed over an earlier unrecorded transfer, where there was no evidence that the subsequent purchaser had any notice of the earlier transfer. In Bankers Capital Corp. v. Brummet, ${ }^{116}$ the court held that an unrecorded assignment was still valid as between the parties to that assignment, since the failure to record only rendered the assignment potentially inferior to subsequent transfers. ${ }^{117}$

\section{Notice - Particularly Inquiry Notice.}

In Vapac Music Pub., Inc. v. Tuff ' $N$ ' Rumble Management, ${ }^{118}$ the court held that the "notice" that a subsequent purchaser must not have to prevail over a prior purchaser under $\S$ 205(d) includes inquiry notice. ${ }^{119}$ Because the plaintiff might be able to prove that the defendants had inquiry notice of the plaintiff's interest at the time the defendant acquired its interest, dismissal of the lawsuit for failure to state a claim was inappropriate. ${ }^{120}$ In Fox v. Riverdeep, ${ }^{121}$ the court denied the defendant's motion for summary judgment on the issue of whether defendant's nonexclusive license prevailed over plaintiff's unrecorded transfer under $\S 205(\mathrm{e})$, because although defendant did not have constructive notice of plaintiff's transfer, it was a question for the jury whether she had actual or inquiry notice. In Banco Popular de Puerto Rico, Inc. v. Latin American Music Co., Inc., ${ }^{122}$ the court held that evidence that the defendant had "in compliance with its regular practices, . . . conducted a copyright search to locate any prior conflicting transfers of . . copyright" before recording a transfer was sufficient to demonstrate that it recorded "in good faith ... and without notice of the earlier transfer" under $\S 205(\mathrm{~d})$.

\section{Registrations in the Context of Recordation.}

A number of courts have addressed the role of registration and registration certificates in the context of determining priority of conflicting transfers of copyright ownership. In Peer International Corp. v. Latin American Music Corp., ${ }^{123}$ and in both the District Court and the Court of Appeals in Latin American Music Co., Inc. v. Archdiocese of San Juan of the Roman

\footnotetext{
114782 F.Supp. 2d 911 (C.D. Cal. Jan. 5, 2011).

115110 F.3d 69, 1997 Copr.L.Dec. P 27,659 (9th Cir. 1997).

${ }^{116} 637$ S.W.2d 424 (Mo. Ct. App. July 27, 1982).

${ }^{117}$ See id. at 430.

1182000 WL 1006257 (S.D.N.Y. July 19, 2000).

${ }^{119}$ See id. at $* 5$.

${ }^{120}$ See id. at $* 5-* 6$.

1212008 WL 5244297 (E.D. Mich. Dec. 16, 2008).

${ }^{122} 685$ F.Supp. 2d 259 (D.P.R. Jan. 19, 2010).

${ }^{123} 161$ F.Supp. 2d 38, 54 (D.P.R. 2001).
} 
Catholic Apostolic Church, ${ }^{124}$ the courts held that a registration could give constructive notice of a prior transfer to a subsequent purchaser, thus defeating that subsequent purchaser's claim to protection under $\S 205(\mathrm{~d})$. This is an issue that is not explicitly addressed by $\S 205$ (d), which only provides that a subsequent purchaser must be "without notice of the earlier transfer." 125 The holding of these courts might be viewed as an erosion of the incentive provided by $\S 205$ (d) for the prior purchaser to record the document by which he or she gained title, and not just to register a claim of copyright. That holding also rests on dubious textual grounds: the courts all rely an earlier decision, Saenger Organization, Inc. v. Nationwide Ins. Licensing Associates, Inc. ${ }^{126}$ that appears to assume that a registration certificate on file at the Copyright Office is a recorded document, which is certainly not the case. ${ }^{127}$ However, requiring a prospective subsequent purchaser to search for conflicting registrations as well as conflicting recorded documents may not impose much of an additional burden. Indeed, a prudent prospective purchaser would search registration records in any case, because they might reveal conflicting claims regarding authorship, a risk against which the recording provisions of the Copyright Act do not protect. Thus, there may be some policy grounds for ruling that subsequent purchasers have constructive notice of both recorded documents and registrations.

Another context in which courts have equated a registration certificate with a recorded document for purposes of constructive notice is that of triggering a statute of limitations. Thus in Daboub v. Gibbons, ${ }^{128}$ the court held that the plaintiffs' state-law claims were barred by applicable statutes of limitations (in addition to being preempted by the federal Copyright Act) because the plaintiffs should have been deemed to have known about the defendants' song as of the time the plaintiffs registered their claim of copyright. The court decided that such a result followed from "the Copyright Act['s] expres[s] provi[sion] that ' $[\mathrm{r}]$ ecordation of a document in the Copyright Office gives all persons constructive notice of the facts stated' in a properly registered document." ${ }^{129}$ Similarly, in Warrick v. Roberts, ${ }^{130}$ the court held that the statute of limitations on a copyright ownership dispute started to run when the defendant registered a claim to copyright in the work at issue, because "[s]ection 205(c) . . states that registration of a copyright 'gives all persons constructive notice of the facts stated in the recorded document."'131 In Gaiman v. MacFarlane ${ }^{132}$ however - a Seventh Circuit decision penned by Judge Richard Posner - the court rejects both the specific rule that registration starts the statute of limitations

\footnotetext{
${ }^{124} 135$ F.Supp.2d 284, 299-300 (D.P.R.2001), affirmed in part and reversed in part, 499 F.3d $32,40-41$ ( $1^{\text {st }}$ Cir. 2007).

12517 U.S.C. $\$ 205(d)$.

${ }^{126} 119$ F.3d 55, 66 (1st Cir. 1997).

${ }^{127}$ See id. at 66 ("Under federal copyright law, recordation of a document in the Copyright Office 'gives all persons constructive notice of the facts stated in the recorded document.' 17 U.S.C. $\S 205$ (c). A copyright registration certificate issued by and filed with the Copyright Office thus serves to put the world on constructive notice as to the ownership of the copyright and of the facts stated in the registration certificate.").

${ }^{128} 42$ F.3d 285 ( $5^{\text {th }}$ Cir. 1995).

${ }^{129}$ Id. at 291 (quoting 17 U.S.C. § 205(d)).

${ }^{130} 2014$ WL 3828287 (N.D. Ill. Aug. 5, 2014).

${ }^{131} \mathrm{Id}$. at $* 9$ (quoting 17 U.S.C. $\S 205(\mathrm{c})$ ).

132360 F.3d 644 ( $7^{\text {th }}$ Cir. 2004).
} 
running on an ownership claim, and the broader rule that registration is a source of constructive notice. "[T]he court [in Saenger Organization] was wrong to say that registration gives constructive notice," 133 Gaiman states. "What the Act actually says is that recording a document in the Copyright Office gives constructive notice of the facts in the document if the document identifies a registered work." "134 That is a correct textual reading of the Copyright Act, and casts doubt on all of the decisions discussed in the last two paragraphs.

Yet another court ruled that a registration could satisfy the "race" element of $\S 205(d)-$ the requirement that a subsequent purchaser record first in order to prevail over a prior purchaser. ${ }^{135}$ This is clearly in error, because $\S \S 205(\mathrm{c})$ and (d) explicitly require a subsequent purchaser both to record and to register the works at issue to satisfy the "race" element and prevail over a prior purchaser. ${ }^{136}$ (That court also ruled that whether the subsequent purchaser had notice of the prior transfer was to be assessed as of the time that the subsequent purchaser registered, ${ }^{137}$ which is another error; notice should be assessed as of the time of the subsequent purchase, and specifically, at the time of payment of consideration. ${ }^{138}$ )

\section{Bankruptcy and the Perfection of Secured Interests.}

Another context that has generated a number of cases interpreting $\S 205$ is that of bankruptcy. This report has already mentioned two principal cases concerning the perfection of security interests in works under copyright. ${ }^{139}$ The 1990 decision in In re Peregrine Entertainment, Ltd. ${ }^{140}$ held that security interests in such works were perfected by recordation in the Copyright Office under $\S 205$. The 2002 decision in In re World Auxiliary Power Co. ${ }^{141}$ limited In re Peregrine Entertainment, Ltd., holding that only security interests in registered works were perfected by recordation in the Copyright Office, while security interests in

\footnotetext{
${ }^{133} \mathrm{Id}$. at 655 .

${ }^{134} \mathrm{Id}$.

${ }^{135}$ See Tuff-N-Rumble Management, Inc. v. Sugarhill Music Pub. Inc., 49 F.Supp. 2d 673, 681 (S.D.N.Y. 1999) (“As Tuff's registration predates Sugarhill's recordation, and the parties do not dispute that the transfer between Tuff and Peter Brown was for good and valuable consideration, in order for Sugarhill to prevail on the affirmative defense of prior transfer, it must establish that Tuff had constructive notice of the assignment from Peter Brown to Sugarhill before the date of plaintiff's registration.").

${ }^{136}$ Section 205(d) provides that the first executed document will prevail if it is recorded "in the manner required to give constructive notice under subsection (c)," within the applicable grace period "or at any time before recordation in such manner of the later transfer." 17 U.S.C. $§ 205(d)$. Thus, for a later transfer to prevail, it must be recorded "in such manner" - that is, "in the manner required to give constructive notice under subsection (c)" - before the earlier transfer. Section 205(c) provides that recording a document will give constructive notice to all persons of the facts stated in the document only if (1) the document specifically identifies the work to which it pertains, and (2)

"registration has been made for the work." 17 U.S.C. § 205(c) (emphasis added). Thus, § 205(c) already makes both recordation and registration prerequisites for a subsequent purchaser to satisfy the "race" element and prevail against a prior purchaser under $\S 205(d)$; registration alone cannot substitute for those dual prerequisites.

137 See Tuff-N-Rumble Management, Inc., 49 F.Supp. 2d at 681.

${ }^{138}$ See, e.g., 5 Tiffany Real Prop. § 1304 (3d ed.); Daniels v. Anderson, 642 N.E.2d 128, 134 (Sup. Ct. Ill. 1994).

${ }^{139}$ See supra p. 39.

${ }_{140} 116$ B.R. 194 (C.D. Cal 1990).

141303 F.3d 1120 (9 $9^{\text {th }}$ Cir. 2003).
} 
unregistered works were perfected by recordation under state law. ${ }^{142}$ In re World Auxiliary Power Co. explicitly overruled decisions in two other cases that had extended the federal recordation scheme under $\S 205$ to all copyrights. ${ }^{143}$ Other decisions have explored whether the transfer of particular kinds of interests are "transfers of copyright ownership" requiring recordation at the Copyright Office under $\S 205$ to preserve priority. Thus, in Broadcast Music, Inc. v. Hirsch, ${ }^{144}$ the court held that an assignment of royalties from a work under copyright was not a transfer of copyright ownership, since it had "no relationship to the existence, scope, duration or identification of a copyright, nor to "rights under a copyright", ${ }^{145}$ as a result, it did not need to be recorded at the Copyright Office. By contrast, in In re Franchise Pictures LLC, ${ }^{146}$ the court held that an order-to-appear-for-examination lien was sufficiently related to a copyright to be governed by the Copyright Act and to require recordation at the Copyright Office. ${ }^{147}$

\section{The Former $§ 205(d)$ Requirement of Recording Before Filing a Lawsuit.}

Finally, a number of cases addressed the statutory requirement, dropped in 1989, that a person who had obtained title to a work by means of a transfer had to record that transfer before filing an infringement lawsuit concerning that work. ${ }^{148}$ Thus, in Raffoler, Ltd. v. Peabody \& Wright, Ltd. ${ }^{149}$ and Forry, Inc. v. Neundorfer, Inc., ${ }^{150}$ the courts held that the plaintiff was not subject to that requirement because it had obtained title to the work in question by means of a corporate merger rather than a transfer. ${ }^{151}$ In Northern Songs, Ltd. v. Distinguished Productions, Inc., ${ }^{152}$ the court held that the documents recorded to satisfy the requirement of recordation before filing an infringement suit did not have to meet the specificity conditions necessary to provide constructive notice under $\S 205(c) .{ }^{153}$ In Swarovski America Ltd. v. Silver Deer Ltd., ${ }^{154}$ the court held that the statutory requirement was satisfied by the recordation of the instrument of transfer by which the plaintiff obtained title of the work in question, and did not necessitate the recording of every transfer in the chain of title from the author of the work. ${ }^{155}$ In Midway Mfg.

\footnotetext{
${ }^{142}$ See id. at 1132.

${ }^{143}$ See id. at 1130 (rejecting the decisions in Zenith Productions, Ltd. v. AEG Acquisition Corp. (In re AEG Acquisition Corp.), 161 B.R. 50 (9th Cir. BAP 1993) (affirming 127 B.R. 34 (Bankr.C.D.Cal.1991)), and In re Avalon Software Inc., 209 B.R. 517 (D.Ariz.1997)).

${ }^{144} 104$ F.3d 1163 ( $9^{\text {th }}$ Cir. 1997).

${ }^{145} \mathrm{Id}$. at 1166 (quoting 37 C.F.R. § 201.4(a)(2)).

146389 B.R. 131 (C.D. Cal. 2008).

${ }^{147}$ See id. at 141-142.

148 That requirement was codified at 17 U.S.C. $§ 205(d)$ (1982). When Congress amended the Copyright Act to drop the requirement, see Berne Convention Implementation Act of 1988, P.L. 100-568, 102 Stat. 2853 , $\$ 5$ (October 31, 1988), the subsection regarding priority between transfers, previously codified as $\S 205(\mathrm{e})$, became $\S 205(\mathrm{~d})$.

${ }^{149} 671$ F.Supp. 947 (E.D.N.Y. 1987).

${ }^{150} 837$ F.2d 259 (6 ${ }^{\text {th }}$ Cir. 1988).

${ }^{151}$ See Raffoler, 671 F.Supp. at 952; Forry, 837 F.2d at 262.

152581 F.Supp. 638 (S.D.N.Y. 1984).

${ }^{153}$ See id. at $640-41$.

154537 F.Supp. 1201 (D. Colo. 1982).

155 See id. at 1230-1231.
} 
Co. v. Artic Intern., Inc., ${ }^{156}$ the court held that a plaintiff that had recorded a transfer by which it had obtained title to the work it alleged defendant was infringing did not also need to record a later transfer that was consistent with the earlier recorded transfer. ${ }^{157}$ Finally, three decisions held that the requirement to record before filing a lawsuit was satisfied only when the Copyright Office actually placed the remitted document on public record, and not when it received the document. Those decisions will be discussed below. ${ }^{158}$

\section{An Electronic Recordation System: Detailed Evaluation and Recommendations}

\section{A. Shortcomings of the Current Recordation System.}

The current recordation system has long been subject to criticism, and the Copyright Office has initiated projects to identify and work towards implementation of needed improvements. In October 2011, the Register of Copyrights noted that the recordation division had not been part of the Office's reengineering effort implemented in August 2007, and announced as two of the Office's "Special Projects" a "Technical Upgrades" project that included recordation, and a project of "Business Process Reengineering of the Recordation Division." part of an effort to reallocate resources to areas of critical importance such as recordation, the Register created and filled the position of the Director of Office of Public Records and Repositories, thus ensuring senior-level leadership to address recordation concerns. ${ }^{160}$

The recordation system criticisms articulated in comments received in response to the Notice of Inquiry published in January 2014, and in the three Roundtables held in March 2014, can be grouped into four categories:

1. Fees. High recordation fees are likely deterring recordation, particularly of smaller-value transactions. ${ }^{161}$

2. Processing Time. The time it takes to process documents for recordation - the delay between remitting the document properly with the correct fee and having the document appear in the Copyright Office Catalog and in the Copyright Imaging System - is far too long. ${ }^{162}$

\footnotetext{
156547 F.Supp. 999 (N.D. Ill. Mar. 10, 1982).

${ }^{157}$ See id. at 1010-1011.

${ }^{158}$ See infra p. 102.

${ }^{159}$ See Maria A. Pallante, Register of Copyrights, Priorities and Special Projects of the Copyright Office October 2011 - October 2013, pp. 13, 15 (October 25, 2011).

${ }^{160}$ See Elizabeth R. Scheffler Appointed Director, Office of Public Records and Repositories, http://copyright.gov/bios/liz scheffler.html.

${ }^{161}$ See NOI Comments of Creative Commons, p. 2 ("[I]f the Copyright Office wishes to increase the diversity and number of users leveraging the recordation system, it should meet the users where they are by providing a simple and inexpensive (or free) - online system to do so."); UCLA Roundtable Transcript, p. 239 (comments of George Borkowski, RIAA, and Susan Lowry, SAG-AFTRA); Stanford Roundtable Transcript, pp. 160 (comments of George Borkowski, RIAA), 184-85 (comments of Peter Holm, Stanford Law School).

${ }^{162}$ See NOI Comments of Screen Actors Guild - American Federation of Television and Radio Artists, p. 2; UCLA Roundtable Transcript, p. 152 (comments of Susan Lowry, SAG-AFTRA) ("I'm far less concerned with the
} 
Stakeholders spoke of repeated difficulties in closing some copyright transactions when they had remitted documents for recordation but had not yet received the documents back along with the recordation certificates. ${ }^{163}$ Delays between remittance and screening can also cause problems with respect to the official date of recordation. That date is usually the date on which a proper document was remitted with the proper fee. If a document with a large number of titles is remitted with a fee that is slightly off due to an error in counting titles (which may be an arithmetical error, or a misunderstanding about how to count works with multiple titles), and that error is not discovered until the document is screened many months later, the remitter may receive a new date of recordation that denies her the protection of the Recording Act for a long period during which she thought she was enjoying that protection.

\section{Difficulties and Mismatches with Business Practices in the Recording Process. The} requirement that paper documents be sent for recording requires remitters to spend time packaging each document, and to spend money on postage to send each document to the Copyright Office. ${ }^{164}$ Stakeholders have commented that "submission of hard copies, and particularly signed originals, is a significant obstacle to recordation," 165 and that "having to convert digital documents to paper ones, and then going through a manual submission and recordation system, adds large amounts of time to the process." 166 As one roundtable participant commented, electronic signatures on PDF documents are becoming more commonly accepted in copyright industry business dealings, and yet those documents still need to be recorded on paper with actual signatures. ${ }^{167}$

4. Inaccuracies in Cataloging Recorded Documents. Stakeholders have commented that cataloging by recordation specialists is sometimes inaccurate, probably due in many cases to the fact that the specialists are unfamiliar with the underlying transaction, and therefore do not immediately recognize transcription errors. ${ }^{168}$

examination of the documents than I am with the movement of the documents to recorded status and notification."); Columbia Roundtable Transcript, p. 68 (comments of Andy Hackett, National Corporate Research, Ltd.).

${ }^{163}$ See UCLA Roundtable Transcript, pp. 276-278 (comments of Mary McGuire, $20^{\text {th }}$ Century Fox, and Bonnie Chavez, SAG-AFTRA).

${ }^{164}$ See UCLA Roundtable Transcript, p. 151 (comments of Susan Lowry, SAG-AFTRA).

${ }^{165}$ See NOI Comments of the Recording Industry Association of America, p. 2.

${ }^{166}$ See NOI Comments of the American Society of Media Photographers, p. 2; see also NOI Comments of Screen Actors Guild - American Federation of Television and Radio Artists, p. 2 ("Electronic recording would save substantial time currently spent in printing electronically received documents, copying originals, manually drafting document cover sheets for each transaction, obtaining signatures for certified copies of originals, and preparing mailings.").

${ }^{167}$ See Stanford Roundtable Transcript, pp. 56-57 (comments of Tegan Kossowicz, Universal Music Group).

${ }^{168}$ See, e.g., NOI Comments of Alter \& Kendrick, LLP, pp. 1-2 ("[I] many cases documents we know, anecdotally, exist cannot be found in the Copyright Office - either because the documents were never recorded, or because the documents are improperly identified or indexed in Copyright Office records.... [R] equiring the remitter to provide the necessary indexing information with respect to recorded documents is likely to improve the accuracy of this information in Copyright Office records given that the remitter typically has an existing understanding of the details provided in the recorded document, such as the parties or works involved, whereas Copyright Office personnel that simply transcribe this information have no such prior knowledge of the facts to draw upon.”). 
In addition, independent investigation has revealed many other shortcomings of the current system, and opportunities to enhance it. For example, in the current Catalog of recorded documents, some data fields are used to store more than one type of information, and in other data fields, there is no standard format in which the information is entered. Virtually all registration numbers are entered in a different format than that used in registration records. Additional normalization and parsing of data would greatly aid searching and potential interoperability of the Copyright Office database with other data sources.

It is clear that the Copyright Office should move to a system in which documents can be remitted electronically for recordation. Documents are now routinely created and circulated between many copyright industry parties in electronic form, and thus printing of documents to send them by mail for recording is an inconvenience. Moreover, even if documents are created on paper, they can be processed much more efficiently if they are scanned and then processed in an electronic system. In 2004, as the Patent and Trademark Office had just launched an electronic recording system for trademark assignments, and was just about to launch such a system for patent assignments, ${ }^{169} 25$ staff members were processing documents remitted for recordation. ${ }^{170}$ By 2011, after implementation of an electronic system, ${ }^{171}$ only 10 staff members were devoted to recordation of documents, even though there had been a steady growth of remitted documents of about 5\% per year. ${ }^{172}$ The Patent and Trademark Office recordation staff of 10 now processes over 480,000 patent and trademark assignments every year, ${ }^{173}$ while the Copyright Office's staff of 12 processes about 11,000 documents per year ${ }^{174}$ - less than onefortieth of the number of documents handled by the slightly smaller staff at the Patent and Trademark Office. The decrease in processing cost has led the Patent and Trademark Office to reduce the fee for recording patent assignments to zero, effective on January 1,$2014 ;{ }^{175}$ in the first five months after that fee reduction, submissions of patent assignments for recordation were up $13 \% .^{176}$

The Patent and Trademark Office is hardly alone. Over 1000 counties in the United States have implemented systems for electronically recording deeds, mortgages, and other

\footnotetext{
${ }^{169}$ The Patent and Trademark Office launched its Electronic Trademark Assignment System in 2003. See Stuart Graham, Alan Marco, and Amanda F. Myers, Monetizing Marks: Insights from the USPTO Trademark Assignment Dataset, USPTO Working Paper No. 2014-2, available at http://ssrn.com/abstract=2430962. It launched its Electronic Patent Assignment System on May 10, 2004. See USPTO Launches Electronic Patent Assignment System, http://ip-updates.blogspot.com/2004/05/uspto-launches-electronic-patent.html (last visited July 28, 2014).

${ }^{170}$ See E-Mail from Ted Parr, United States Patent and Trademark Office to Mark Polutta, United States Patent and Trademark Office, June 2, 2014, forwarded by Mark Polutta to Robert Brauneis, June 9, 2014.

${ }^{171}$ See Electronic Trademark Assignment System, http://etas.uspto.gov/; Electronic Patent Assignment System, http://epas.uspto.gov/.

${ }^{172}$ See id.

${ }^{173}$ See id.

${ }^{174}$ See pp. 33 and 35, supra.

${ }^{175}$ See 78 Fed. Reg. 4212, 4240 (Jan. 18, 2013).

${ }^{176}$ See E-Mail from Ted Parr to Mark Polutta, supra n. 170.
} 
documents affecting title to real property. ${ }^{177}$ The federal courts have implemented a system for electronically filing pleadings, opinions and other documents in federal litigation. ${ }^{178}$ The Copyright Office itself has implemented a system for electronically filing registration applications. ${ }^{179}$

The details of an electronic system, however, deserve careful consideration. Because an electronic system necessarily has different capacities and constraints, it would be neither possible nor wise to recreate in electronic form all of the existing features of paper-based document processing. Consideration must be given to any technical, statutory, and regulatory changes necessary to implement such a system. The next two sections of this report make a series of recommendations concerning the details of an electronic recordation system for documents pertaining to copyright. Part IV.B. makes nine recommendations about the principal features of such a system, and discusses the considerations underlying each recommendation. Part IV.C. makes a number of additional recommendations.

\section{B. The Principal Features of an Electronic Recordation System.}

This report recommends that the Copyright Office consider implementing an electronic recordation system with the following nine principal characteristics and features:

1. Documents can be remitted in electronic form through a web interface. An electronic system would not replace the current paper-based system, but would provide remitters with the option of remitting documents in electronic form through a web interface, much as eCO now allows copyright claimants to register their claims and in many cases upload deposits through the Copyright Office website.

2. Documents can be signed electronically as well as in handwriting. Any document bearing an identifiable electronic signature within the meaning of the federal E-Sign Act could be remitted for recordation, as well as any document that included an image of a handwritten signature and (in the case of documents remitted on paper) any document bearing original handwritten signatures.

3. Remitters should provide sworn certifications for all electronically submitted documents. Each electronic remitter would be required to create a remitter account with the Copyright Office before remitting documents, and would have to submit a sworn statement with each document that he or she remitted, certifying that to the best of his or her knowledge, the document signatures are authentic and the documents have not been altered after signing.

4. A Repository of Documents in Portable Document Format Should Be Available on the Internet. Remitters would submit documents electronically in Portable Document

\footnotetext{
${ }^{177}$ See http://www.pria.us/files/public/Committees/Technology/eRecording_XML/eRecordingCountyListPublic.xlsx (list of 1131 countries with electronic recording systems) (last visited July 28, 2014).

${ }^{178} \mathrm{See}$ http://www.uscourts.gov/FederalCourts/CMECF/Courts.aspx (list of federal courts accepting electronic filings) (last visited July 29, 2014).

${ }^{179}$ See Electronic Copyright Office, https://eco.copyright.gov/ (last visited July 28, 2014).
} 
Format (PDF format), which is now an open standard for electronic document exchange maintained by the International Organization for Standards (ISO) as ISO 32000. PDF files can accommodate images of scanned paper documents; formatted text of electronically created documents; and electronic signatures, including digital signatures that protect the authenticity and integrity of the document. The Copyright Office document repository would preserve the PDF files as submitted, with each page electronically labeled with the recordation number and page number. The repository would be accessible on the Internet.

5. Copyright Office staff members should not individually screen remitted documents; remitters should certify that the documents meet stated requirements. In general, electronically remitted documents would not be individually screened by recordation specialists for compliance with requirements concerning signatures, completeness, legibility, identification of transferor and transferee, and words of conveyance. Remitters would be asked to certify that remitted documents met stated requirements regarding legibility, completeness, signatures, and pertinence to copyright, and cautioned that failure of the remitted documents to meet these requirements could lead to the loss of legal benefits associated with recordation. Recordation staff would spot-screen documents to see whether remitters were being effectively instructed and guided, or whether such instruction and guidance could be improved. Certain specialized documents, such as terminations of transfers, might continue to be screened individually.

6. Remitters would provide cataloging information. Remitters would provide all information necessary for cataloging or indexing remitted documents, including party names, titles and registration numbers of works, and other associated information. Remitters could correct errors if and when they discovered them, but a publicly available $\log$ or audit trail would permanently record all changes and the date and time that they were made.

7. Remitters would be responsible for providing documents and cataloging information that provided constructive notice. Remitters would assume responsibility for submitting proper cataloging information to provide constructive notice on the basis of searchability by title or registration number - constructive notice that also underlies priority in case of conflicting transfers. If omissions or errors in that information rendered the document unlocatable by reasonable search with respect to certain works, it would cease to provide constructive notice with respect to those works. Constructive notice could not be provided by a catalog entry alone; the remitted document must also conform to the entry.

8. Remitters should receive electronically a labeled version of documents they submit, together with a certificate of recordation. When recordation is complete, remitters would receive a version of their document with each page labeled with the recorded document number and the page number. They would also receive a certificate of 
recordation. These could be sent as a PDF file attached to an e-mail, and could also be accessed through links available in user accounts.

9. No new legal benefits or disabilities should be created as further incentives to record for the time being. Commentators have suggested that more transactions might be recorded if new legal incentives to record were created. However, there is no good estimate available of how many transactions take place that are not recorded; what is clear is that the current recording system - expensive, slow, and entirely paper-based - is itself a disincentive to record. ${ }^{180}$ Until that system is improved and we gain a better idea about how many transactions still might go unrecorded, consideration of new legal incentives is premature.

This section will discuss each of these recommendations in turn. In reviewing these recommendations, two considerations should be kept in mind. First, although the recommendations have already been shaped by substantial feedback from stakeholders, many are intended to be potential starting points for rulemaking proceedings, not last-word conclusions. In particular, the issues of signature requirements, redaction, certification, authentication, and recordation of documents without the authorization of a signer would seem to be appropriately handled through rulemakings. Second, although this report concludes that its recommendations can be implemented under the current Copyright Act, it will also recommend, in section $\mathrm{C}$ of this Part below, that the Copyright Act be amended to clear up possible confusion and fully empower the Copyright Office to implement a 21 st-century recording system.

\section{Optional Electronic Submission of Documents.}

Stakeholders have uniformly supported the implementation of a system that would allow them to submit documents for recordation electronically. No one, however, has advocated immediate discontinuation of the paper-based recording system. The Notice of Inquiry proposed that "[p]aper-based recordation would continue to be available," "181 but noted that "the fee would likely be a multiple of several times that of electronic recordation." 182 It is also contemplated that remitters could continue to hand-deliver documents for recordation to the Public Information Office, in addition to mailing them. While at least one commenter has suggested that the Copyright Office might phase out acceptance of documents for recordation on paper, ${ }^{183}$ most have recommended that the paper-based option be maintained indefinitely, almost certainly with

\footnotetext{
${ }^{180}$ See Columbia Roundtable Transcript, pp. 234-236 (comments of Rachel Fertig, Association of American Publishers).

${ }^{181}$ Notice of Inquiry of Recordation Reengineering at 2698.

${ }^{182} \mathrm{Id}$.

${ }^{183}$ The American Intellectual Property Law Association did not favor immediate discontinuance of paper-based recordation, but it did suggest that "[i]f a guided remitter system is successful, the Copyright Office should consider eventually phasing out paper submissions." NOI Comments of the American Intellectual Property Law Association, p. 2.
} 
substantially higher fees, as is currently the case for registration of claims to copyright. ${ }^{184}$ Thus, this report recommends that the Copyright Office implement an electronic system, while maintaining the option to remit documents for recordation on paper.

\section{Allowing Identifiable, Discrete Electronic Signatures on Recorded Documents.}

The issue of signatures on documents remitted for recordation is one of the most complicated in the design of an electronic recordation system. Because, as detailed below, courts have recently held that electronically signed transfers of copyright ownership are valid, and because Congress has strongly encouraged agencies to accept electronic signatures, this report recommends that the Copyright Office accept electronic signatures on documents remitted for recordation. The federal E-Sign Act defines "electronic signature" so broadly that it can include an action taken by a signer that does not necessarily result in any discrete, fixed signature. Because the Copyright Office's recording function concerns documents, this report recommends that the Office accept only electronic signatures that form discrete, identifiable parts of remitted documents.

Under current Copyright Office practice, each document remitted for recordation must exist somewhere in hard-copy form with handwritten signatures of the parties affixed to it, ${ }^{185}$ even if the copy of the document actually remitted is only a photocopy of the original. Before the year 2000, this requirement was almost certainly congruent with the conditions for validity of any assignment of exclusive rights. Section 204(a) of the Copyright Act required every valid "transfer of copyright ownership" to be "in writing and signed by the owner of the rights conveyed or such owner's duly authorized agent."186 When that provision was enacted in 1976, before the widespread use of personal computers, word processing, e-mail, and even fax machines, it is likely that the signature contemplated was a handwritten signature on paper. Thus, every transfer of copyright ownership that was validly executed under $\S 204$ (a) was eligible to be recorded under $\S 205$ (a). Indeed, for 130 years, from 1870 to 2000, it seems likely that no validly executed copyright assignment was ineligible for the benefits of recordation. ${ }^{187}$

In June of 2000, however, Congress passed the Electronic Signatures in Global and National Commerce Act, ${ }^{188}$ or E-Sign Act. The E-Sign Act provides that "with respect to any transaction in or affecting interstate or foreign commerce . . . a signature, contract, or other record relating to such transaction may not be denied legal effect, validity, or enforceability

\footnotetext{
${ }^{184}$ See NOI Comments of Association of American Publishers, p. 3; NOI Comments of the Motion Picture Association of America, p. 4; NOI Comments of Soundexchange, Inc., pp. 2-3; Columbia Roundtable Transcript, p. 67 (comments of Richard Bengloff, American Association of Independent Music).

${ }^{185}$ As described above, see p. 16, supra, current Copyright Office practice interprets the statutory requirement of an "actual signature" on a document as mandating an "actual handwritten signature of an individual person." Compendium II $\S \S 1606.05(a), 1606.07$.

18617 U.S.C. $\$ 204(a)$.

${ }^{187}$ See, e.g., Copyright Act of 1909, Pub. L. No. 60-349, § 42, 44, 35 St. 1095 (1909).

${ }^{188}$ P.L. 106-229 (June 20, 2000).
} 
solely because it is in electronic form." 189 It defines "electronic signature" very broadly, as "an electronic sound, symbol, or process, attached to or logically associated with a contract or other record and executed or adopted by a person with the intent to sign the record." $" 190$ The two courts that have considered whether the E-Sign Act applies to $\S 204(a)$ 's requirement of a signed writing, and therefore renders valid electronically-signed transfers of copyright ownership, have both concluded that it does. ${ }^{191}$ Most prominently, the Fourth Circuit, in Metropolitan Regional Information Systems v. American Home Realty Network, ${ }^{192}$ held that assent by clicking "yes" to a terms-of-use agreement that included an assignment of copyright in submitted photographs validly transferred copyright in those photographs.

The E-Sign Act does not affect legal restrictions that may exist on the form of signatures on certain specified types of documents, including some that may be eligible for recordation at the Copyright Office, such as wills ${ }^{193}$ and court pleadings and orders. ${ }^{194}$ If other state or federal laws preclude electronic signatures on these types of documents, those restrictions are still valid. However, under the Metropolitan Regional Information Systems case, most documents recordable at the Copyright Office under $\S 205$, such as copyright assignments, grants of security interests, options, and exclusive licenses, fall within the scope of the E-Sign Act, and therefore are valid even when signed only electronically; wills and court pleadings and orders may be too, if applicable laws so provide.

The Copyright Act establishes separate signature requirements for several types of specialized documents. In two cases, the E-Sign Act would seem to make electronic signatures clearly valid. Exclusive rights in a mask work may be transferred or licensed "by any written instrument signed by [the] owner [of the rights] or a duly authorized agent of the owner,"195 and rights in vessel hull designs "may be assigned, granted, conveyed, or mortgaged by an instrument in writing, signed by the grantor . . .."196 Notices of termination of transfer under $\S \S$ 203, 304(c), and 304(d) of the Copyright Act may be slightly more complicated. The Copyright Act requires them merely to be "signed,"197 and from that language alone, it would appear that

\footnotetext{
189 15 U.S.C. $\$ 7001($ a) (2012).

19015 U.S.C. $\$ 7006$.

${ }^{191}$ See Metropolitan Regional Information Systems v. American Home Realty Network, 722 F.3d 591, 601-02 (4th Cir. 2013) (holding that a subscriber who clicks "yes" in response to electronic terms of use agreement prior to uploading copyrighted photographs has signed a written transfer of exclusive rights of copyright ownership in those photographs); Newton v. American Debt Services, 854 F.Supp. 2d 712, 731 (N.D. Cal. Feb. 22, 2012) (finding a valid signature when the signatory had to choose an electronic signature, click to apply it on multiple parts of the document, confirm signing at the end of the document, and had received notice that he was signing a binding contract).

192722 F.3d 591 (4th Cir. 2013).

${ }^{193}$ See 15 U.S.C. $\$ 7003$ (a)(1) (the E-Sign Act does not apply to a contract or other record to the extent that it is governed by "a statute, regulation or other rule of law governing the creation and execution of wills, codicils, or testamentary trusts").

${ }^{194}$ See 15 U.S.C. $\$ 7003(b)(1)$.

19517 U.S.C. $\$ 903(\mathrm{~b})$.

19617 U.S.C. $\S 1320($ b).

197 See 17 U.S.C. $§ 203(a)(4) ; 17$ U.S.C. § 304(c)(4); 17 U.S.C. § 304(d)(1) (incorporating 17 U.S.C. § 304(c)(4)).
} 
under the E-Sign Act, electronic signatures would be valid. The Copyright Act grants the Register of Copyrights authority to promulgate regulations regarding the "form, content, and manner of service" of notices of termination of transfer, and under that authority, the Register has promulgated a regulation requiring notices of termination of transfer to bear "handwritten signature[s]. ${ }^{198}$ This regulation is arguably in tension with a provision in the E-Sign Act that requires any agency with authority to interpret statutory signature requirements to interpret them consistently with the E-Sign Act's validation of electronic signatures. ${ }^{199}$ However, terminations of transfer are effective only if notices are filed with the Copyright Office, ${ }^{200}$ and hence the handwritten signature requirement may fall under the E-Sign Act's exemption for government filing requirements, ${ }^{201}$ which is discussed in the next paragraph.

While many recordable documents may thus validly bear electronic signatures, Copyright Office practice has continued to require a handwritten signature on some copy of a document that is remitted for recordation, even if the copy actually remitted is a photocopy of the handsigned original. That requirement appears to be unaffected by the E-Sign Act. An argument could be made that the term "actual signature" in $\S 205(\mathrm{a})$, which establishes requirements for recordation, should also be subject to the E-Sign Act's language mandating the acceptance of signatures in electronic form. However, the E-Sign Act specifically provides that, subject to compliance with the Government Paperwork Elimination Act (which will be considered below), nothing in it "limits or supersedes any requirement by a Federal regulatory agency, selfregulatory organization, or State regulatory agency that records be filed with such agency or organization in accordance with specified standards or formats." ${ }^{202}$ This strongly suggests that the E-Sign Act would not supersede the Copyright Office's regulatory requirements, validly promulgated under authority granted by 17 U.S.C. $\S 702$, that documents remitted for recordation under $\S 205$, as well as mask work documents remitted under $\S$ 903(c)(1) and vessel hull design documents remitted under $\S 1320(\mathrm{~d}),{ }^{203}$ be provided in hard copy with handwritten signatures or as photocopies accompanied by signed certifications. It also does not affect Copyright Office regulations that a notice of termination of transfer can only be recorded if it

\footnotetext{
${ }^{198}$ See 37 C.F.R. $§ 201.10$ (c)(5) ("The handwritten signature of each person effecting the termination shall either be accompanied by a statement of the full name and address of that person, typewritten or printed legibly by hand, or shall clearly correspond to such a statement elsewhere in the notice.").

${ }^{199}$ See 15 U.S.C. $\S 7004(\mathrm{~b})(2)(A)$. Independently of $\S 205(\mathrm{a}), \S 302$ provides for the recordation of statements concerning the identity of the author of an anonymous or pseudonymous work, or of the death or continuing life of an author. See 17 U.S.C. $\S \S 302(c), 302(d)$. That section does not require such statements to be signed. It authorizes the Register of Copyrights to promulgate regulations concerning the form and content of such statements, but no such regulations have ever been promulgated. The general regulations regarding recording of documents specifically state that they do not apply to statements under $\S 302$. See 37 C.F.R. $\S 201.4(a)$ (vi). Therefore, statements under $\S 302$ should be able to be recorded without any signature.

${ }^{200}$ See 17 U.S.C. $\S 203(\mathrm{a})(4)(A) ; 17$ U.S.C. $\$ 304(\mathrm{c})(4)(A) ; 17$ U.S.C. $\S 304(\mathrm{~d})(1)$ (incorporating 17 U.S.C. $\S$ $304(\mathrm{c})(4)(\mathrm{A}))$.

${ }^{201}$ See 15 U.S.C. $\S 7004(a)$.

20215 U.S.C. $\S 7004(\mathrm{a})$.

${ }^{203}$ Copyright Office regulations make all rules regarding recordation under 17 U.S.C. § 205 applicable to recordation of mask work documents under 17 U.S.C. $§ 903(c)(1)$ and recordation of vessel hull design documents under $\S 1320(d)$. See 37 C.F.R. $\S 211.2$ 1; 37 C.F.R. $\S 212.6$.
} 
includes "the actual signature or signatures, or a reproduction of the actual signature or signatures, appearing on the notice." ${ }^{204}$

Under these recent interpretations of the E-Sign Act, §204(a) of the Copyright Act, and § 205(a) of the Copyright Act as applied by the Copyright Office, it has apparently been possible since 2000 to execute a valid transfer of copyright ownership that cannot be recorded. The result is that, for the first time since recordation of copyright documents began in 1870, many who have validly obtained all or some of the exclusive rights of copyright in a work cannot protect their ownership interests by recording the transfer instruments and gaining the benefits of constructive notice and priority. Such assignees will remain vulnerable to subsequent transfers of the same rights by their assignors to others. Members of the public who wish to learn the identity of the current owner of copyright in a work are also disadvantaged. In many cases, they will not be able to do so by searching the Copyright Office Catalog, because instruments that validly transfer copyright ownership but do not bear a handwritten signature cannot be recorded and will not gain entries in the Catalog. Now that it is clear that electronically signed documents can be effective to transfer copyright, the interests both in protecting copyright assignees, thereby supporting a market in works of authorship, and in informing the public of copyright ownership through the Copyright Office's recorded document repository and catalog thereof, would seem to weigh strongly in favor of accepting such documents for recordation.

Another impetus for accepting electronic signatures is the Government Paperwork Elimination Act, which was signed into law on October 21, 1998. ${ }^{205}$ Section 1705 of that Act requires the Office of Management and Budget to ensure that, commencing not later than October 21, 2003,

Executive agencies provide -

(1) for the option of electronic maintenance, submission, or disclosure of information, when practicable as a substitute for paper; and

(2) for the use and acceptance of electronic signatures, when practicable. ${ }^{206}$

The Copyright Office is not an "executive agency" subject to this Office of Management and Budget mandate, so it is not directly affected by the Government Paperwork Elimination Act. However, the Act expresses the intent of Congress to enable citizens to interact electronically with the federal government, and in particular to be able to use electronic signatures whenever signatures are required in documents submitted to the government. That intent also weighs in favor of Copyright Office acceptance of electronic signatures on documents remitted for recordation.

\footnotetext{
20437 C.F.R. $\S 201.10(f)(1)$.

${ }^{205}$ See Government Paperwork Elimination Act, P.L. 105-277, Title XVII.

${ }^{206}$ Government Paperwork Elimination Act, P.L. 105-277, § 1705 (codified at 44 U.S.C. 3504 note).
} 


\section{a. The Statutory Interpretation Issue: Can Electronic Signatures be "Actual}

Signatures" Within the Meaning of \$205(a)? Although the Copyright Office has interpreted $\S$ 205(a) to require the existence of a document with a handwritten signature, $\S 205$ (a) requires only an "actual signature." Neither that term nor its context in the Copyright Act precludes a reinterpretation that would include electronic signatures. However, for reasons to be explained below, §205(a) likely requires a certification to accompany each electronically submitted electronic signature.

The term "actual signature" might be given two readings: a broad "but for causation" reading and a narrower "first fixation" reading. In the context of $\$ 205(a)$, the latter, narrower reading is more likely the correct one.

Under the broad "but for causation" reading, any mark or trace that would not exist but for a valid act of signing that occurred sometime in the past would count as an "actual signature." Thus, for example, someone might electronically sign an agreement by typing her name between slashes in a text field on a web form, and clicking "submit." That action might result in the typed signature being communicated over the Internet, passing through several routers on which transient copies of the signature data are stored, to a server that more permanently stores the signature in a particular record and field of a database. Later, a document in PDF format might be generated by combining the text of the agreement with the typed signature stored in the database. That PDF document could then be remitted for recordation at the Copyright Office. Under the broad "but for causation" reading of "actual signature," the PDF document received by the Copyright Office would bear an actual signature, because the signature displayed in the PDF would not exist but for an earlier act of signing. The E-Sign Act seems implicitly to adopt such a "but for causation" concept in its definition of "electronic signature," but of course it is not defining the term "actual signature" as it appears in $\S 205(\mathrm{a})$.

By contrast, under the "first fixation" reading of "actual signature," an actual signature includes only the signature as initially fixed. This reading is a generalization from the specific case of the traditional handwritten signature, fixed in ink on paper by the movement of a hand grasping a pen. It could, however, be applied to electronic signatures. For example, if the act of electronically signing a document on a computer directly caused that signature to be stored together with the signed document on a USB storage device, we could say that that USB device contained a document with an "actual signature."

There is a good argument that Section 205(a) is better read as incorporating this narrower "first fixation" reading. That follows, not from the term "actual signature" itself, but from the remainder of the language in $\S 205$ (a), which contemplates that a document submitted to the Copyright Office might not bear an "actual signature," but should nevertheless be accepted for recordation "if it is accompanied by a sworn or official certification that it is a true copy of the original, signed document." 17 U.S.C. § 205(a). That language contemplates the existence of "copies" that are not "originals" and that therefore must be accompanied by certifications. Only 
the "first fixation" reading of "actual signature" can support a distinction between "originals" and "copies." Under the "but for causation" reading," any mark or trace attributable to an act of signing, no matter how many generations of copies removed, counts as an "actual signature."

A "first fixation" reading of $\S 205$ (a) can accommodate electronic signatures, but in practice it may be safer to require a certification for every remitted document. The process of remitting a document electronically, by sending it over the Internet, does not send the copy on the remitter's computer to the Copyright Office, but creates a new copy of that document, and of any signature contained in it. ${ }^{207}$ Even the copy of the document held by the remitter will in many cases not contain the "first fixation" of the signature. One could argue that when § 205(a) speaks of "a true copy," it is contemplating copies that are degraded, and that therefore a perfect digital copy is not a "copy" within the meaning of $\S 205$ (a), but a duplicate original. Yet this is not an obvious reading of $\S 205(\mathrm{a})$, a provision that was not drafted in anticipation of digital transmission of electronic signatures. Requiring a certification by the remitter for every electronically remitted document, however, is actually a recommendation of this report that will be discussed in greater detail below. Thus, an interpretation of $\S 205$ (a) as embodying such a requirement does not, in the view of this report, necessitate a statutory amendment.

\section{b. Copyright Office Electronic Signature Regulations for Remitted Documents:} "Discrete and Identifiable" Signatures. While $\S 205(a)$ in its current form can thus be interpreted as allowing the Copyright Office to accept electronic signatures on remitted documents, albeit likely with certifications, some consideration should be given to the forms or types of electronic signatures that Copyright Office regulations should allow. The regulations should allow a very broad range of electronic signatures. For at least the near future, the majority of signatures on remitted documents will be digitized images of handwritten signatures, and so those clearly should be allowed. Because of the desirability of accommodating the bulk of transfers of copyright interests that are valid under $\S 204$ (a), a range of other forms of electronic signatures should be allowed, from typed signatures to sophisticated digital signatures. ${ }^{208}$ If a "yes" click to a terms-of-use agreement is programmed to create a file that contains the text of the terms of use together with the notation "Assented to by user logged in as Dorothy Smith, from a computer at IP address 167.89.202.31, at 5:04 PM GMT, June 12, 2014," that notation could be considered a valid electronic signature. Parties who want a more secure form of electronic signature should be able to choose such a form for themselves, and to demand it in negotiation from those with whom they will contract. As will be discussed below, the Copyright Office document repository should be able to preserve more secure forms of

\footnotetext{
${ }^{207}$ Cf. Capitol Records, LLC v. Redigi Inc., 934 F. Supp. 2d 640, 649 (S.D.N.Y. 2013) (“It is simply impossible that the same 'material object' can be transferred over the Internet.").

${ }^{208}$ For a discussion of digital signatures and their preservation in the Copyright Office document repository, see p. 72 below.
} 
electronic signature. ${ }^{209}$ Yet if parties decide on a less secure form of signature, that form should generally be accommodated as well. ${ }^{210}$

There is one way in which Copyright Office regulations should probably stop short of accommodating everything that could count as a signature under the E-Sign Act. The E-Sign Act's definition of "electronic signature" includes "an electronic . . . process, . . . logically associated with a contract . . .and executed by a person with the intent to sign . . .."211 That definition may be so broad that it includes acts that do not generate a trace that is easily remitted as "a signature" on "a document." 212 For example, a "yes" click on a terms-of-use agreement may not be stored as a discrete piece of information at all. Rather, the system may simply be designed not to let the user take a certain action, such as uploading a photograph, without having clicked "yes." In that situation, the computer code that allowed the user to proceed only upon assent to the terms of use, together with the uploaded photograph, would be the only evidence available that the user did, in fact, click "yes." Would submission of that computer code, together with evidence that the user did upload a photograph and the text terms of use, count as a "signed document"? The difficulty of figuring out whether particular code would in fact invariably require assent before proceeding is a good reason to require more discrete evidence of the act of assent. Thus, Copyright Office regulations might require that an electronic signature be in a "discrete and identifiable form" on the remitted document. ${ }^{213}$ It is important to recall that there are separate regulations for specific document types such as notices of terminations of transfer, so that if the electronic recordation system will accommodate such documents, as it

\footnotetext{
${ }^{209}$ See infra p. 72.

${ }^{210}$ To be sure, allowing weak forms of signature makes it easier for third parties to forge signatures and create false documents. Although a weak signature will provide weak evidence that the party whose signature was forged actually signed the document, that party is still burdened with having to prove that he did not sign the document. Casual forms of signature, such as mouse clicks on buttons, are also less likely to serve the "cautionary" function of warning parties that they are about to take a legally significant act, such as granting valuable rights in a work of authorship. These concerns, however, would be better addressed through an amendment to $\S 204$, which establishes the formal requirements for transfers of copyright ownership. Recognizing a transfer as valid under $\S 204$ but refusing to place it on public record under $\S 205$ has serious drawbacks, as expressed in the text above.

211 15 U.S.C. $\$ 7006$.

${ }^{212}$ By way of comparison, under current registration practice the Copyright Office "will accept an application that names the owner of a website as the claimant for [user-generated content] that has been uploaded to that site . . [under] a 'click through' agreement or terms of service agreement," but "the claimant must know and have a record of the names of the authors who transferred ownership of all the exclusive rights to the claimant." Compendium of Copyright Office Practices, Third Edition, $§ 1005$ (public draft August 15, 2014). Such a "record of the names of the authors" might fall short of preserving anything that could be identified as "signatures" of the authors.

${ }^{213}$ Such a requirement would be consistent with the E-Sign Act's provision regarding requirements that contracts or other records be in writing:

Notwithstanding subsection (a), if a statute, regulation, or other rule of law requires that a contract or other record relating to a transaction in or affecting interstate or foreign commerce be in writing, the legal effect, validity, or enforceability of an electronic record of such contract or other record may be denied if such electronic record is not in a form that is capable of being retained and accurately reproduced for later reference by all parties or persons who are entitled to retain the contract or other record.

15 U.S.C. $\S 7001(\mathrm{e})$.
} 
should, several different regulations, and the accompanying sections of the Copyright Office Compendium, will need to be amended. ${ }^{214}$

\section{Requiring Remitters to Submit Sworn, Electronically-Signed Certifications.}

If a document filed for recordation does not bear the "actual signature" of the person who executed it, $\S 205$ (a) requires the document to be "accompanied by a sworn or official certification that it is a true copy of the original, signed document." ${ }^{215}$ Current Copyright Office regulations add two more specific requirements for sworn certifications. First, a sworn certification must be "signed by at least one of the parties to the signed document, or by an authorized representative of that person." 216 Second, the sworn certification must be notarized, as it is defined as "an affidavit under the official seal of any officer authorized to administer oaths within the United States, or if the original is located outside of the United States, under the official seal of any diplomatic or consular officer of the United States . . ..,217

a. Remitter Certifications. This report recommends that both of these more specific requirements be reconsidered, and that the Office instead consider adopting regulations that require the remitter of a document, rather than a party to the document, to make certain sworn statements that are not notarized.

The regulatory requirement that certifications must be signed by a party to the signed document, or an authorized representative of a party, may be difficult to satisfy for an electronic recordation system in which every remitted document will require a certification. There will be circumstances under which no signer of a document is available to certify, or to authorize someone else to certify. In the case of some documents, such as wills, the signatories may no longer be alive. In other cases, the current owner of copyright may want to record several documents in the chain of title of a work, but has never had any contact with and cannot locate the persons who signed a document that constitutes a previous link in that chain. ${ }^{218}$ If the documents in question are paper documents with handwritten signatures, and the remitter has original copies in his or her possession, then as long as the Copyright Office maintains the paperbased recordation system along with an electronic system, the remitter will have the option of submitting the originals. If, however, the documents are native electronic documents, a certification requirement could not be met and the documents could not be recorded. It would be unfortunate to design an electronic recordation system that would exclude all documents the signers of which could not submit separate certifications or authorize someone to do so.

\footnotetext{
214 See p. 14, supra.

21517 U.S.C. $\S 205(a)$.

21637 C.F.R. § 201.4(c)(1).

21737 C.F.R. § 201.4(a)(3)(i).

${ }^{218}$ See, e.g., UCLA Roundtable Transcript, pp. 84, 87-88 (comments of Susan Lowry, SAG-AFTRA) ("[Y]ou may not ever be able to find the grantor. You might not even know where the grantor is or even, you know, let's say that it's a turnaround document from a studio from ten years ago, right, there isn't going to be anybody left at the studio who's going to be able to say, oh yes, that's an original, you know.”).
} 
The regulatory requirement that all sworn certifications be notarized, or "under official seal," is in fact not currently enforced by the Copyright Office. Sworn certifications are typically furnished on a Document Cover Sheet form that is distributed by the Copyright Office. ${ }^{219}$ That form does not have any space for notarization, and the Office accepts those sworn certifications without notarization. The process of notarizing an electronic signature is even more complicated than that of notarizing a handwritten signature, and standards for electronic notarization are still developing. ${ }^{220}$ Because the Copyright Office does not currently require notarization of handwritten signatures on certifications, and because notarization of electronic signatures on sworn certifications would be even more complicated, this report recommends dropping the notarization requirement.

The certification that accompanies every electronically remitted document should be provided by whoever is remitting the document. The remitter is more likely to be held accountable for a certification, because the process of establishing a user account to remit documents can include verification of identity and contact information. It is also more convenient to have the remitter provide a certification as part of the process of remitting documents, because the remitter is by definition present and active during that process, while the signers of the documents in most cases are not.

b. Contents of the Certification. Section 205(a) requires a certification that the remitted copy of the document "is a true copy of the original, signed document." ${ }^{221}$ Such a certification was designed for paper-based transactions and recordation, and does not fit well with the realities of electronic transactions and recordation. It assumes a world in which the person making the certification is in a position to see the original and the copy side-by-side and to compare them, and then to send the copy that has been compared and verified as a "true copy" to the Copyright Office, which receives the same physical copy that the certifier examined. In many transactions that are now conducted electronically, documents are circulated between the parties as e-mail attachments, and if the document is signed by one party with a handwritten signature, that party will scan the signature page and send the scan to the other party, rather than sending the hard copy with the ink signature. As a result, many remitters will not have, and will never have had, possession of a hard copy with a handwritten signature, nor the first fixation of an electronic signature. In that case, it will be impossible for a remitter to truthfully swear that the copy she has in her possession is "a true copy of the original, signed document." Although many remitters might be willing to make such a statement anyway in order to get the document recorded, the

\footnotetext{
${ }^{219}$ See Document Cover Sheet: Basic Information, http://www.copyright.gov/forms/formdoc.pdf (last visited July 28, 2014).

${ }^{220}$ The Wikipedia article on "eNotary" lists 18 states that have passed statutes regarding electronic notarization. See Wikipedia, “eNotary,” http://en.wikipedia.org/wiki/ENotary (last visited July 28, 2014).

${ }^{221} 17$ U.S.C. $\S 205(a)$.
} 
Copyright Office should not put remitters in the position of having to shade the truth by providing a statement that does not fit widespread commercial realities. ${ }^{222}$

In addition, as already noted above, ${ }^{223}$ when a document is remitted electronically, the copy "sent" by the remitter is not the copy received by the Copyright Office. The remitter is actually initiating the transmission of a document, and that transmission results in the creation of a new copy on a Copyright Office computer. Although this may seem like a technicality, it is a technicality to which the Copyright Office should be particularly sensitive. As a result, the modified $\S 205$ (a) certification should be in some form resembling the following statement:

I swear, under penalty of perjury, that to the best of my knowledge, the document that I am transmitting to the Copyright Office has not been edited or altered in any way since it has been signed.

This form of certification recognizes that the remitter may not have been in a position to compare side-by-side an original with a copy. It also recognizes that the remitter is transmitting a document, rather than sending a copy. Yet it preserves the substance of the $\S$ 205(a) certification, which is to require an additional assurance of the integrity of the document from its signing to its receipt by the Copyright Office. The ideal course of action might be to amend $\S 205$ (a) to more precisely reflect the new realities. However, enough of the substance of the $\S 205$ (a) certification is preserved in the proposed formulation that such a formulation should fit within the authority of the Register to promulgate regulations interpreting and applying the statute under $\S 702$ of the Copyright Act, and under the last sentence of $\S 205$ (a) itself, which grants authority to the Register to establish regulations regarding electronically submitted certifications.

A certification that a document has not been altered since signing, however, is not the only certification that would ideally be sought from a remitter. For example, a remitter might know that the signatures on a document had been forged, or know that the document contained false statements, but still truthfully certify that the document had not been altered since it was signed. Section 205(a) only requires a certification that the document has not been altered. Section 506(e) of the Copyright Act provides a criminal penalty for making false statements, but only in connection with registration applications. ${ }^{224}$ However, under 18 U.S.C. $§ 1001$,

\footnotetext{
${ }^{222}$ As one roundtable participant noted, the problem of certifying that a reproduction is a true copy of an original document already arises with respect to older documents: "[W] require the entire chain of title for a work to be recorded ... [a]nd we get a lot of complaints from people that . . .they don't have the original chain of title document. They have a copy of it that they got from someone else and . . the chain of title can sometimes go back years. And that actually creates an obstacle because really nobody wants to take the additional step to say well, I'm willing to swear that this is . . a viable copy of the original, when you really can't say. So we get a lot of push-back from producers, for example, who say they don't want to record this document because they can't swear that it's a [true] copy of the original." UCLA Roundtable Transcript pp. 83-84 (comments of Susan Lowry, SAG-AFTRA). ${ }^{223}$ See p. 64, supra.

${ }^{224}$ See 17 U.S.C. $\$ 506(\mathrm{e})$ ("Any person who knowingly makes a false representation of a material fact in the application for copyright registration provided for by section 409, or in any written statement filed in connection
} 
originally enacted as the False Statements Accountability Act of 1996, ${ }^{225}$ a person who knowingly remitted a forged document for recordation would be guilty of a federal crime. Section 1001(a) states:

[W]hoever, in any matter within the jurisdiction of the executive, legislative, or judicial branch of the Government of the United States, knowingly and willfully . . . (3) makes or uses any false writing or document knowing the same to contain any materially false, fictitious, or fraudulent statement or entry [shall be subject to a criminal fine or imprisonment. $]^{226}$

Thus, at the very least, a remitter could be required to make a statement of the following type:

I hereby acknowledge that if I submit a document for recordation that I know contains any materially false statement or forged signatures, or if I knowingly submit false information about the document, I could be subject to federal criminal prosecution under 18 U.S.C. $\S 1001$.

It would perhaps be ideal if $\S 205$ (a) granted the Register broader authority to require the remitter to make such certifications as would tend to ensure that documents submitted have been signed by those represented as having signed it, contain no false statements, and have not been altered, or if the Copyright Act specified particular criminal penalties for knowingly remitting false documents or providing false information in connection with remitted documents, as $\S 506(\mathrm{e})$ does for false statements made in connection with registration applications. However, the certification and $\S 1001$ statement above can still

with the application, shall be fined not more than $\$ 2500$.”). There is a strong argument that the general criminal liability for making false statements and submitting false documents to the federal government under 18 U.S.C. $\S$ 1001 does not apply to making false statements in connection with a registration application, since the more specific criminal provision of $\S 506(\mathrm{e})$, which limits potential criminal liability to a fine of not more than $\$ 2500$, should govern. There is a weaker argument that the existence of $\S 506(\mathrm{e})$ means that Congress did not intend $\S 1001$ to apply to document recordation, since it considered criminal liability in connection with Copyright Office activities and decided to criminalize only false statements made in connection with registration applications.

${ }^{225}$ Pub. L. 104-292 (1996). A remitter statement, and in particular a statement made under penalty of perjury and with knowledge of criminal sanctions under 18 U.S.C. $\S 1001$, was suggested by representatives of the Recording Industry Association of America and $20^{\text {th }}$ Century Fox at the Recordation Roundtable at UCLA. See UCLA Roundtable Transcript, pp. 81-82 (comments of George Borkowski, Recording Industry Association of America); id. at 82 (comments of Mary McGuire, $20^{\text {th }}$ Century Fox).

${ }^{226} 18$ U.S.C. $\S 1001$ (a). There is some limitation of this criminal liability with respect to the legislative branch, but even assuming that the Copyright Office would for these purposes be considered part of the legislative branch, knowingly remitting a forged document for recordation would still arguably trigger criminal liability under $\S 1001$, either because it pertains to an "administrative matter," or because it involves "a document required by law, rule, or regulation to be submitted to the Congress or any office or officer within the legislative branch." 18 U.S.C. $§ 1001$ (c). Congress may been concerned about criminalizing the making of false statements in petitions asking for legislative action, but knowingly submitting a forged document for recordation does not implicate those concerns. 
deter remitters from remitting false or forged documents for recordation, or from submitting false cataloging information.

c. User Account Creation and Electronic Signatures on Certifications. As noted above, when a person remits a document for recordation, the Copyright Office will want that person's signature on a certification. Obtaining an adequate signature from a remitter may be simpler in two ways than obtaining an adequate signature on a stand-alone document. First, each remitter can be required to create a user account; verification of identity during the one-time account creation process can be more extensive than it is each time the remitter uses the account to remit a document. Second, the remitter's signature does not need to protect the integrity of a document. Because the signature will be submitted interactively on a website, and because the statement to be signed will always be the same, there is no danger that the statement will be altered after signing.

In its eCO registration system, the Copyright Office requires everyone who creates a user account to enter a mailing address, a telephone number, and an e-mail address. It does not, however, currently verify the identity of the account creator in any way. ${ }^{227}$ There are a wide variety of types of verification that would be possible. For example, the telephone number, address and/or e-mail could be checked against databases to ensure that they are valid and in service. ${ }^{228}$ A token can be e-mailed or texted or even mailed to an account creator at the submitted e-mail address, telephone number or mailing address, and the creator could be required to enter the token on the Copyright Office website to verify that he or she received it. A geolocation service can use the Internet Protocol address of the account creator's computer to estimate the creator's location, and flag it if, for example, a computer in a distant foreign country is being used to create an account with a U.S. address. A credit card number submitted by the account creator can also be checked using a formula to ensure that it is a valid number, and it also can be submitted to a service to check identity. ${ }^{229}$

As part of creating a user account, a user creates a username and password; the password is typically required to be of a certain minimum complexity. In the case of the eCO registration system, the user also creates a "challenge question" and the answer thereto, which can be used to reset the password in case it is lost. ${ }^{230}$

\footnotetext{
${ }^{227}$ Nor does the system send a confirmation e-mail when an account is created. Conversation with Stephen Oswald, Copyright Technology Office, July 10, 2014.

${ }^{228}$ For a list of telephone verification methods, see Wikipedia, "Telephone Number Verification," http:/en.wikipedia.org/wiki/Telephone number verification. A variety of vendors provide contact information verification services. See. e.g., MelissaData Data Quality Solutions, https:/www.melissadata.com/dqt/solutions.htm (last visited July 28, 2014).

${ }^{229}$ See, e.g., Experian, Credit Card Verification, http://www.experian.com/decision-analytics/credit-cardverification.html (last visited July 28, 2014).

${ }^{230}$ The system currently allows the creation of multiple accounts with the same e-mail address, which then becomes a problem when a user forgets a password, because the password retrieval program generates an error message when
} 
When signing a certification as part of an electronic registration application, the user must be signed into the user account. The user submits his or her username and password using hypertext transfer protocol over secure socket layer (https), protecting against interception. To sign the certification, the user checks a box next to the text of the certification, and then types his or her name. The acts of checking the box and typing a name may serve the "cautionary" function of signatures - ensuring that the signer understands that he or she is performing a legally significant act - but the "evidentiary" function - ensuring that there is good evidence that the person who allegedly signed actually $\operatorname{did}^{231}-$ is also served by the submission of the username and password.

The Copyright Office could use more extensive methods of identity verification for electronic document recordation than it does for electronic registration, and more secure electronic signatures. However, there seems to be little need to do so. The eCO registration system has been in use for about seven years. During that time, there have been no reported incidences in which a user account was compromised and used by someone not authorized to do so by the account holder, or in which an electronic signature was discovered to have been forged. ${ }^{232}$

\section{A Public Digital Document Repository: Preserving Documents in Portable Document Format and Making Them Available on the Internet.}

As noted above, ${ }^{233}$ the Copyright Office's current document repository preserves documents as a series of page images, and is available only to users on site at the Copyright Office. Moving to a more advanced digital document repository would have three principal advantages: the preservation of digital signatures; the storage of documents as text and associated advances in search and accessibility; and the eventual accommodation of selfcataloging documents. Making that repository available on the Internet would make it practical for the public actually to learn that of which it is deemed to have constructive notice, and could also provide further utility to parties to the documents that are recorded, and to those with other interests in the works affected. Any proposal to do so, however, raises policy issues that require further deliberation, several of which are addressed below.

\footnotetext{
it is asked to retrieve a password for an account and there is more than one account, with more than one password, for a single e-mail address. Conversation with Stephen Oswald, Copyright Technology Office, July $10,2014$.

${ }^{231}$ For one account of the various functions served by formalities, including signatures, see Lon L. Fuller, Consideration and Form, 41 COLUM. L. REV. 799, 800-01 (1941).

${ }^{232}$ Several account holders have reported what they thought were intruders in their accounts, but in every case it turned out that what the account holders thought was movement on their screens caused by an intruder was actually the long-delayed response of the Office server to the account holders' own actions. Conversation with Audrey Miller, Copyright Technology Office, July 10, 2014. The United States Computer Emergency Readiness Term (USCERT) has on occasion reported to the Copyright Office that it had reason to believe that user account usernames and passwords may have been compromised, but there has been no confirmation that those usernames and passwords were ever used to gain access to the accounts. Conversation with Jannie Gillus, Copyright Technology Office, July 10, 2014.

${ }^{233}$ See supra p. 27.
} 
a. The Advantages of a Digital Document Repository. The first of the principal advantages of moving to a more advanced digital document repository is that such a repository could store documents with digital signatures. While "electronic signature" has come to have a very broad meaning, due in part to the broad definition of the term in the E-Sign Act, ${ }^{234}$ "digital signature" has a narrow, specific meaning based on a particular technology used to ensure that a document has been signed by a particular person and has not been altered after signing. A digital signature relies on the possibility of distributing a "public key" that can be used to decrypt an encrypted message, but from which the "private key" that was used to encrypt the message cannot practically be derived. Although the public key and private key are mathematically linked, the inability to derive the latter from the former means that as long as the sender keeps the private key secret, the recipient who is able to decrypt the message with the provided public key can be certain of the identity of the sender. ${ }^{235}$

To digitally sign a document, the signer does not encrypt the entire document, because the goal is not to hide the contents of the document from anyone. ${ }^{236}$ Rather, the signer first applies a mathematical formula to the document to create a number that is extremely unlikely to have been created from a document with any other contents. That number is called a "message digest," a "message hash," or a "hash." 237 The signer then encrypts the hash with her private key, and adds the encrypted hash as a kind of digital appendix to the document. Anyone who has the public key and the hash formula provided by the sender can produce a new hash of the document, decrypt the encrypted hash that accompanies the document, and compare the two hashes. If they are the same, then the document has not been altered since it was signed, and as long as the private key has not been compromised, the document has been signed by the holder of the private key. (Signatures can also be date- and time-stamped, so that later compromise of a private key does not enable a signer to deny having signed a document.)

Digital signatures are not yet widespread in copyright transactions, but they will almost certainly become more common, as their advantages in assuring both the identity of the signer and the integrity of the document are obvious. The Copyright Office's construction of a document repository that would accommodate and preserve digital signatures would enable parties to a transaction to choose a more secure document option, and would promote certainty in copyright transactions.

Second, an advanced digital document repository could store documents as text, or as a combination of text and images, rather than only as images. This increases the information available in the documents, while in most cases decreasing their size. When documents are stored as images alone, they can be read by fully-sighted human beings if properly displayed, but

\footnotetext{
${ }^{234}$ See supra p. 59.

${ }^{235}$ See Christof Paar and Jan Pelzl, Understanding Cryptography, 123-127 (2010).

${ }^{236}$ See id. at 213-216.

${ }^{237}$ See id. at 239-241.
} 
to computers they are merely patterns of black on white. That means that they cannot be full-text searched, or made available to the visually impaired with a text-to-speech program.

Full-text searching within a single document can be helpful to locate a particular passage or check whether a particular work is mentioned, and any document that was available in the Copyright Office repository as text could then be full-text searched as a single document. Perhaps more importantly, storing documents as text could enable the construction of a full-text search engine that could search all recorded documents at once. Such a search engine would operate completely independently of traditional cataloging of recorded documents, and would provide important additional search capabilities. Traditionally, recorded copyright documents have been manually cataloged by the names of the assignor and assignee and the titles of the works involved. If there is an omission or mistake in cataloging, the document becomes invisible, lost among hundreds of thousands of other documents. Full-text searching can locate a document even when it has been miscataloged. It can also locate documents meeting criteria that are not indexed. For example, someone who is interested in locating ownership information about the works of a particular author might be able to locate that information without knowing the titles of all of the works by that author. For that reason, a number of stakeholders have supported the development of full-text search capabilities. ${ }^{238}$ Full-text searching can work both with digital documents that have been created as text using a word processing program - which is how most copyright documents are now created - or with paper documents that have been scanned and then processed with an Optical Character Recognition (OCR) program. Perhaps the most famous example of the latter is the Google Books Library Project. ${ }^{239}$

This report does not propose that the Copyright Office immediately construct a full-text search engine for its recorded document repository, but if the repository can store text as well as images, it will be ready for the construction of such a search engine, either by the Copyright Office, or by an independent entrepreneur.

Storing documents as text can also make access to them by visually impaired people much easier. Text-to-speech programs can read aloud documents that are stored as text, whereas they cannot read documents stored as images without the cumbersome and potentially inaccurate step of Optical Character Recognition processing.

Third, an advanced digital repository could accommodate self-cataloging documents documents with their own tagged and structured cataloging data built into the document. Selfcataloging documents will be discussed in more detail below. Although this report does not

\footnotetext{
${ }^{238}$ See NOI Comments of the Motion Picture Association of America, p. 9 ("It would, however, be helpful to have text within documents that is searchable, including PDF documents."); NOI Comments of Screen Actors Guild American Federation of Television and Radio Artists, p. 3 ("[K] eyword searching linked to the content of recorded documents would be invaluable in the search process.").

${ }^{239}$ See http://books.google.com/googlebooks/library/ (last visited July 28, 2014).
} 
recommend immediately building a system that could process such documents, the ability to support such a system in the future is an important feature.

b. The Portable Document Format Standard. The obvious standard that should be adopted for an advanced digital repository is the Portable Document Format (PDF) standard. ${ }^{240}$ The PDF standard was originally developed as a proprietary standard by Adobe Systems Incorporated. However, in 2007, Adobe released the full standard for purposes of publication by the International Organization for Standardization (ISO). ${ }^{241}$ In addition, Adobe granted a public license to patents that were necessary to implement the standard. ${ }^{242}$ ISO published its first version of the standard as ISO 32000, and now maintains and develops it. PDF files are multiformat containers that can contain both images of scanned documents and text from documents that are created in a word processor. Thus, PDF is "backwards compatible" in the sense that it can be used to store scanned document images that are now stored in TIFF format in the Copyright Imaging System. However, it also accommodates native digital documents stored as text, and text files produced by OCR processing of scanned images. PDF also has digital signature support. ${ }^{243}$ Thus, Portable Document Format could be the next step in a copyright document repository that over the last 144 years has transitioned from handwritten transcriptions to typing, paper photocopies, microfilm, and digital imaging.

Within the Portable Document Format family of standards, a promising specific standard is Portable Document Format/Archival, or PDF/A. PDF/A is a version of the Portable Document File format that conforms to an archiving standard. ${ }^{244}$ The purpose of the PDF/A standard is to ensure the stability of digital documents over time, even as operating systems and application programs change. PDF/A accomplishes this through a series of additional requirements for PDF files, such as the requirement that fonts be embedded in text-based documents, so that they display and print correctly even if the computers used to display or print them do not have the fonts used in the documents. Most computer programs used to create PDF files have the option to save the files as PDF/A files.

Significantly, the Case Management / Electronic Case Filing (CM/ECF) system now used by all federal courts uses the PDF format. All courts accept PDF/A documents, and they will soon be transitioning to requiring PDF/A documents. ${ }^{245}$ Thus, many attorneys and law firm staff

\footnotetext{
${ }^{240}$ The Portable Document Format was specifically mentioned by the Graphic Artists Guild. See NOI Comments of Graphic Artists Guild, Inc., p.4.

${ }^{241}$ See http://www.adobe.com/devnet/pdf/pdf reference.html (last visited July 28, 2014).

${ }^{242}$ See http://partners.adobe.com/public/developer/support/topic legal notices.html (last visited July 28, 2014).

${ }^{243}$ See, e.g., PDF Association, Technical Note TN0006 - Digital Signatures in PDF/A-1, http://www.pdfa.org/publication/technical-note-tn0006-digital-signatures-in-pdfa-1/ (last visited July 28, 2014).

${ }^{244}$ As of this writing, the most recent publication in the series of PDF/A standards is PDF/A-3, issued as ISO 190053:2012. See ISO 19005-3:2012, Document management - Electronic document file format for long-term preservation - Part 3: Use of ISO 32000-1 with support for embedded files (PDF/A-3), http://www.iso.org/iso/home/store/catalog ics/catalog detail ics.htm?ics $1=37 \&$ ics $2=100 \&$ ics $3=99 \& \mathrm{csnumber}=572$ 29 (last visited July 28, 2014).

${ }^{245}$ See http://www.pacer.gov/announcements/general/pdfa.html (last visited July 28, 2014).
} 
members that record documents are familiar with PDF filing requirements, and will soon be familiar with the PDF/A standard. PDF/A is also listed by the National Archives and Records Administration (NARA) as among its preferred formats for both scanned documents and textual data, including formatted and unformatted text files. ${ }^{246}$

c. Making Documents Available on the Internet. The current Copyright Imaging System can be accessed only from terminals inside the Copyright Office. This limitation has a number of disadvantages. Perhaps the most serious is that it makes it expensive, timeconsuming, and in many cases impractical for members of the public to actually gain the knowledge that the Copyright Act deems them to have. Under $\S 205$ (c) of the Act, if a document can be found through a reasonable search under the title or registration number of a work, all persons are deemed to have constructive notice of "the facts stated in the recorded document.",247 In other words, members of the public cannot rely on the facts stated in the Copyright Office Catalog about the parties to a transaction, or the nature of that transaction, or the date on which it took place. Rather, they are supposed to locate documents in the Catalog through a search by title or registration number, and then go read the documents themselves to obtain accurate information about the transactions that they represent. This is in principal a good rule, because the documents themselves contain the best and most complete information about the state of title of works under copyright. However, under the current system, there is a vast difference in practicality and cost of accessing the Copyright Office Catalog, and accessing the document repository. The Catalog is available online worldwide; the documents are available at only one location in Washington D.C. Those who are interested in examining the documents themselves must either come to Washington D.C., or pay someone else to do so. ${ }^{248}$ Thus, the current recording system deems everyone to have knowledge that it makes very expensive for everyone to obtain, and that can be obtained only with the delay necessitated by having to arrange for an agent to visit the Copyright Office during its opening hours. ${ }^{249}$

It is not technically difficult to make all documents available on the Internet. Even the current Copyright Imaging System is accessed through a web browser and hypertext transfer protocol, and thus could be made available on the Internet simply by changing access restrictions. There are, however, policy concerns about making documents available worldwide on the Internet, including concerns about exposing "personally identifiable information" and sensitive financial and non-copyright terms of transactions. The issue of unwanted exposure of

\footnotetext{
${ }^{246}$ See http://www.archives.gov/records-mgmt/policy/transfer-guidance-tables.html\#textualdata (last visited July 28 , 2014).

24717 U.S.C. $\S 205(\mathrm{c})$.

${ }^{248}$ As one stakeholder put it, "[R]ight now the online catalog does not give a lot of information on a particular recordation. ... So if we really want to look at the document we have to send our service . . down to the Copyright Office to get a copy." Stanford Roundtable Transcript, p. 59-60 (comments of Susanne Morales, Fenwick \& West LLP).

${ }^{249}$ As one roundtable participant commented, "It would help a lot to be able to get [recorded documents] rapidly and without paying for it, essentially, page by page." UCLA Roundtable Transcript, p. 117 (comments of Susan Lowry, Screen Actors Guild - American Federation of Television and Radio Artists).
} 
information through online availability of documents has two dimensions: prospective and retrospective. Concerns associated with prospective online availability of documents that have yet to be remitted may be more easily addressed, because various preventive and cautionary measures will be available. Concerns associated with retrospective online availability of documents that have already been remitted may be less easily addressed, since the documents may have been remitted without the expectation that they would be so widely available. This report will first address the issues of personally identifiable information and sensitive financial and non-copyright terms in the context of prospective online availability, and will then consider separately retrospective online availability.

i. Personally Identifiable Information. Stakeholders have expressed concerns about exposure of personal information contained in recorded documents that might be used to commit various forms of identity theft, or to locate individuals in ways that would raise security concerns. $^{250}$ This kind of information has come to be known as "personally identifiable information." 251

Prospectively, the problem of personally identifiable information should be manageable through a combination of education, warnings, allowed pre-recording redactions, and allowed post-recording redactions. Most personally sensitive information does not need to be included in documents effecting copyright transactions. Attorneys and others drafting such documents should be made aware that they should avoid including in those documents such items as social security numbers, driver's license numbers, credit card numbers, dates of birth, home addresses, and home telephone numbers. Remitters should be warned, as they now are on the Copyright Office's eCO registration website, ${ }^{252}$ that information submitted to the Copyright Office will be made public on the Internet, and that in creating user accounts, remitting documents, and submitting cataloging information, they should avoid submitting information that they do not want to be public. Remitters should also be made aware that they can comply with obligations to provide contact information yet avoid revealing home addresses, e-mail addresses, and the like, by creating new contacts - thus, as the privacy F.A.Q. page on the eCO website states, "Applicants who ... do not want to provide personal details can use third-party agents, post

\footnotetext{
${ }^{250}$ See, e.g., NOI Comments of the Motion Picture Association of America, p. 4; UCLA Roundtable Transcript p. 119 (comments of Lawrence Liu, Universal Studios).

${ }^{251}$ See, e.g., Erika McCallister, Tin Grance \& Karen Scarafone, National Institute of Standards and Technology, U.S. Department of Commerce, NIST Special Publication 800-122 Guide to Protecting the Confidentiality of Personally Identifiable Information (PII) (April 2010), available at http://csrc.nist.gov/publications/nistpubs/800122/sp800-122.pdf.

${ }^{252}$ The eCO website contains the following warning regarding privacy: "Personally identifying information, such as your address, telephone number, and email address, that is submitted on the registration application becomes part of the public record. Some information will be viewable in the Copyright Office's on-line databases that are available on the Internet. For this reason, you should provide only the information requested. Please do NOT provide any additional personal information that is not requested, such as your social security number or your driver's license number." Notices, http://www.copyright.gov/eco/notice.html (last visited July 28, 2014).
} 
office boxes, or designated email accounts." ${ }^{, 253}$ If items such as social security numbers do end up in documents pertaining to copyright, Copyright Office policy should allow for their redaction from the documents before they are remitted. ${ }^{254}$ If, as a result of oversight, a document is remitted without allowable redaction of sensitive personal information, the remitter should be able to request that that information be redacted, but only with the payment of a fee to offset the Copyright Office's costs in performing that redaction. ${ }^{255}$ The United States Patent and Trademark Office currently has such a policy of permitting justified post-recording redaction upon payment of a fee. It requires the filing of a petition to the Director to waive the rule prohibiting removal of recorded documents from the public record, and charges a fee of $\$ 100{ }^{256}$

Two kinds of personally identifiable information - personal names and signatures - are not as easily dealt with. The names of parties to a transaction, or of representatives of those parties, are information that is essential to understanding the transaction and holding the parties accountable. Signatures also are important to proving that a document was executed, and executed by the people who are represented as having executed it. An individual who does not want his or her name to appear in any recorded documents can undertake various extraordinary measures. These might include creating a company and becoming an employee of that company so that any works created by the individual are works made for hire that do not need to be

\footnotetext{
${ }^{253}$ Privacy: Copyright Public Records, http://www.copyright.gov/help/faq/faq-privacy.html (last visited July 28, 2014). As one roundtable participant has noted, some private copyright databases, such as those of ASCAP and BMI, simply do not display any contact information for authors or publishers through their public interfaces. See UCLA Roundtable Transcript pp. 120-121 (comments of Michael Ligon, Dean Ligon Entertainment). The purposes of those interfaces, however, are simply to identify the works for which those organizations act as non-exclusive public performance licensing agents. By contrast, the Copyright Office Catalog and repositories have a role as at least a "last resort" provider of contact information for authors and owners of copyright, to prevent works from becoming "orphaned" when their owners cannot be located. As another roundtable participant put it, "I think there are legitimate privacy concerns about personal information, but on the flip side ... is the ability to then contact people who now own the license or own the work." Stanford Roundtable Transcript, p. 61 (comments of Peter Holm, Stanford Law School). For other recommendations on keeping contact information available and current, see Part IV.C.5. below, at p. 126.

${ }^{254}$ For comments expressing support for a policy allowing redaction of personal information, see NOI Comments of Motion Picture Association of America, p. 4; Stanford Roundtable Transcript p.61 (comments of Mary Minow, Dominican University and Stanford University).

${ }^{255}$ The current policy with regard to social security numbers, driver's license numbers, credit card numbers, and bank account numbers in registration applications is stated in $\S 1804.2$ of the Compendium of Copyright Office Practices III. See Compendium of Copyright Office Practices, Third Edition $\S 1804.2$ (public draft August 15, 2014). It states that registration specialists will remove such information from applications without notification to the applicant, and that if such information enters into the online public record or registration certificate, the Copyright Office will remove it upon request. See id. Recorded documents are not exact analogues of registration applications. Documents can be much more lengthy and complicated than registration applications; it is the recommendation of this report that remitted documents not be individually screened by recordation specialists; and in any event redaction of a remitted document without consulting the remitter would be a questionable practice. Thus, remitters should be on notice that they are primarily responsible for ensuring that personally identifiable information not be included in a document remitted for recordation. If such information is included on a document that enters the repository, it would not be inequitable to charge a fee for the cost of substituting a properly redacted document.

${ }^{256}$ See Trademark Manual of Examining Procedure $\S 404$; USPTO Fee Information > Current Fee Schedule, available at http://www.uspto.gov/web/offices/ac/qs/ope/fee010114.htm\#tm (last visited July 28, 2014).
} 
transferred to the company, or declining to be the individual that represents a company in a transaction. If an individual is named in a document as a party to a transaction, or as the representative of a party, the name cannot be redacted from the document before recordation.

Most electronic signatures, from typed signatures to digital signatures, should not pose a security problem, because their appearance in a document does not enable significant imitation. A typed signature does not display any personal characteristics susceptible of imitation, and a digital signature can only be imitated if someone obtains the signer's private key, which is not included in the public document. ${ }^{257}$ Images of handwritten signatures, however, pose at least in theory a risk of enabling imitation, and stakeholders have mentioned that risk. ${ }^{258}$ One option for reducing that risk would be to maintain a non-public copy of a document that includes signature images, but to redact the signature on the public copy. The Copyright Office has chosen this option with regard to designations of agents for notification of claims of infringement under $\S$ 512(c)(2) of the Copyright Act. ${ }^{259}$ However, many more documents are recorded every year than designations of agents under $\S 512(\mathrm{c})(2)$ are filed, and the signature lines on recorded documents, unlike those $\S 512(\mathrm{c})(2)$ agent designation forms, are not in standard positions. Thus, creating and maintaining separate copies of each remitted document with unredacted and redacted signatures would be costly.

The United States Patent and Trademark Office has since 2011 made freely available on the Internet millions of recorded patent and trademark assignments, and had previously made available on the Internet millions of other documents filed during patent and trademark prosecution, without redacting handwritten signatures from those documents. Recordation and legal staff at the Patent and Trademark Office, however, were unable to recall any problem or complaint involving the imitation of a signature on a document made available by the Office. ${ }^{260}$ This experience suggests that the risk of injurious signature imitation based on a recorded document is exceedingly small. Thus, this report recommends prospectively making documents available to the public on the Internet without redaction of handwritten signatures.

ii. Sensitive Financial and Non-Copyright Terms. Stakeholders have also expressed concern about public disclosure of financial terms in recorded documents, as well as sensitive terms that are not related to copyright in a complex transaction, such as agreements regarding

\footnotetext{
${ }^{257}$ For a discussion of digital signatures, see supra p. 72.

${ }^{258}$ See, e.g., UCLA Roundtable Transcript, p. 119 (comments of Lawrence Liu, Universal Studios).

${ }^{259}$ See 17 U.S.C. § 512(c)(2) (providing that the limitations on liability for online service providers established in $\S$ 512(c) "apply to a service provider only if the service provider has designated an agent to receive notifications of claimed infringement," and has provided contact information of that agent on its website and to the Copyright Office, which is obligated to maintain a current directory of agents); United States Copyright Office, Directory of Service Provider Agents for Notification of Claims of Infringement, available at http://www.copyright.gov/onlinesp/list/a_agents.html.

${ }^{260}$ Conversation at the United States Patent and Trademark Office on May 15, 2014 with Mark Polutta, Senior Legal Advisor, Office of Patent Legal Adminstration; Joyce Johnson, Manager, Assignments Recordation Branch; DawnMarie Sanok, Attorney Advisor, Office of Deputy of Trademarks; Alain Lapter, Trademark Examining Attorney.
} 
trade secrets. ${ }^{261}$ As a prospective matter, this concern should be addressable through a combination of education and redaction policy. Parties to a copyright transaction often execute, not only a complete assignment or license agreement, but also a "short form" that includes legal details while omitting financial terms, and then record only the short form. Those parties and attorneys who are not aware of the possibility of including a short form in the documentation of a transaction should ideally be made aware of that possibility through a variety of educational channels. However, short forms are apparently not customary in some copyright industries, ${ }^{262}$ and some transactions proceed in multiple stages that make the execution of a short form difficult. Under those circumstances, it may be appropriate to allow parties to redact the portions of documents that contain sensitive financial terms, and those that contain terms unrelated to copyright, as long as all of the details that affect the state of title of the copyrighted works at issue remain intact. In this regard, the policy on redaction in the current draft of the Copyright Office Compendium seems appropriate:

A redacted document may be recorded, provided that the following conditions have been met:

- The remitter must satisfy the recordation requirements specified in Section 2309.7 .

- The blank or blocked-out portions of the document must be initialed or labeled "redacted" (regardless of whether the redactions appear in the document itself or the attachments thereto).

- Each page of the document must be accounted for. ${ }^{263}$

The "requirements specified in Section 2309.7" include those of legibility, completeness, and signatures. Thus, signatures cannot be redacted; redactions must be marked "redaction," so that readers can determine that the obscuring of language in the document was intentional, and does not represent a legibility problem; and pages cannot be omitted, nor page numbers redacted, so that it can be determined that the document was not mistakenly recorded in incomplete form.

Of course, redaction poses a danger to the parties to a transaction: If a redacted document no longer contains the essential terms of the transaction it memorializes, it will almost certainly

${ }^{261}$ See Columbia Roundtable Transcript, p. 67 (comments of Richard Bengloff, American Association of Independent Music).

${ }^{262}$ See Columbia Roundtable Transcript pp. 134-135 (comments of Christos Badavas, Harry Fox Agency).

${ }^{263}$ Compendium of Copyright Office Practices, Third Edition $\S 2309.9(E)$ (public draft, August 15, 2014). These Compendium rules track the Interim Policy on Redaction of Documents announced in 2005:

Documents containing blank or blocked-out sections, with the deletions initialed or labeled "redacted," will be accepted for recordation if the document otherwise meets the recordation requirements and each page is accounted for, even if entire pages are redacted. Documents with missing pages will be returned as incomplete. The policies with respect to attachments as stated in 37 CFR 201.4(c)(2) will be applied, except that redactions will also be permitted in an attachment.

Library of Congress, Copyright Office, Recordation of Documents, Notice of Policy Decision, 70 Fed. Reg. 44049, 44051 (August 1, 2005). In that policy statement, the Copyright Office warned that "[a]fter the Office has completed its inquiry into this issue ... it is possible that the Office may decide to eliminate the possibility of redaction entirely, or to limit its application." Id. However, it has not yet done so. 
be held not to provide constructive notice of that transaction, or to provide priority of the transfer it memorializes over a conflicting transfer. In this respect, the warning contained in a 2005 Copyright Office policy statement on redactions would still seem appropriate:

$[\mathrm{P}]$ ersons submitting documents for recordation are cautioned that they would be welladvised to be conservative in the practice of redacting material from the submitted documents, limiting their omissions to small amounts of sensitive information, such as financial terms. It is possible that excessive redaction might deprive the document of the constructive notice provided under section 205. The Office notes that under section 205(c), constructive notice applies only to "facts stated in the recorded document." A document which has been substantially redacted would necessarily limit constructive notice to that which appears in the document as recorded and could raise questions as to whether the Office's regulations were complied with - that is, whether the Office should have recorded the document with such redactions. ${ }^{264}$

A redaction regulation formulated as a list of specific redaction categories that are allowed, rather than as a general prohibition on redactions that obscure the essential terms of a transaction, may be easier for remitters to follow. However, a list of allowed categories that ends up not allowing the redaction of some financial details, or portions of a document unrelated to copyright, runs the danger of deterring recordation of some documents that it would be beneficial to have on public record.

A warning concerning redaction could be built into the online recordation process. A remitter could be asked to indicate if the document being remitted had been redacted in any way. If the remitter checked "yes," a screen could remind the remitter of Copyright Office policy concerning allowable recordation, and display a warning similar to the following: "Redaction of terms necessary to understand the legal effect of the document on copyright interests, including such terms as names of parties, titles and other identifiers of works, and operative language, may limit or negate the legal benefits accorded to validly recorded documents."

iii. Proposals for Limited Internet Access. Some stakeholders, concerned about the risks of exposure of sensitive information, have suggested that documents be made available on the Internet only to a limited audience, such as the parties to the documents, or those who demonstrate some legitimate interest in the documents. ${ }^{265}$ As others commented, however, limiting access to parties clearly seems too narrow, and there are a very wide variety of interests that could be deemed legitimate. For example, authors who have royalty and reversionary rights in a work under a contract with a publisher would legitimately want access to assignments regarding that work from that publisher to another publisher, so that they could understand the

\footnotetext{
${ }^{264}$ Library of Congress, Copyright Office, Recordation of Documents, Notice of Policy Decision, 70 Fed. Reg. 44049, 44051 (August 1, 2005).

${ }^{265}$ See UCLA Roundtable Transcript, pp. 107-08 (comments of Carly Seabrook, Universal Studios).
} 
scope of the assignment and communicate with the assignee about royalties and reversion. ${ }^{266}$ Moreover, to facilitate a market in works, it is important to provide ownership information, not only to those who have a current legal interest in a work, but to those who would like to obtain such an interest. ${ }^{267}$ Thus, it does not seem practical to limit Internet access to recorded documents to some particular defined group. Alternatively, access to documents could be open to the public, but members of the public could be required to register before gaining access, just as library patrons are required to register before borrowing books and in some cases before entering libraries. This could enable tracking of access to particular documents that were later found to have been misused. However, building and maintaining a registration system to regulate access to recorded documents would increase the cost of the document repository, and tracking access of each registered user to each document could raise privacy concerns. Lastly, any system for restricting access or registering users would likely be implemented and maintained with limited resources, and therefore subject to defeat by those intent on circumventing it; announcing the existence of such a system might therefore give remitters a false sense of security.

iv. Retrospective Availability. As noted above, ${ }^{268}$ since 1997, remitted documents have been digitally imaged, and those images have been maintained in a repository accessible through a web browser and hypertext transfer protocol. It would be relatively easy to make those images available on the Internet. With enough resources, even earlier microfilm images could be scanned, organized, and made available on the Internet. However, some commenters and roundtable participants expressed particular concerns about making available on the Internet documents that have already been recorded. Because those documents were recorded at a time when it took considerable effort to gain access to a recorded document, remitters may not have been as careful about ensuring that there was no sensitive information in remitted documents. Making those documents available on the Internet could cause what one commenter called a "disruption of expectations." 269 Some of these concerns were specifically directed to personally identifiable information such as signatures. ${ }^{270}$ Others were concerned about financial information that might not have been redacted due to an understanding that the Copyright Office placed limitations on redaction. $^{271}$ A number of other commenters, however, noted that

\footnotetext{
${ }^{266}$ See Columbia Roundtable Transcript, pp. 137-38 (comments of Susan E. Davis, National Writers Union).

${ }^{267}$ See UCLA Roundtable Transcript, p. 108 (comments of Mary McGuire, $20^{\text {th }}$ Century Fox) ("[T]here are a lot of times when an attorney will come to me and say . . . figure out who owns this property, we're interested in it. And . . . at this point we're an interested party, but we're not an interested party. . . I would love to be able to get my hands on that assignment, see exactly what was assigned. Were there any . . mitigating factors related to the assignment or . . . if there were a license or there's a limitation on the territories, the term.").

${ }^{268}$ See supra p. 25.

${ }^{269}$ UCLA Roundtable Transcript, p. 123 (comments of Catherine S. Bridge, The Walt Disney Company).

${ }^{270}$ See UCLA Roundtable Transcript, pp. 118-20 (comments of Lawrence Liu, Universal Studios).

${ }^{271}$ See UCLA Roundtable Transcript, p. 106 (comments of Catherine S. Bridge, The Walt Disney Company).
} 
recorded documents have always been a matter of public record, and that remitters did take or should have taken account of that. ${ }^{272}$

When the U.S. Patent and Trademark Office made recorded documents available on the Internet in 2011, it did so retroactively for documents dating back to 2003, the year it first made electronic recordation available. For those documents recorded before 2011, the Office has a policy of providing redaction of sensitive personal information displayed in those documents free of charge upon request. ${ }^{273}$ It has responded to several requests to redact credit card numbers that were inadvertently included in those documents, but recordation staff members are not aware of any occasion on which sensitive information in publicly available recorded documents was misused. ${ }^{274}$

If the Copyright Office were to adopt the same approach as the Patent and Trademark Office, it would retroactively make available on the Internet the documents that are now available on the Copyright Imaging System, which date back to 1997. In order to address concerns about personally identifiable information, the Office could announce in advance that it would be making the Copyright Imaging System available on the Internet, and give remitters some period of time - perhaps six months - to request redaction of certain specified types of information if any imaged documents were found to contain such information. However, particularly if a new document repository will be Portable Document Format-based, rather than image-based, and if there will be technical issues associated with integrating the two repositories, it may be easier to make the new document repository available on the Internet from the outset, and to leave the Copyright Imaging System available only on site at the Copyright Office.

\section{Copyright Office Screening of Documents and Remitter Certification of Document Compliance.}

As noted above, ${ }^{275}$ recordation specialists currently screen or examine each remitted document for compliance with a number of requirements, including completeness, legibility,

\footnotetext{
${ }^{272}$ See UCLA Roundtable Transcript, p. 114 (comments of Bill Colitre, Music Reports, Inc.) ("I think we should begin with the principle that these are public records. If I could travel to D.C. and look at them, I could see them. . . And why should they not be available on the Internet? We would need a much more compelling set of reasons to make them not available before we'd make a decision on this . ..."); id., p. 117 (comments of Susan Lowry, Screen Actors Guild - American Federation of Television and Radio Artists) ("[I] know that for us we don't have anything that we wouldn't want anyone to see that we would be recording with the Copyright Office because it's a matter of public record."); Stanford Roundtable Transcript, p. 61 (comments of Mary Minow, Dominican University and Stanford University) ("I work with libraries and if there's something doubtful we just don't put it up."); Columbia Roundtable Transcript, p. 141 (comments of Andy Hackett, National Corporate Research, Ltd.) ("[T]his is a public record, and I don't see it - I mean, these concerns about bad guys doing things or information that shouldn't be included in these documents; it is a public record. Anybody can go into the Copyright Office and obtain these documents.").

${ }^{273}$ Conversation at the United States Patent and Trademark Office on May 15, 2014 with Mark Polutta, Senior Legal Advisor, Office of Patent Legal Adminstration; Joyce Johnson, Manager, Assignments Recordation Branch; DawnMarie Sanok, Attorney Advisor, Office of Deputy of Trademarks; Alain Lapter, Trademark Examining Attorney. ${ }^{274} I d$.

${ }^{275}$ See supra p.16.
} 
handwritten signature, pertinence to copyright, and payment of proper fee. Recordation specialists also correspond with remitters about other issues that do not implicate requirements for recording but may cause the document to fail to implement the parties' intent.

Electronic recording could conceivably result in an increase of time spent on screening. Recordation specialists could continue to screen for all current requirements, and in addition, instead of transcribing cataloging information themselves, they could check that each item of cataloging information provided by the remitter (as will be recommended below) matches each item of information in the document, including titles and registration numbers of works that can run into the thousands. Screening, however, is a time-consuming process that makes recordation costly, and the cost of recordation appears to affect the number of documents recorded. ${ }^{276}$ Thus, if the goal of recordation is to develop a public record that is as complete and accurate as possible, but the cost of recordation must be covered by recordation fees and cannot be subsidized, there is a real tradeoff in engaging in thorough document-by-document screening. The quality of the documents recorded may increase, but the number of documents recorded may decrease.

This report therefore recommends that the Copyright Office cease to screen each document that is remitted for recordation. A sample of documents should be screened on a regular basis, to identify problems that arise systematically, with the goal of trying to reduce those problems through corrective measures such as better education, ${ }^{277}$ warnings displayed on screen during the online recordation process, and so on. The Office may decide that some particular types of documents should be screened for certain requirements on a document-bydocument basis, because of the known frequency of defects in those document types. When recordation specialists do find defects in documents, they can correspond with the remitter to request correction of those defects. Remitters who affirmatively want assistance should still be able to contact the Public Information Office and obtain that assistance. ${ }^{278}$ Finally, as will be recommended below, remitters should certify that a remitted document meets all recordation requirements after viewing the document as uploaded to the Copyright Office server. However, recordation specialists should no longer screen each remitted document to see whether it meets each requirement for recording.

\footnotetext{
${ }^{276}$ See supra p. 53.

${ }^{277}$ See Columbia Roundtable Transcript, pp. 105-106 (comments of Rachel Fertig, Association of American Publishers) (" $[\mathrm{A}]$ nother way to approach trying to minimize the error rates that would be important to our members is doing a circular, an FAQ, some sort of education to help people on the front-end know what you're actually looking for. So, if you see common mistakes and you can identify those and give people ... some step-by-step instructions then maybe you would actually reduce that problem from the beginning.").

${ }^{278}$ The American Association of Independent Music, Inc. stated that "[f]or newer music labels filing for the first time a Copyright Office help center reviewing a music label's initial filings for compliance would be a plus." NOI Comments of the American Association of Independent Music, Inc., p. 2. While the Public Information Office would not provide the kind of review that an experienced attorney, paralegal, or filing specialist would, it would be available to answer questions about recordation by e-mail or telephone, or in person, and technical specialists would be available to assist with technical problems with the online recordation system.
} 
This recommendation may generate more uneasiness than any other recommendation in this report, because ceasing to screen each document seems tantamount to giving up control over the quality of the public record. Nonetheless, it is supported by the following considerations:

First, it is the legal benefits of recordation, including constructive notice and priority, that are motivating all document remitters to record. Without those legal benefits, people would not go to the trouble of sending documents to the Copyright Office and paying recording fees. A core violation of any of the requirements for which the Copyright Office currently screens result in a loss of those legal benefits, or even more fundamentally in invalidity of the document. Recording a document only gives "constructive notice of the facts stated in the recorded document"; ${ }^{279}$ thus, when a document is incomplete, in the sense that it is missing any facts regarding the terms, works, or parties associated with a transaction, it will partially or wholly fail to give constructive notice of that transaction. A document that is partially or wholly illegible will also be missing some facts, and will therefore also fail to give constructive notice of those facts. If, as suggested below, the Copyright Office decides to promulgate regulations specifying that a document is only properly recorded if remitters provide correct and complete information about the document, then remitters will also have an incentive to list all of the titles of the works to which the document refers, and Copyright Office computers will be able to automatically count the correct number of titles for purposes of calculating the recording fee. Lastly, a document that purports to transfer copyright ownership, as the vast majority of recorded documents do, but is unsigned, will not be valid, and the intended transaction will completely fail. ${ }^{280}$ Thus, remitters have a strong incentive not to violate any of the screening requirements the same incentive that drives them to record in the first place - and if an electronic recording system properly educates and guides them, it is likely that they will rarely do so.

Second - and probably as a result of remitter incentives - rates of noncompliance with requirements identified by recordation specialists are in most cases already quite low. As the screening and correspondence study revealed, ${ }^{281}$ by far the largest category of problems with recorded documents involves miscalculation of recording fees. Fee issues affected $16.44 \%$ of the documents in the study sample. Yet the problems from which fee issues arose - either miscounting of work titles or submission of more than one document under a single cover sheet should both be greatly reduced in an electronic recording system. There is no evidence that remitters are deliberately miscounting titles; rather, when faced with paper lists of thousands of titles, they make counting mistakes. In an electronic system, they would have the opportunity to submit titles electronically in bulk, and Copyright Office computers would do the counting for them. Remitters would have no incentive to omit titles in order to reduce the recordation fee,

\footnotetext{
${ }^{279} 17$ U.S.C. § 205(c).

${ }^{280}$ See 17 U.S.C. $§ 204$ (providing that transfers of copyright ownership are only if they are in writing and signed by the owner or the owner's agent); 17 U.S.C. § 101 (defining "transfer of copyright ownership" as "an assignment, mortgage, exclusive license, or any other conveyance, alienation, or hypothecation of a copyright or of any of the exclusive rights comprised in a copyright ....”).

${ }^{281}$ See supra p. 19.
} 
because under the constructive notice rules proposed below, ${ }^{282}$ omitting a title would vitiate constructive notice for that title, and thus defeat the only purpose that is motivating the remitter to record at all. Similarly, the current cover sheet requires very little information to be entered about the accompanying document - for example, only the name of the first party in the document. If there are multiple documents in which the name of the first party is the same, it may be relatively easy to attach those documents to a single cover sheet. In the electronic recordation system, remitters would be entering in much more detailed information about each document, including the names of all parties, the type of document, the titles of all works, dates of execution, and so on. Under those circumstances, it is much less likely that remitters will record two or more documents while submitting only one set of cataloging information.

As for the other screening requirements, completeness was an issue for only $2.74 \%$ of documents in the screening and correspondence study, and in all of those cases, the issue was apparently that the remitter had not included an appendix that concerned non-copyright aspects of a complex transaction. ${ }^{283}$ While that omission might technically violate Copyright Office requirements regarding completeness, the documents in question still gave complete information about those parts of the transactions that "pertain[ed] to a copyright" 284 - the sole goal of the copyright recordation system, and the sole reason that those documents could be recorded at the Copyright Office.

Signatures created an issue for $2.05 \%$ of the documents, but in all of those cases, the issue was that the remitter had remitted a photocopy of the document that included images of handwritten signatures, but did not bear original handwritten signatures in ink. Under this report's recommendations, ${ }^{285}$ images of handwritten signatures in an electronically remitted document would count as valid electronic signatures, and therefore would not violate any requirement as long as they were accompanied by certifications. Legibility was an issue for $1.37 \%$ of documents, but apparently concerned only documents that were submitted as photocopies rather than originals. ${ }^{286}$ This figure would likely decrease if remitters could remit PDF files that were created directly from word processed documents, rather than having to send in photocopies, or second- or third-generation photocopies, of paper originals.

Third, the Patent and Trademark Office has not been individually screening patent and trademark documents for at least a decade, yet that has not generated any known complaints about the quality of its document repository. ${ }^{287}$

Fourth, in their Notice of Inquiry comments and recordation roundtable remarks, stakeholders have generally supported the proposal to end document-by-document screening. For

\footnotetext{
${ }^{282}$ See infra p. 86.

${ }^{283}$ As per Zarifa Madyun, Head of the Recordation Section.

28417 U.S.C. $\S 205(a)$.

${ }^{285}$ See supra p. 64.

${ }^{286}$ As per Zarifa Madyun, Head of the Recordation Section.

${ }^{287}$ See Stanford Report, supra note 4, p. 35.
} 
example, SoundExchange stated that "[i]mposing the responsibility for accuracy on remitters (as opposed to Copyright Office staff) represents a reasonable accommodation between perfect accuracy and cost containment." ${ }^{\text {"288 }}$ Microsoft stated that it "supports modification of online processes that ... makes copyright owners responsible for the accuracy of the information they submit." ${ }^{289}$ Stakeholders have also specifically supported the proposal to move to spot-checking of documents: "AIPLA agrees that the Copyright Office should ... perform targeted spot-checks to ensure the proper functioning and accuracy of the system."290 Author Services, Inc. "agree[s] with the proposal that the recordation specialist would not check all submissions and would do spot checks and continue to refine the set up."291

In a system in which recordation specialists are not screening every document, it is important to ensure that each remitter is aware of the requirements that documents must meet, and that he or she takes the time to consider whether each remitted document meets those requirements. Therefore, this report recommends that after the remitter uploads a document file to the Copyright Office server, the document as it is stored on the server be displayed in the remitter's browser window for review. This can be easily accomplished if the document is uploaded in PDF format as recommended above. After having had an opportunity to review the document, the remitter would be asked to electronically sign a certification such as the following:

I hereby state that I have had an opportunity to review this document as it has been uploaded to the Copyright Office, and that it meets the following requirements:

- All text in the document is clearly legible.

- The document is complete; it is not missing any appendices or schedules mentioned in the text, and if it is redacted, the redactions are only of the types allowed and are initialed.

- The document is signed, and the signatures are identifiable as such.

- The document pertains to copyright, which is to say that it actually or potentially concerns or affects an interest in one or more copyrighted works.

Each of these bullet points could be hyperlinked to additional information, such as an explanation of the types of redactions allowed. Alternatively, with regard to redactions, remitters could be asked to check a box if the document was redacted, and they would then be presented with another screen detailing the requirements for redactions and asking them to certify that their redactions met those requirements.

\footnotetext{
${ }^{288}$ NOI Comments of Soundexchange, Inc., p. 2.

${ }^{289}$ NOI Comments of Microsoft Corporation, p. 3.

${ }^{290}$ NOI Comments of the American Intellectual Property Law Association, p. 2.

${ }^{291}$ NOI Comments of Author Services, Inc., p. 1.
} 


\section{Remitter Provision of Cataloging Information.}

This report also recommends that remitters provide the catalog or index information that becomes part of the Copyright Office Catalog, through a web interface similar to that now used by the eCO copyright registration system. Remitter provision of information would generate substantial cost savings, since the current method of manual transcription of catalog information from remitted documents by Copyright Office recordation specialists is extremely time consuming. Having remitters submit catalog information should not simply shift the labor cost onto them, but should result in substantial overall savings, due to the use of techniques such as templates and bulk input of titles and other standard work identifiers.

Stakeholders who submitted comments to the Notice of Inquiry or attended one of the recordation roundtables generally reacted very positively to the proposal to have remitters submit catalog information for electronic recordations. For example, Andy Hackett of National Corporate Research, Ltd. noted that "[o]ur clients are familiar with similar electronic filing systems through the Patent and Trademark Office, and are familiar and comfortable with that system. And I don't think it would be a concern, especially if there were a payoff of faster recordation." 292 Microsoft Corporation supported "replac[ing] the Office's laborious manual review with online input processes that increase data entry accuracy by copyright owners.",293 Rachel Fertig of the Association of American Publishers stated: "We also did a survey with our members. ... [W] represent trade, academic, and book and journal publishers ... And we have large multinational publishers and, also, about three-quarters of our members are small and medium-sized enterprises. . . . [O]verwhelmingly they were in favor of a guided remitter recordation system.",294

a. Templates. Just as eCO allows registration applicants to save templates that automatically provide recurring information such as names, addresses, telephone numbers, and email address, an electronic recordation system can also allow users to save templates, cutting down on the time needed to enter information manually.

b. Bulk Submission of Titles, Registration Numbers and other Work Identifiers. In addition, many remitters already have work titles and registration numbers in electronic form; an electronic recordation system can allow remitters to upload those identifiers in bulk, without any need for manual entry. ${ }^{295}$ As noted above ${ }^{296}$ the Copyright Office recently published a Final

\footnotetext{
${ }^{292}$ Columbia Roundtable Transcript, p. 68 (comments of Andy Hackett, National Corporate Research, Ltd.).

${ }^{293}$ NOI Comments of Microsoft Corporation, p. 3. See also Stanford Roundtable Transcript, p. 14 (comments of Susan Morales, Fenwick \& West); NOI Comments of Graphic Artists Guild, Inc., p.4; NOI Comments of the Recording Industry Association of America, p. 2; UCLA Roundtable Transcript, p. 151 (comments of Susan Lowry, SAG-AFTRA).

${ }^{294}$ Columbia Roundtable Transcript, p.69 (comments of Rachel Fertig, Association of American Publishers).

${ }^{295}$ See, e.g., NOI Comments of the American Society of Composers, Authors and Publishers and Broadcast Music, Inc., pp. 6-7 ("[I]t is often the case that transfers are made at the catalog level and not the single work level (for example, a full publisher catalog), in which case, the Office would need to consider and implement batch submission processing that would match the operational processing given to single work recordations.").
} 
Rule more allowing for electronic submission of titles and associated registration numbers when a document contains 100 or more titles. ${ }^{297}$ The U.S. Patent and Trademark Office simply allows document remitters to copy and paste multiple patent numbers, or trademark registration numbers, into an entry box on a web page, separated by commas. ${ }^{298}$

Although copyright registration records currently accommodate other standard work identifiers, such as International Standard Book Numbers, International Standard Work Codes, and International Standard Recording Codes, document recordation records currently do not. This report recommends that the Copyright Office also begin to accept the submission of other standard work identifiers in recordation records. ${ }^{299}$ To facilitate bulk submission of such identifiers, the Office should consider providing remitters with a template for work identifier submission in a format such as Microsoft Excel. Both the Copyright Clearance Center and The Harry Fox Agency provide Microsoft Excel templates to copyright owners for submission of work identifiers. ${ }^{300}$ The Copyright Office might consider designing a template that is compatible with those templates, or consider working with those companies or others to design a template that could be used both for recording documents at the Copyright Office and for other transactional purposes. In addition, for more technically sophisticated remitters, the Copyright Office could consider publishing an XML schema for information about works in connection with recordation, and allow submission of information using that schema. ${ }^{301}$ Such a schema could more easily accommodate some of the potential complexities of work information than an Excel-based template. For example, one-to-many relationships, such as multiple standard identifiers associated with a single registered work (as when different "edits" of a registered sound recording might be represented by multiple International Standard Recording Codes) are awkward to represent on a single spreadsheet. However, less technically sophisticated remitters would find it more difficult to work directly with an XML schema. ${ }^{302}$

\footnotetext{
${ }^{296}$ See supra p. 22.

${ }^{297}$ Changes to Recordation Practices, 79 Fed. Reg. 55633 (September 17, 2014).

${ }^{298}$ See epas.uspto.gov (last visited July 28, 2014); etas.uspto.gov (last visited July 28, 2014).

${ }^{299}$ See infra p. 118.

${ }^{300}$ See CCC Title Loading Spreadsheet, available at http://www.copyright.com/content/dam/cc3/marketing/documents/xls/Electronic-Load-Template.xls (last visited July 28, 2014); Columbia Roundtable Transcript, p. 70 (comments of Heather Reid, Copyright Clearance Center); NOI Comments of the National Music Publishers' Association and The Harry Fox Agency, Inc., p. 7; Columbia Roundtable Transcript, pp. 128-130 (comments of Christos Badavas, The Harry Fox Agency).

${ }^{301}$ For general information on XML schema, see W3C, Standards $>>$ XML $>>$ Schema, at http://www.w3.org/standards/xml/schema (last visited August 13, 2014); see also UCLA Roundtable Transcript pp. 72-73 (comments of Nicholas Bunin, 20th Century Fox).

${ }^{302}$ See NOI Comments of Paul Jessop, Founder and Director, County Analytics Ltd, pp. 5-6:

The Copyright Office should not underestimate the effort required from users to transition from current manual processes to automated ones. [I]f there is a low level of documents submitted for recordation, the change may not in fact be justified. The Copyright Office should recognize this and make these more efficient processes optional unless there is a consensus that they can be supported without material inconvenience to users. However, the documentation of specifications in widely understood formats (such as formal schemas) will encourage the provision of communication tools by third parties (who will themselves see a large enough market to justify the development effort).
} 
c. Interactive Guidance. The Notice of Inquiry published in January 2014 described in detail remitter responsibility for cataloging, and asked for comment on a "guided remitter responsibility model" of electronic recordation. As the Notice of Inquiry explained, most of the guidance would be provided by a number of interactive features on the web pages on which information would be submitted:

For example, when a limited number of answers to a question are valid, electronic forms can provide enumerations such a dropdown boxes or buttons, rather than empty fields, to eliminate entries that are invalid or contain typographical errors. Many entries can be validated against lists of valid values or templates of valid formats, and rejected or questioned if the entries are not found in the lists or entered in valid formats. Crucial information can be required to be entered twice, and consistency between the entries can be checked. ${ }^{303}$

Additional features could assist in assuring that information was entered accurately. "Help" links next to particular entry boxes could lead to more detailed explanations of the information required. Some commenters noted that guidance might be enhanced if dropdown boxes were tailored to particular types of documents or particular types of works referenced in the document. ${ }^{304}$ While too many branching paths would be difficult to manage, there are certainly some specialized types of documents that require particular information - for example, notices of terminations of transfer require information about the date and manner of service and that information could be gathered only in connection with the type of document to which it was relevant. ${ }^{305}$ One stakeholder commented that if a remitter is recording more than one document with the same date of execution, it would be helpful to have the ability to indicate the sequence in which the documents should be considered executed, in order to keep a chain of title in the correct sequence. ${ }^{306}$

Remitters must be cautioned that all cataloging information that they provide must be found in the document; they cannot use the "electronic cover sheet" to add details that are missing from the remitted document. When the Copyright Office began to provide a cover sheet form in 1993, it believed that the form would aid cataloging, because information on the cover

\footnotetext{
${ }^{303}$ Notice of Inquiry of Recordation Reengineering at 2698.

${ }^{304}$ See NOI Comments of Alter \& Kendrick, LLP, p. 2 ("Further, the efficacy of drop-down lists may be increased if such drop-down lists are specific not only to the type of document being recorded, but also the category of copyrighted work to which the document applies, taking into consideration the various industry standard agreements that apply to each category."); NOI Comments of Copyright Clearance Center, Inc., p. 4 (“[T]he Office would benefit substantially from building the equivalent of electronic 'decision trees' in the recordation process .....").

${ }^{305}$ There is one specialized type of document - the $\S 508$ litigation notification, see 17 U.S.C. $\S 508-$ that disappeared from the Copyright Office Catalog in 1981, but that could reappear and provide tremendous informational benefits without additional Copyright Office labor if a particular input path were devoted to it and courts were requested to file such statements using the electronic recordation system. For further discussion, see infra p. 122.

${ }^{306}$ See E-Mail from Zarifa Madyun to Elizabeth Scheffler and Robert Brauneis, May 20, 2014 (forwarding E-Mail from Jean Paterson to Zarifa Madyun, May 19, 2014).
} 
sheet would be easier to enter into the Copyright Office Catalog than information in the document itself. In a 2005 Federal Register notice, however, the Office stated:

It was discovered . . . that often information was designated in the cover sheet which did not appear in the document. As a result, the Copyright Office had to limit indexing strictly to information appearing in the document, and copyright owners may have misinterpreted the purpose of the cover sheet as permitting the addition to the public record of information outside of the document by listing it in the cover sheet. ${ }^{307}$

As discussed above, when the remitter uploaded the document in PDF format, ${ }^{308}$ the copy on the Copyright Office server could be displayed back to the remitter, and the remitter could be asked to certify that the copy displayed was legible and complete, pertained to copyright, and bore the proper signatures. ${ }^{309}$ In addition, after the remitter completes the relevant certifications, but before he makes a final submission of his completed entry, a review screen could allow the remitter to check all entries before submitting. ${ }^{310}$ Roundtable discussion also led to a suggestion that the remitter have an option to have the review screen contents sent to him in an e-mail, allowing the remitter to circulate the information to other parties in a multi-party transaction, or to other employees in the remitter's own company, before making final submission. ${ }^{311}$

Lastly, even after final submission, remitters could have the ability to submit corrections of any errors that they made which resulted in catalog entries that did not reflect the contents of the recorded document, perhaps using on online form for this purpose. A number of stakeholders suggested that the system should have this capacity. ${ }^{312}$ While this makes sense, the Copyright Office should consider charging an extra fee for corrections, because they will take additional time to process. In addition, whenever cataloging information has already entered the public Copyright Office Catalog, any change in that information should result in a log entry that notes that a change was made, notes when it was made, and preserves the erroneous, pre-change

\footnotetext{
${ }^{307}$ Library of Congress, Copyright Office, Notice of Policy Decision, Recordation of Documents, 70 Fed. Reg. 44050, 44052 (Aug. 1, 2005); see NOI Comments of Robert Colton, p. 2:

The Office tried a paper version similar to this in the early 1990s. Remitters were supposed to complete a document cover sheet accurately reflecting the information in the document. Unfortunately many remitters submitted document cover sheets with their documents with basic errors such as the transferee identified as the transferor and the transferor identified as the transferee. Information about works often differed and remitters added information that was not in the document. The Office returned to using the document as the source of the catalog record. If an electronic version is developed, it will need to be made absolutely clear to the remitters that the staff will not check many records against documents.

${ }^{308}$ See supra pp. $71-82$.

${ }^{309}$ For further discussion, see p. 86 supra.

${ }^{310}$ See, e.g., NOI Comments of Association of American Publishers, Inc., p.2; NOI Comments of SoundExchange, Inc., p. 2; Stanford Roundtable Transcript, p.29 (comments of Susanne Morales, Fenwick \& West LLP).

${ }^{311}$ See, e.g., NOI Comments of the National Music Publishers' Association and the Harry Fox Agency, Inc., p.6; NOI Comments of Association of American Publishers, Inc., p.2.

${ }^{312}$ See UCLA Roundtable Transcript, p. 152 (comments of Susan Lowry, SAG-AFTRA); id. at 156 (comments of George Borkowski, RIAA).
} 
information. The current practice is to implement valid change requests by making the changes directly in the Copyright Office Catalog, without generating and preserving any change log or audit trail. As will be discussed further below, ${ }^{313}$ however, change logs are important both to determine the state of constructive notice at any given time, and to prevent tampering. The regulation concerning electronic submission of titles in documents referencing 100 or more titles has provisions consist with these recommendations, as it provides for a fee for making corrections, and for a note placed in the Catalog record for a document indicating that corrections were made, and the date of those corrections. ${ }^{314}$

d. Structured Electronic Documents. The Notice of Inquiry also noted that the Copyright Office was "considering whether to adopt standards for and accept structured electronic documents in which tagged indexing or cataloging information is integrated into the documents themselves." ${ }^{315}$ As the Notice of Inquiry elaborated,

Such documents contain several linked layers or folders. The name of a granting party displayed in the sentence that grants an interest in a copyrighted work, for example, is drawn from a field that identifies that name as a granting party name for cataloging purposes. ${ }^{316}$

If standards for such documents were adopted, and the Copyright Office built a system to handle them, recordation could be even more automated. Once such a document was uploaded to the Copyright Office system, the system itself would extract all cataloging information and add it to the Catalog. The remitter would not need to enter any information manually.

This technology is promising in theory, and has been implemented by a number of government agencies that record documents conveying interests in real property. ${ }^{317}$ Some Notice of Inquiry commenters and roundtable participants stated that the Copyright Office could make recording with structured electronic documents an option, as long as it was not mandatory. ${ }^{318}$ However, most stakeholders were generally not familiar with the technology, and many expressed skepticism that they would use it, since it would require drafting a document from the very beginning to meet certain technical standards that they do not use in any other

\footnotetext{
${ }^{313}$ See infra p. 116.

${ }^{314}$ See Changes to Recordation Practices, 79 Fed. Reg. 55633, 55636 (September 17, 2014) (regulations to be codified at 37 C.F.R. $\S 201.4(\mathrm{c})(4)(\mathrm{v})$ ). The Office has proposed a fee for corrections of seven dollars per corrected title. See Library of Congress, U.S. Copyright Office, Fees for Submitting Corrected Electronic Title Appendices, 79 Fed. Reg. 55694 (September 17, 2014).

315 Notice of Inquiry of Recordation Reengineering, at 2699.

${ }^{316} \mathrm{Id}$.

${ }^{317}$ For developments in the real estate recording industry, see the websites of the Property Records Industry Association, www.pria.us, and of the Mortgage Industry Standards Maintenance Organization, www.mismo.org.

${ }^{318}$ See, e.g., NOI Comments of the Motion Picture Association of America, p. 8; NOI Comments of Soundexchange, Inc., p. 3.
} 
correspondence or transaction. ${ }^{319}$ In light of this reaction, and the fact that there are not widely known and used adaptable examples of structured electronic documents, this report recommends not to pursue a structured electronic document option in the initial phase of constructing an electronic recording system.

e. Legal Authority for Requiring Remitters to Provide Cataloging Information. The Copyright Office clearly does not need to have its own employees perform all acts involved in preparing a catalog or index of recorded documents. Section 705(a) of the Copyright Act provides that " $[\mathrm{t}]$ he Register of Copyrights shall ensure that records of deposits, registrations, recordations, and other actions taken under this title are maintained, and that indexes of such records are prepared." ${ }^{, 320}$ That language stems from a 2000 amendment that replaced the version original to the Copyright Act of 1976, which had provided that " $[\mathrm{t}]$ he Register of Copyrights shall provide and keep in the Copyright Office records of all deposits, registrations, recordations, and other actions taken under this title, and shall prepare indexes of all such records." ${ }^{321}$ The legislative history of the amendment makes clear that its purpose was to allow the Register to have some cataloging duties performed outside of the Copyright Office. ${ }^{322}$

Whether the Copyright Office can require remitters to provide cataloging information is a somewhat more complicated issue. As a general matter, the validity of a Copyright Office regulation requiring remitters to provide cataloging information would be reviewed under the two-step test articulated in Chevron U.S.A., Inc. v. National Resources Defense Council, Inc. ${ }^{323}$ First, a court would look to "whether Congress has directly spoken to the precise question at issue." ${ }^{324}$ If it has, the court and the agency "must give effect to the unambiguously expressed

\footnotetext{
${ }^{319}$ See, e.g., NOI Comments of the Screen Actors Guild - American Federation of Television and Radio Artists, p. 3 ("SAG-AFTRA believes that mandating a format for documents submitted electronically is unnecessary and unduly burdensome for individuals and companies to revamp all of their documents.); NOI Comments of the Recording Industry Association of America, p. 7 ("We cannot advocate that the Office make a significant investment in pursuing this application of structured electronic document standards. The computer systems and business processes used in the copyright departments of the major record companies cannot at this time create or submit structure electronic documents."); NOI Comments of the National Music Publishers Association and the Harry Fox Agency, Inc., p. 7 ("In the music industry, however, structured electronic documents are not widely adopted and we, therefore, have limited experience with them. If the Office's goal is to supplement manual entry of data and the uploading of documents with a more automated submission process, that process would be web-based with real-time validation of formatting and the like in order to 'future-proof' the effort."); NOI Comments of Author Services, Inc., p. 2 ("I do not use structured documents such as what is described in the NOI and do not intend on using them in the foreseeable future."); NOI Comments of Robert Colton, p. 2 ("Given the variety of documents being recorded and remitters ranging from individual authors to large corporations, [structured electronic documents] see[m] unrealistic.")

${ }^{320} 17$ U.S.C. $\S 705(a)$.

${ }^{321} 17$ U.S.C. $§ 705$ (a) (1982); see Work Made for Hire and Copyright Corrections Act of 2000, Pub. L. No 111-295, 124 Stat. 3180, 3181 (substituting the current language).

${ }^{322}$ See H.R. Rep. No. 106-861, at 5-6 (2000) (noting that the amendment would allow the function of maintaining records of deposits of serials to be performed by the Serials Records Division of the Library of Congress rather than the Copyright Office).

${ }^{323} 467$ U.S. 837, 842-43 (1984); see City of Arlington, Tex. v. F.C.C., 133 S.Ct. 1863, 1868 (2013).

${ }^{324}$ Chevron, 467 U.S. at $842-843$.
} 
intent of Congress. ${ }^{" 325}$ However, "if the statute is silent or ambiguous with respect to the specific issue," the court would move to the second part of the test, and ask "whether the agency's answer is based on a permissible construction of the statute. ${ }^{326}$ Under this second part, the court will defer to the agency and find the regulation binding unless it is "procedurally defective, arbitrary or capricious in substance, or manifestly contrary to the statute." ${ }^{327}$ The Chevron inquiry, and its deference, is only appropriate "when it appears that Congress delegated authority to the agency generally to make rules carrying the force of law, and that the agency interpretation claiming deference was promulgated in the exercise of that authority." ${ }^{328}$ However, if the agency has such authority, this deference applies with equal force no matter whether the Congressional delegation of authority constituted general rule-making authority or was specific to the exact statutory provision at hand. ${ }^{329}$

The Copyright Act certainly does not explicitly ban the Copyright Office from requiring remitters to provide cataloging information when remitting a document for recordation. Any argument that "Congress has spoken directly to the issue" of requiring remitters to provide such information would have be grounded on a construction of $\S 205(b)$ of the Act. That section provides: "The Register of Copyrights shall, upon receipt of a document as provided by subsection (a) and of the fee provided by section 708, record the document and return it with a certificate of recordation." 330 The argument would be that $\S 205$ (b) imposes a duty on the Copyright Office to record when two and only two conditions are fulfilled by the remitter: presentation of a document that is eligible for recordation under $\S 205(\mathrm{a})$, and payment of the appropriate fee. If Congress has determined that those are the only two conditions that can be placed on recordation, then Congress has spoken, and no other conditions - such as a condition that a remitter provide cataloging information - can be imposed.

That construction of $\S 205(\mathrm{~b})$, however, is not the most persuasive. First, it seems likely that $\S 205$ (b) speaks to "substantive," rather than "procedural" and "formal" requirements. Section 205(b) establishes that the Copyright Office cannot exclude a category of documents from recordation that is eligible for recordation under $\S 205(\mathrm{a})$. Thus, for example, the Copyright Office cannot refuse to register documents conveying contingent future interests in works of authorship on the ground that the interests are too speculative. Nor could it refuse to record documents that do not specifically identify the works to which they pertain on the ground that those documents do not give constructive notice under $\S 205(\mathrm{c})$ and are therefore of little value.

\footnotetext{
${ }^{325} \mathrm{Id}$.

${ }^{326} I d$. at 843.

${ }^{327}$ U.S. v. Mead Corp., 533 U.S. 218, 227 (2001).

${ }^{328}$ Id. at 226-227.

${ }^{329}$ Mayo Foundation for Medical Educ. and Research v. U.S., 131 S.Ct. 704, 713-714 (2011).

${ }^{330} 17$ U.S.C. $\S 205(\mathrm{~b})$.
} 
However, § 205(c) leaves the Copyright Office free to impose reasonable "procedural" and "formal" requirements that are consistent with the recordation system that the Office runs. For example, the Office can require that the document remitted be not only "legible," but "capable of being imaged or otherwise reproduced in legible copies by the technology employed by the Office at the time of submission." 331 Thus, the Copyright would refuse to record a document that was of a type substantively eligible for recordation - an ordinary assignment - if it were written on all sides of a basketball, and that refusal would not violate $\S 205$ (c). Similarly, the Copyright Office may determine that an electronic recordation system is vastly more efficient when remitters, appropriately guided, provide cataloging information, just as it has already determined with respect to its electronic registration system, and just as the United States Patent and Trademark Office has with respect to recordation of patent and trademark documents, ${ }^{332}$ and as the Canadian Intellectual Property Office has with respect to recordation of copyright and patent documents. ${ }^{333}$ If it does so, then it should be able to impose the procedural requirement that remitters provide cataloging information. So long as that burden is not so onerous as to amount to a substantive bar to recording, ${ }^{334}$ it should not fall afoul of $\S 205(\mathrm{~b})$.

By way of comparison, the practice of the Patent and Trademark Office would suggest that $\S 205$ (b) would not preclude requiring remitters to submit cataloging information. Since 2004, the Patent and Trademark Office has been requiring those who remit patent documents electronically to complete an electronic cover sheet that provides cataloging information about those assignments. ${ }^{335}$ It also requires those who remit patent assignments on paper to complete and submit paper cover sheets with the documents. ${ }^{336}$ The section of the Patent Act that governs recording of assignments provides as follows:

\footnotetext{
33137 C.F.R. $\S 201.4(\mathrm{c})(3)$.

332 See supra p. 55.

${ }^{333}$ See Canadian Intellectual Property Office, Transfer Ownership, http://www.cipo.ic.gc.ca/eic/site/cipointernetinternetopic.nsf/eng/wr00054.html (last visited July 29, 2014) (regarding copyrights); Canadian Intellectual Property Office, Request for Registration of a Transfer, http://www.cipo.ic.gc.ca/eic/site/cipointernetinternetopic.nsf/eng/wr03404.html (last visited July 29, 2014) (regarding patents); Stanford Report, supra note 5, at 25 (discussing copyright document recordation procedures in Canada).

${ }^{334}$ Cf. Tafas v. Doll, 559 F.3d 1345, 1352 (Fed. Cir. 2009), vacated in preparation for rehearing en banc, 328 Fed.Appx. 658, dismissed as moot after change in regulations sub nom. Tafas v. Kappos, 586 F.3d 1369 (upholding Patent and Trademark Office requirements that applicants who submitted a certain number of claims provide the examiner with information about prior art and about why they believe the claims are patentable) ("[a] procedural rule does not become substantive simply because it requires the applicant to exert more effort to comply, so long as the effort required is not so great that it effectively forecloses the possibility of compliance.").

335 The Patent and Trademark Office launched its Electronic Patent Assignment System on May 10, 2004. See USPTO Launches Electronic Patent Assignment System, http://ip-updates.blogspot.com/2004/05/uspto-launcheselectronic-patent.html (last visited July 28, 2014).

${ }^{336}$ See 37 C.F.R. $\S 3.28$ ("Each document submitted to the Office for recording must include a single cover sheet (as specified in $\S 3.31$ ) referring either to those patent applications and patents, or to those trademark applications and registrations, against which the document is to be recorded.").
} 
The Patent and Trademark Office shall maintain a register of interests in patents and applications for patents and shall record any document related thereto upon request, and may require a fee therefor. ${ }^{337}$

This provision, like the provision concerning recordation of copyright documents, states that the government agency "shall" record any eligible document upon request, and the only explicit condition it allows is the payment of a fee. Nonetheless, the Privacy Policy Statement on the home page of the Electronic Patent Assignment System states the following with regard to the requirement that the remitter provide cataloging information for remitted patent assignments:

This collection of information is required by 36 USC $\S \S 261$ and 263 and is used by the public to submit (and by the USPTO to process) patent assignment recordation requests using the Electronic Patent Assignment System (EPAS). This collection is estimated to take 30 minutes to complete, including gathering the necessary information, filling out the online forms, and submitting the completed request to the USPTO. ${ }^{338}$

Over the past decade of operation of the Electronic Patent Assignment System, no one has challenged the Patent and Trademark Office's requirement of submitting cataloging information for patent documents.

If $\S 205(b)$ does not directly speak to the issue of whether the Copyright Office can require remitters to provide cataloging information, then surely a regulation creating such a requirement would be "based on a permissible construction of the statute." 339 The Copyright Act does grant the Copyright Office the authority "to establish regulations not inconsistent with law for the administration of the functions and duties made the responsibility of the Register under [title 17]. ${ }^{340}$ One of those duties is to create and maintain a system for recording documents pertaining to copyright. ${ }^{341}$ If the Register determines that the most efficient way of designing and running that system is to have remitters provide cataloging information as they are remitting documents, she should be able to promulgate regulations that enable that system to run in that manner.

\footnotetext{
${ }^{337} 35$ U.S.C. $\S 261$. By contrast, the only statutory reference to recording trademark documents at the Patent and Trademark Office is in Section 10 of the Lanham Act: "The United States Patent and Trademark Office shall maintain a record of information on assignments, in such form as may be prescribed by the Director." Thus, there is no equivalent issue as to whether cataloging information can be required from remitters of trademark documents.

${ }^{338}$ Electronic Patent Assignment System (EPAS) Privacy Policy Statement, epas.uspto.gov (last visited July 28, 2014). Although the statement refers to 35 U.S.C. $\S 261$ and 35 U.S.C. $§ 263$, the latter does not exist; 35 U.S.C. § 261 is the only provision in the Patent Act that governs recording.

${ }^{339}$ Chevron, 467 U.S. at 843.

${ }^{340} 17$ U.S.C. $\S 702$.

${ }^{341}$ See 17 U.S.C. $\S \S 205,705$ (a).
} 
If the Copyright Office were still concerned about a challenge to the requirement of remitter provision of cataloging information, it could maintain the option of remitting a document on paper without a cover sheet. Indeed, it may want to maintain that option anyway, since some people will still want to remit documents on paper, and a paper cover sheet does not create the same efficiencies that electronic submission of cataloging does: a paper cover sheet cannot use techniques like validation to limit errors, and a recordation specialist still must transcribe paper cover sheet entries into an electronic record. With respect to remitters choosing the paper option, the Copyright Office would follow the dictate of $\S 205(b)$ even under the strictest interpretation of that provision: it would record any eligible document that was submitted with payment of the fee set by the Office. No remitter could claim that he did not have the opportunity to remit a document with a fee and have the document recorded. However, the Office would also allow people to remit documents electronically, with cataloging information, and would charge a substantially lower fee in that case. With those procedures in place, the legal issue would be whether the Copyright Office could "unbundle" its services - whether it could allow recordation of any document even without a cover sheet, but offer a discount for those remitters who provided cataloging information and therefore did not require the Office to perform transcription services. It seems highly unlikely that a court would refuse to allow the Office to offer such a discount.

\section{Remitter Responsibility for Constructive Notice that Requires Both Satisfactory Documents and Accurate Cataloging.}

This report recommends that a document be considered to provide constructive notice of its effect on the ownership of a particular work only as of that date on which the remitter has submitted a proper document, the proper fee, and accurate key cataloging information with respect to that work. For a document recorded only under the provisions of $\S 205$ of the Copyright Act, the crucial information for cataloging purposes would be the title(s) or registration number(s) of the work(s) referenced in the document. ${ }^{342}$ If a document concerns more than one work and the cataloging information is accurate with respect to some of the works but not others, then constructive notice would be given as to those works for which cataloging information is accurate, but not as to those for which cataloging information is inaccurate.

Placing the burden on the remitter to ensure that the cataloging information that he or she furnishes is sufficient to provide constructive notice is another aspect of the "guided remitter responsibility model" that was proposed in the January 2014 Notice of Inquiry. ${ }^{343}$ That burden is a crucial incentive for the remitter to furnish accurate information for the Copyright Office

\footnotetext{
${ }^{342}$ For a discussion of why the title and registration number are the crucial elements under $\S 205(\mathrm{c})$, see p. 75, supra. Some documents may fall within the scope of different and more particular provisions. For example, $\S \S 302$ (c) and (d) create certain legal consequences if a statement regarding the death, continued life, or identity of an author is recorded. See 17 U.S.C. $\S 302$. The crucial information with regard to those statements is likely the name of the author, not the titles or registration numbers of the works he or she has created.

${ }^{343}$ See Notice of Inquiry of Recordation Reengineering, at 2698.
} 
Catalog. If having a document placed in the Copyright Office's document repository were alone sufficient to provide constructive notice, then remitters could afford to be sloppy when providing cataloging information, knowing that mistakes or omissions would have no effect on the legal benefits of recordation.

Under some circumstances, at least, it would be efficient and fair to place an even greater burden on the parties to a document: the burden, not just to provide accurate cataloging information to the Copyright Office, but to check the public record as it was eventually displayed in the Copyright Office Catalog, and to ensure that no malfunction of the system had resulted in missing or inaccurate information in that record. The problem to be solved is an information problem - the problem of ensuring that a prospective purchaser, licensee, or secured creditor can obtain information about the state of title of a work under copyright. From the standpoint of efficiency, given the existence of a recording system, the "least cost avoider" of the information problem is clearly the remitter, who knows that a particular document exists, and who can take steps to check whether it has been properly indexed, and to have any omissions or errors corrected. By contrast, the prospective subsequent purchaser, secured lender, or exclusive licensee to be protected by $\S 205$ (d) has no previous actual knowledge of the existence of a document effecting a transfer (such actual knowledge would defeat a claim to be "in good faith . . . and without notice of the earlier transfer" under that section ${ }^{344}$ ). At least until some future time when full-text searching of recorded documents might be possible, the only alternative to a search of an accurate document index is to read every document in the repository, or at least every document in the repository within a particular time span. The cost of reading thousands or tens of thousands of documents is undoubtedly higher than the cost of checking to see that a known document has been properly indexed, and of then taking steps to ensure that any errors are corrected.

From a fairness perspective, the plight of a remitter who has delivered a document meeting all requirements to the Copyright Office with the proper fee may seem poignant. Such a remitter has done everything in his or her direct control to record a document, but under a remitter responsibility rule still may not have the protection of constructive notice and priority if the document is not properly indexed. Under the opposite rule, however, the prospective purchaser is equally powerless - by definition, he or she has no knowledge of a document, and can take no practical steps to find it, yet is nonetheless being told that she has constructive knowledge of it. Thus, under either rule, one of the parties can suffer a loss beyond his or her control due to some action or inaction of the Copyright Office. The only difference is that the remitter can check whether proper action has been taken and try to prompt the Office to take it if it hasn't, whereas the party who would be deemed to have constructive notice has no means of even knowing that there is some action that the Copyright Office could and should take. The Copyright Office may well be more aware of the remitters' point of view, because remitters have

\footnotetext{
${ }^{344} 17$ U.S.C. § 205(d).
} 
the knowledge they need to lodge complaints. The remitters also pay fees, and it may therefore be tempting to view them as clients, while not viewing those deemed to have constructive notice as clients, because they are not paying fees. Yet a recording system is only fair if those deemed to have constructive notice of a document can practically learn of it; if they cannot, then the payment of a fee by the remitter does not cure the resulting unfairness of the imputation of notice.

Although there is a policy case to be made for remitter responsibility for accuracy of the Copyright Office Catalog, under current circumstances, this report recommends burdening remitters only with the responsibility to provide accurate cataloging information - in particular, the correct title(s), and registration number(s) if available, of the works referenced in the remitted document. Congress has provided a grace period for prior transferees to record to maintain priority over conflicting subsequent transfers: one month for documents executed in the United States, and two months for documents executed abroad. ${ }^{345}$ It is clear from the existence of the grace periods that Congress intends remitters who record within a reasonable time to have the opportunity to maintain seamless protection of their transactions against subsequent purchasers, licensees, and secured creditors. Given the current and longstanding document processing backlog, ${ }^{346}$ it would be impossible for ordinary remitters to check within the grace period whether the information that they had provided had been accurately entered into the public Catalog. True, remitters have the opportunity to pay an additional "special handling" fee of $\$ 550$ to expedite recordation, ${ }^{347}$ and it is conceivable that a remitter who remitted a document the day after execution and paid the special handling fee could view the catalog entry for the document within one month and request corrections. Yet requiring remitters to pay such a special fee to maintain the protection that Congress intended to make available generally does not seem defensible.

The Patent and Trademark Office states that electronically remitted trademark assignments will generally be recorded in one day, and paper assignments will be recorded in one week. $^{348}$ If the Copyright Office can attain that speed with an electronic recording system, then the entire recording process, including indexing and correction of any misindexing, might comfortably be accomplished within a month. At that time, it might be appropriate to revisit the issue whether remitters should have the responsibility for checking catalog entries to see that they are accurate.

\footnotetext{
34517 U.S.C. $\S 205(d)$.

${ }^{346}$ For a chart showing delays between dates of recordation and dates of entry of information into the Copyright Office Catalog, see p. 35 supra.

347 See "Special Handling," http://www.copyright.gov/help/faq/faq-special.html (last visited July 29, 2014); "Fees," http://www.copyright.gov/docs/fees.html (last visited July 29, 2014).

${ }^{348}$ See United States Patent and Trademark Office, Assignments: Change of Owner and Change of Owner Name, http://www.uspto.gov/trademarks/process/assign.jsp (last visited July 28, 2014).
} 
Stakeholder reaction to the question of whether constructive notice should depend on correct cataloging information was mixed. In part, this was due to some confusion over the hypothetical circumstance in which cataloging information described a transaction that never took place, but could have. ${ }^{349}$ Suppose that remitter-provided cataloging information described a copyright assignment in a certain work from $\mathrm{A}$ to $\mathrm{C}$ (and $\mathrm{C}$ was a real person or company), but there never was such an assignment, and the document to which the catalog entry pointed effected an assignment from A to B. When we say that constructive notice depends on the submitted cataloging information, do we mean that in the hypothetical posed, everyone would have constructive notice that $\mathrm{C}$ now owns copyright in the referenced work? The statutory answer is "no." The catalog is only an index; someone who is interested in the state of title of a work needs to look at the document itself, not just at the index. As explained previously above, ${ }^{350} \S 205$ (c) provides that proper recordation "gives all persons constructive notice of the facts stated in the recorded document, ${ }^{, 351}$ not of facts stated in the Copyright Office Catalog. In a system in which constructive notice depends upon proper indexing, an inaccurate index entry that fails to point searchers to the document it is supposed to may result in no constructive notice of any kind being given. However, it does not result in constructive notice of a fictional transaction represented in the inaccurate entry. ${ }^{352}$

With that issue clarified, there were two commenters who supported placing the burden of proper indexing on the remitter, ${ }^{353}$ while one commenter, a former Copyright Office employee who stated that he "created and implemented the current recordation procedure that has been in place since 1982," opined that "[r]esponsibility should remain with the Copyright Office in determining the accuracy of the information appearing in the Catalog." 354

Even if remitters are only held responsible for providing accurate cataloging information, it would be helpful if, once the record for a document entered the Copyright Office Catalog, the Copyright Office sent the remitter a link to that record, and recommended that the remitter check to see that the record, and all connected records regarding works specifically referenced in the document, are accurate. That link and reminder would further reduce the remitter's burden in assuring Catalog accuracy, and would be good preparation for future consideration of whether

\footnotetext{
${ }^{349}$ For discussion of such a situation in which catalog information and referenced document diverged, see UCLA Roundtable Transcript, pp. 155-56; Stanford Roundtable Transcript, pp. 31-32; Columbia Roundtable Transcript, pp. 83-87

${ }^{350}$ See p. 75 , supra.

35117 U.S.C. $\S 205$ (c) (emphasis added).

${ }^{352}$ For comments that come to this conclusion, see Stanford Roundtable Transcript, pp. 31-32 (comments of George Borkowski, Recording Industry Association of America); Columbia Roundtable Transcript, p. 85 (comments of George Borkowski, Recording Industry Association of America); Columbia Roundtable Transcript, pp. 86-87 (comments of Brad Prendergast, SoundExchange Inc.).

${ }^{353}$ See UCLA Roundtable Transcript, p. 152 (comments of Susan Lowry, SAG-AFTRA); Stanford Roundtable Transcript, pp. 14-15 (comments of Susanne Morales, Fenwick \& West).

${ }^{354}$ Letter of March 24, 2014 from Bernard C. Dietz to Mr. Ryland Hawkins, p.1, submitted as an attachment to NOI Comments of Author Services, Inc.
} 
remitters should have a legal burden to ensure such accuracy. The link and reminder would preferably sent in the same e-mail that transmitted the recordation certificate and labeled document (see recommendation 8 below), but if Copyright Office workflow made that difficult, it could be sent in a separate e-mail. Although the Office will likely continue a paper-based system in which recordation specialists create the catalog record through transcription, the report recommends that it also send a notice to the remitter of paper documents that provides the link to the Catalog record, and that recommends that the remitter check to see that the record is accurate.

\section{a. The Legal Framework for Remitter Responsibility for Accurate Catalog} Information. The Copyright Act does not explicitly allocate the responsibility for proper indexing of a document between prior and subsequent purchasers. It refers to "recording" and to "recordation" of a document, but those terms are ambiguous, and are susceptible to a range of interpretations that could include or exclude indexing as a component of proper recordation. This conclusion is supported by the decisions of state courts, which are deeply split as to whether a misindexed document concerning interests in real property is properly recorded or not. Thus, a Copyright Office regulation that provided that a document would only be considered recorded if it were properly indexed, or only if the document were remitted with proper indexing information, would be a permissible construction of the statute.

The issue of allocating the risk of inaccurate indexing information was first raised in the 1958 study on recordation that formed part of the legislative process that eventually led to the Copyright Act of 1976. That study noted that "[t]he burden of discovering the assignment may sometimes be a heavy one; the document may occasionally be indexed or recorded incorrectly. ${ }^{, 355}$ It continued:

Section 31 of the present law imposes the duty to record on the Register of Copyrights, but is silent as to the effect of an error in recording or filing. Perhaps clarification of this question by definition of the term "recorded" or by a "constructive notice" provision is warranted. ${ }^{356}$

The 1961 Report of the Register of Copyrights took up the issue of clarifying constructive notice, but it did not address the effect of errors in indexing. Rather, it focused on the issues of references in a recorded document to an unrecorded document, and of blanket transfers that covered "all the copyrights" owned by a transferor with no identification of individual works. With regard to the first issue, it concluded that "[t]he statute should ... indicate that constructive

\footnotetext{
${ }^{355}$ Alan Latman, assisted by Lorna G. Margolis and Marcia Kaplan, Study No. 19, The Recordation of Copyright Assignments and Licenses (September 1958), in Copyright Law Revision, Studies Prepared for the Subcommittee on Patents, Trademarks, and Copyrights of the Committee on the Judiciary, United States Senate, $86^{\text {th }}$ Congress, $2 \mathrm{~d}$ Session. ${ }^{356} I d$.
} 
notice is confined to the facts specified in recorded instruments, ${ }^{, 357}$ and should not extend to facts that might be found in unrecorded documents referenced in the recorded documents. With regard to the second issue, it concluded that "the statute should indicate that constructive notice is confined to the copyrights in works specifically identified by the recorded instrument." 358

These recommendations led to what is now the introductory portion of $\S 205(\mathrm{c})$ and $\S$ 205(c)(1), which provide:

Recordation of a document in the Copyright Office gives all persons constructive notice of the facts stated in the recorded document, but only if -

(1) the document, or material attached to it, specifically identifies the work to which it pertains so that, after the document is indexed by the Register of Copyrights, it would be revealed by a reasonable search under the title or registration number of the work. $^{359}$

Section 205(c)(2), which adds the condition that "registration has been made for the work,",360 was added in a later draft in $1965 .{ }^{361}$ The final House report to the Copyright Act of 1976 only repeats these conditions:

The recording and priority provisions of section 205 are intended to clear up a number of uncertainties arising from sections 30 and 31 of the present law and to make them more effective and practical in operation. Any "document pertaining to a copyright" may be recorded under subsection (a) if it "bears that actual signature of the person who executed it," or if it is appropriately certified as a true copy. However, subsection (c) makes clear that the recorded document will give constructive notice of its contents only if two conditions are met: (1) the document or attached material specifically identifies the work to which it pertains so that a reasonable search under the title or registration number would reveal it, and (2) registration has been made for the work. ${ }^{362}$

Interpretation of $\S 205(c)$ needs to begin with the very first clause: "Recordation of a document in the Copyright Office gives all persons constructive notice of the facts stated in the recorded document ...." Though $\S \S 205(c)(1)$ and 205(c)(2) place further conditions on this first statement - this first statement is true "only if" the conditions in those subsections are also met - they do not change the fact that "all persons" have "constructive notice of the facts stated in the recorded document" only if an act or event has taken place, namely, "[r]ecordation of [the]

\footnotetext{
${ }^{357}$ Report of the Register of Copyrights on the General Revision of the U.S. Copyright Law (July 1961), p. 96. ${ }^{358} \mathrm{Id}$.

${ }^{359} 17$ U.S.C. $\$ 205(c)$.

${ }^{360} 17$ U.S.C. $\S 205(c)(2)$.

${ }^{361}$ See Supplementary Register's Report on the General Revision of the U.S. Copyright Law (1965), p. 77.

362 Copyright Law Revision, H.R. Rep. No. 94-1476 (1976), p. 128.
} 
document in the Copyright Office." Thus, the first question to ask is, under what conditions has a document been "recorded" in the Copyright Office? A remitter might take the position that receipt of a document by the Copyright Office, with the proper fee, itself constitutes recordation of that document. Section 205(b), however, clearly envisions "recording" to be something other than "receipt," for it provides that "upon receipt of a [qualifying] document . . . and of the [proper] fee," "[t]he Register of Copyrights shall . . record the document . . ..363 Thus, "recordation" is an act or group of acts taken by the Copyright Office other than mere receipt of the document and fee. ${ }^{364}$

A thorough search has uncovered only three published judicial opinions on the issue of what counts as recordation at the Copyright Office. ${ }^{365}$ None of them is concerned with defining recordation for purposes of determining when a document gives constructive notice. Rather, they all concern the issue of what should count as recordation under an earlier version of $\S 205(d)$ of the Copyright Act, which required plaintiffs who claimed to own copyright in a work by virtue of a transfer to record that transfer as a prerequisite to filing suit. ${ }^{366}$ However, they all conclude that recordation is an act performed by the Copyright Office that is different and separate from mere receipt of proper documents and fees.

The plaintiffs in the three cases all presented evidence that the Copyright Office had received the relevant documents and fees for recordation, and argued that receipt should count as recordation for purposes of $\S 205(d)$, particularly since, with respect to registrations, $\S 410(d)$ provides that "the effective date of a copyright registration is the day on which an application, deposit, and fee, which are later determined by the Register of Copyrights and by a court of competent jurisdiction to be acceptable for registration, have all been received in the Copyright Office." 367 In each case, however, the court rejected that argument. As the court in Greenwich Film Productions S.A. v. DRG Records, Inc. ${ }^{368}$ put it, "[s]ince the evidence established only that

\footnotetext{
${ }^{363} 17$ U.S.C. $\S 205(b)$.

${ }^{364}$ Accord 3 Melville B. Nimmer \& David Nimmer, Nimmer on Copyright § 10.07[A][1][a] ("If an appropriately specific document is filed at the Copyright Office, then its effective date for purposes of constructive notice is the date on which the recordation in fact takes place (not, as in the registration context, the date that the relevant document is received by the Copyright Office).") This statement in the Nimmer treatise is not supported by any citations, and is not a correct description of the law under current Copyright Office regulations, which provide that the effective date is indeed the date on which the Copyright Office receives a proper document and fee. See 37 C.F.R. $§ 201.4(\mathrm{e})$.

${ }^{365}$ See Greenwich Film Productions S.A. v. DRG Records, Inc., 833 F. Supp. 248 (S.D.N.Y. 1993); McNabb Bennett \& Associates, Inc. v. Terp Meyers Architects, 1987 WL 7817, at*3 (N.D. Ill.); Patch Factory, Inc. v. Broder, 586 F. Supp. 132 (N.D. Ga. 1982).

${ }^{366}$ See 17 U.S.C. $\S 205$ (d) (1976) ("No person claiming by virtue of a transfer to be the owner of copyright or of any exclusive right under a copyright is entitled to institute an infringement action under this title until the instrument of transfer under which such person claims has been recorded in the Copyright Office, but suit may be instituted after such recordation on a cause of action that arose before recordation.") This requirement was removed by the Berne Convention Implementation Act of 1988, P.L. 100-568, 102 Stat. 2853, § 5 (October 31, 1988).

${ }^{367} 17$ U.S.C. $\S 410$ (d). As will be discussed below, Copyright Office regulations provide a similar formulation to determine the date of recordation.

${ }^{368} 833$ F. Supp. 248 (S.D.N.Y. 1993).
} 
the documents were received, and not that actual recording has in fact taken place, it would not be appropriate to find that the transfer has yet been recorded." 369 The court in Patch Factory, Inc. v. Broder ${ }^{370}$ added that "receipt of a transfer recordation application does not mean the application is automatically approved; the Copyright Office may detect irregularities in the application to warrant denial of the requested recordation." 371

If recordation is an act performed by the Copyright Office, what are the components of that act? When can it be said that a document has, in fact, been properly recorded? There is a good argument that the terms "record" and "recordation" are ambiguous enough that there is a range of "permissible construction[s] of the statute" "372 that the Copyright Office would be authorized to adopt, and that a definition that included indexing as an essential component of recordation would be within that range.

The Fifth Edition of Black's Law Dictionary, published in 1979, contains the following definition of the verb "record":

To make an official note of; to write, transcribe, or enter in a book, file, docket, register, computer tape, or disc, or the like, for the purpose of presenting authentic evidence of. To transcribe a document, or enter the history of an act or series of acts, in an official volume, for the purpose of giving notice of the same, of furnishing authentic evidence, and for preservation. ${ }^{373}$

Part of this definition assumes the use of technology that the Copyright Office has not used for almost a century, but of course at one time the Office did "record" documents by means of transcribing them "in an official volume, for the purpose of giving notice of the same." Under a narrow reading of that definition, indexing is not part of recording; it is the transcription of the document into a volume open to public inspection, not the creation of an index to one or more volumes, that constitutes the recording of that document. Applying that narrow definition to current technology, we would say that the modern analogue of transcription is digital imaging the act that preserves the contents of the document at the Copyright Office - and thus that a document has been recorded when it has been imaged.

That narrow reading, however, artificially isolates one portion of Copyright Office practice from another that has always accompanied it. From the very first volume of recorded documents created in 1870 to the present, an index has always been created as part of the same

\footnotetext{
${ }^{369} I d$. at 252.

370586 F. Supp. 132 (N.D. Ga. 1982).

${ }^{371} I d$. at 133 .

${ }^{372}$ Chevron U.S.A., Inc. v. National Resources Defense Council, Inc., 467 U.S. 837, 843 (1984); see p. 92 supra (discussing the Chevron framework for assessing the validity of agency regulations).

${ }^{373}$ Black's Law Dictionary 1144 (5th ed. 1979).
} 
process as transcribing, imaging, or otherwise copying the contents of remitted documents. That first volume of documents, which like many others after it contains handwritten transcriptions of documents, also contains an index at the front of the volume with handwritten index entries. It appears quite clear that the person who transcribed a document also had the duty of creating an entry in the index at the front of the volume for that document. Thus, transcription and indexing were always part of the same process, and there was a reason that they were. "Recording" a document was undertaken "for the purpose of giving notice of the same," and it was understood from the very beginning that effective notice would only be given if there were some reasonable method of searching for a document. Before electronic full-text searching became available, the creation of some kind of catalog or index was the only way to enable a reasonable search. Since the Copyright Office has never implemented full-text search, creation of an entry in the Copyright Office Catalog is still the only way to enable a reasonable search. Under current practice, which apparently has been unchanged as long as the Copyright Office has been recording documents, the Copyright Office creates a recordation certificate for a document only after a document has been both imaged (or previously, transcribed) and indexed. Thus, it is entirely reasonable to construe recordation as including indexing.

State court rulings on whether a misindexed document affecting title to real property is still considered to give constructive notice are deeply split, thus giving further support to the position that the term "record" is susceptible to range of permissible constructions. Thus, for example, in New York, any error in indexing prevents a recorded document from giving constructive notice, and only from the time the error is corrected does that document give constructive notice. ${ }^{374}$ The same is true in California, where filing a lis pendens before purchasers acquired title to the subject property does not give constructive notice if the lis pendens is not indexed until after closing. ${ }^{375}$ A New Jersey court has held that a "reasonable search" is a search of the index, and that therefore a misindexed document does not give constructive notice because it cannot be found. ${ }^{376}$ On the other hand, in Pennsylvania and Florida, documents that are accepted for recording will give constructive notice even if they are not properly indexed. ${ }^{377}$

To construe recording as including indexing leaves open the issue of how documents are indexed. From 1870 through 1927, most of the documents recorded at the Copyright Office were indexed solely by the names of the assignor and the assignee. ${ }^{378}$ Beginning in 1928 , documents were also indexed by the titles of the works identified in the document, if any.

\footnotetext{
${ }^{374}$ See In re Hojnoski, 335 B.R. 282 (Bankr. W.D. N.Y. 2006).

${ }^{375}$ Lewis v. Superior Court, 30 Cal. App. $4^{\text {th }} 1850,37$ Cal Rptr. 2 d 63 (2d Dist. 1994).

${ }^{376}$ See Howard Savings Bank v. Brunson, 582 A.2d 1385 (N.J. Super. 1990).

${ }^{377}$ See In re Haburjak, 309 B.R. 170 (Bankr. W.D. Pa. 2004); Anderson v. North Florida Production Credit Ass'n, 642 So. 2d 88 (Fla. Dist. Ct. App. 1st Dist. 1994); see generally Failure properly to index conveyance or mortgage of realty as affecting constructive notice, 63 A.L.R. 1057.

${ }^{378}$ See supra p. 26.
} 
Copyright Catalog entries now sometimes contain other information about documents and the works referenced by them, such as the headings at the tops of documents, the registration numbers of works referenced in a document, the names of the authors of such works, and so on. Because an index entry - a Catalog entry - for a document cannot contain information that is not contained in the document itself, some recorded documents generate more extensive index entries - that is, Catalog entries - than others.

Section 205(c)(1) assumes that the Copyright Office generally maintains an index of documents by the titles and registration numbers of works referenced in the documents, and that it may well maintain other indexes as well. The purpose of $\S 205(\mathrm{c})(1)$ is to make clear that, for purposes of granting the legal benefit of constructive notice, being able to locate a document by a reasonable search of a title or registration number index is crucial. Thus, a document may be recorded - it may be placed in the Copyright Office's document repository, and it may be indexed by the names of the assignor and assignee, or by some other means of indexing - but if it is not indexed by titles or registration numbers of works that the document concerns, it will not give constructive notice.

Section 205(c)(1) refers to a requirement that "the document, or material attached to it, specifically identifies the work to which it pertains," and then uses the phrase "after the document is indexed by the Register of Copyrights." A superficial reading of this language might lead to the conclusion that the remitter's only duty is to remit a document that specifically identifies the work to which it pertains, and that, once such a document is remitted, it is considered recorded, and indexing by the Register is something that occurs after recordation. That reading, however, does not withstand serious scrutiny. First, as a matter of the structure of $\S 205$ (c), subsection (1) of that section plays no part in defining what "recordation" means. The first clause of 205(c) states that a document will give constructive notice if it is recorded. Sections 205(c)(1) and 205(c)(2) then add further conditions for constructive notice. That is to say, under $\S \S 205(c)(1)$ and 205(c)(2), there will be some documents that are "recorded" within the meaning of the introductory clause, and yet do not give constructive notice, because they do not meet additional conditions beyond recording. Thus, $\S \S 205(\mathrm{c})(1)$ and 205(c)(2) do not define "recording" or "recordation"; rather, they define conditions for constructive notice other than "recordation."

Second, although $\S 205(\mathrm{c})(1)$ is drafted in a convoluted manner, there is a reason for that convolution that has nothing to do with allocating the risk of misindexing. Section 205(c)(1) first requires that a document "specifically identif[y] the work to which it pertains"; only more than twenty words later do we find out that the "specific identification" should be "by title or registration number." Why doesn't $\S 205$ (c)(1) simply say that "the document, or material attached to it, should identify the work to which it pertains by title or registration number?" The answer is that the drafters wanted to include the concept of a reasonable search, to ensure that 
certain minor variations in title would not defeat constructive notice. Thus, for example, suppose that the title of a song on published copies was "A Grecian Lullaby," but the recorded document identifies the song as "Grecian Lullaby." Technically speaking, the document did not identify the song by title, because it omitted the article at the beginning of that title. However, it did specifically identify the song such that, "after the document is indexed by the Register of Copyrights, it would be revealed by a reasonable search under the title . . of the work," because a "reasonable search" by title should include a search without any article that might appear at the beginning of the title, since articles are often omitted from titles in indexing and in other references to works. The same is true for words that have common alternative spellings: a reasonable search for "The Doughnut Cookbook" might include "The Donut Cookbook"; a reasonable search for a book on "New York Theatres" might include "New York Theaters."

In order to introduce the concept of reasonable search into the specification of how a document had to identify works to give constructive notice, the drafters chose to pose a hypothetical question at a time after the document had been indexed: would a reasonable search by title or registration number at that time find that document? In the course of framing that hypothetical question, the statute mentions in passing the indexing of the document by the Register, but it does so, not to indicate that recordation does not include indexing, but merely to introduce the concept of a reasonable search. Thus, $\S 205(c)(1)$ would still read perfectly naturally if the introductory clause of $\S 205$ explicitly stated that recordation included transcription and indexing of the document:

Transcription and indexing of a document by the Copyright Office gives all persons constructive notice of the facts stated in the recorded document, but only if -

(1) the document, or material attached to it, specifically identifies the work to which it pertains so that, after the document is indexed by the Register of Copyrights, it would be revealed by a reasonable search under the title or registration number of the work.

While the reference in $\S 205$ (c)(1) seems to be at least assuming that indexation is a task being carried out by the Register, ${ }^{379}$ that reference must be read in light of the later-amended $\S$ 705(a), which provides that " $\mathrm{t}]$ he Register of Copyrights shall ensure that . . . indexes of such records are prepared." ${ }^{380}$ As the legislative history of this provision confirms, ${ }^{381}$ it empowers the Copyright Office to contract with others to perform its tasks with respect to recordation, including the various tasks associated with indexing. As explained above, ${ }^{382}$ there is no reason that this does not include the power to arrange to have the remitter to perform the task of providing cataloging information about the document. In order to assign incentives correctly, and to protect a subsequent purchaser from the effects of any error or omission, the Copyright

\footnotetext{
${ }^{379} 17$ U.S.C. $\S 205(\mathrm{c})(1)$.

${ }^{380} 17$ U.S.C. $\S 705$ (a) (emphasis added).

${ }^{381}$ See supra p. 22.

${ }^{382}$ See supra p. 92.
} 
Office can then adopt a definition of recordation that includes the submission of indexing information that allows a document to be found through a reasonable search.

Thus, although at an appropriate time the Copyright Act might be amended to more explicitly indicate the framework appropriate for a modern recording system, the current Act can accommodate that framework.

b. Copyright Office Regulations Regarding Recordation. Copyright Office regulations are generally silent with respect to remitter responsibility for constructive notice. The new regulation on the electronic submission of titles referenced in a remitted document, however, provides for remitter responsibility. It states:

The Office will rely on the electronic list of titles for purposes of indexing recorded documents in the Public Catalog and the remitter will bear the consequences, if any, of inaccuracies in the electronic list in relation to the recorded document, including with respect to the application of 17 U.S.C. 205(c) and 205(d). ${ }^{383}$

Such a statement could and should be generalized to cover all information submitted by the remitter in an electronic recordation system. This interpretation of the statute is easily justified as being appropriate in conjunction with the implementation of a new, more efficient recording system, and as a policy judgment regarding the appropriate degree of protection of those who are deemed to have constructive notice.

\section{Remitter Receipt of Recordation Certificate and Labeled Document in Electronic Form}

This report recommends that once the Copyright Office has processed a remitted document, it send to the remitter a copy of the remitted document, labeled on each page with the recorded document number and the page number, and a recordation certificate, in electronic form - probably as Portable Document Format files attached to an e-mail. A remitter's user account could also contain a page for "recorded documents" that would contain links to the PDF files, so that the user could retrieve them at through the account any time. ${ }^{384}$ Both the certificate and the labeled document could be digitally signed by the Copyright Office to ensure their authenticity. ${ }^{385}$

${ }^{383}$ Changes to Recordation Practices, 79 Fed. Reg. 55633, 55636 (September 17, 2014) (to be codified at 37 C.F.R. $\S 201.4(\mathrm{c})(4)(\mathrm{v}))$.

${ }^{384}$ See UCLA Roundtable Transcript, p. 116 (comments of Richard Bengloff, American Association of Independent Music); NOI Comments of the Association of American Publishers, p. 4 (“AAP's members have repeatedly told us that it would be very useful to be able to use an electronic recordation system to access official copies of assignments, transfers, and certificates of recordation that could be printed by rights holders.").

${ }^{385}$ For a discussion of digital signatures, see supra p. 72. 
Stakeholders were uniformly in favor of receiving recorded documents and certificates electronically rather than on paper, since electronic delivery would be faster and less expensive than delivery by mail. ${ }^{386}$ Some stakeholders indicated that they would still like to be able to order certified hard copies of recordation certifications and recorded documents from the Copyright Office if they needed them. ${ }^{387}$ Other stakeholders stressed the importance of receiving a version of their recorded documents that was labeled with the document number and page number on each page, since judges wanted to see these as proof of recordation. ${ }^{38}$ There was no objection to having the Copyright Office digitally sign certificates and labeled documents, but stakeholders who commented thought that digital signatures were unnecessary. ${ }^{389}$

a. The Statutory Framework. The recommendations outlined above should be able to be implemented under current statutory provisions, without amendment. Section 205(b) provides that the Register shall "record the document and return it along with a certificate of recordation." 390 If the term "document" refers to a physical object, then an electronic certification system could not satisfy this requirement. Transmitting a copy of the document electronically would not return any physical object to the remitter, and even printing out a copy and sending it to the remitter would not "return" anything that the remitter has sent, since under an electronic system the remitter would be making a transmission that would result in a new copy of the document being made on the Copyright Office server.

It may well be that $\S 205$ (b) was drafted with the paper-based recordation system in mind, under which the remitter is returned the same physical object that he or she sent to the Copyright Office. However, "document" can also be interpreted in a more abstract sense, as meaning an arrangement of text, possibly with signatures or images - in copyright terms, a "work" rather than a "copy." The use of the term "document" in this sense is also quite common - one can speak of two copies of the same document, or of duplicate originals. It is in this sense that an electronic recordation system can comply with $\S 205(\mathrm{~b})$ - it can return the same document (the same "work") that was remitted, albeit by transmitting a different copy thereof. Under that interpretation, the form in which this report recommends that the Copyright Office send the recordation certificate and document to the remitter will comply with the requirements of $\S 205(b)$.

\footnotetext{
${ }^{386}$ See Stanford Roundtable Transcript, pp. 34-35 (comments of Suzanne Morales, Fenwick \& West); Stanford Roundtable Transcript, p. 56 (comments of Tegan Kossowicz, Universal Music Group); UCLA Roundtable Transcript, p. 94 (comments of Ed Arrow, Universal Music Publishing Group); id., (comments of Mary McGuire, $20^{\text {th }}$ Century Fox); $i d$. at 94-95 (comments of George Borkowski, Recording Industry Association of America); id. at 102 (comments of Patrick T. Perkins, Warner Bros. Entertainment, Inc.); Columbia Roundtable Transcript, p. 116 (comments of Andy Hackett, National Corporate Research, Ltd.).

${ }^{387}$ See Stanford Roundtable Transcript, pp. 34-35 (comments of Suzanne Morales, Fenwick \& West)

${ }^{388}$ See NOI Comments of Author Services, Inc., p. 4; UCLA Roundtable Transcript, p. 96 (comments of Nicholas Bunin, $20^{\text {th }}$ Century Fox).

${ }^{389}$ See UCLA Roundtable Transcript, p. 96 (comments of Nicholas Bunin, $20^{\text {th }}$ Century Fox); Columbia Roundtable Transcript, p. 116 (comments of Andy Hackett, National Corporate Research, Ltd.).

${ }^{390} 17$ U.S.C. $\S 205(b)$.
} 


\section{New Legal Incentives to Record.}

This report recommends that consideration of any new legal incentives to record be postponed until after an electronic recordation system is created, and more is learned about the number and kind of documents that are still not recorded when an efficient, low-cost recordation option is available.

There are already substantial legal incentives to record in $\S \S 205(c)$, (d), and (e): constructive notice and priority, which protect purchasers, licensees and secured creditors from the risk of losing their interests in case of conflicting grants or bankruptcy. The power of such incentives is demonstrated by the likely effect of the decision in the 1990 case of In re Peregrine Entertainment, Ltd. $^{391}$ on the number of financing documents recorded in that Office. As shown above, ${ }^{392}$ after that decision held that that security interests in copyrighted works should be perfected by recording in the Copyright Office, the number of financing documents recorded every year increased dramatically. Of course, the juxtaposition of the In re Peregrine decision and the rise in financing document recordation does not prove causation; there may be other causes for the increase, such as an increase in financing transactions involving copyrighted works, and those have not been ruled out. However, the fact that the trend flattened out after the Ninth Circuit decided in the 2002 case of In re World Auxiliary Power Co. ${ }^{393}$ that security interests in unregistered works are not perfected by recording in the Copyright Office increases the likelihood of a causal relationship.

At the same time, it is important to note that not all legal incentives to record have a discernable impact on overall recording rates. Until 1989, § 205(d) of the Copyright Act provided that all those who owned copyright by virtue of a transfer needed to record that transfer before suing for infringement of that interest. ${ }^{394}$ The abolishment of that requirement by the Berne Convention Implementation $\mathrm{Act}^{395}$ had, as far as can be ascertained, no measureable impact on rates of recording. ${ }^{396}$

Recently, a number of academics have proposed creating additional legal incentives to record. ${ }^{397}$ These range from conditioning statutory damages and attorneys' fees on recordation

\footnotetext{
391116 B.R. 194 (C.D. Cal. 1990).

${ }^{392}$ See supra p. 39.

${ }^{393} 303$ F.3d 1120 (9th Cir. 2002).

${ }^{394}$ See 17 U.S.C. § 205(d) (1976) ("No person claiming by virtue of a transfer to be the owner of copyright or of any exclusive right under a copyright is entitled to institute an infringement action under this title until the instrument of transfer under which such person claims has been recorded in the Copyright Office, but suit may be instituted after such recordation on a cause of action that arose before recordation.") .

${ }^{395}$ P.L. 100-568, 102 Stat. 2853, § 5 (Oct. 31, 1988).

${ }^{396}$ For trends in recording of assignments before and after 1990, see Figure 3 on p. 38, supra. Of course, the purpose of the former $\S 205$ (d) requirement may not have been to increase recording rates overall, but to provide specific information about works that were becoming the subject of litigation.

${ }^{397}$ See, e.g., Jane C. Ginsburg, With Untired Spirits and Formal Constancy" Berne Compatibility of Formal Declaratory Measures to Enhance Copyright Title-Searching, 28 BERKELEY TeCH L.J. 1583 (2013); Daniel Gervais
} 
of any transfer to the current owner of copyright before the commencement of infringement, ${ }^{398}$ to allowing judges to consider "diligent recordation" as a factor in granting injunctive relief, ${ }^{399}$ to conditioning the validity of transfers on recording them. ${ }^{400}$ If these incentives resulted in the recording of many documents pertaining to copyright that have previously not been recorded, this would increase the information available about copyright ownership, and likely reduce the number of "orphan works" of which the owner is unknown or unlocatable. ${ }^{401}$

These proposals for new incentives were among the topics on which the Copyright Office asked for comment in its January, 2014 Notice of Inquiry. ${ }^{402}$ Commenters responded overwhelmingly negatively to such proposals. ASCAP and BMI, for example, commented that while they "fully support[ed] the idea of creating incentives for document recordation and the building of a fuller public repository, it should not be done in a retributive manner that punishes those who fail to do so." 403 The American Society of Media Photographers stated that "[s]uch [p]roposal[s] would have the practical effect of making almost every copyright owned by professional photographers unenforceable, and such proposals must be rejected outright.",404 PACA, Digital Media Licensing Association contended that the proposals were "unduly burdensome and would essentially strip creators of their rights under copyright if additional requirements were to become mandatory." 405 The Screen Actors Guild - American Federation of Television and Radio Artists specifically raised doubts about the proposal to link validity of copyright transfers to recording. "Copyright moves among and between parties at all levels of sophistication," it noted, "from fledgling creators to sophisticated multi-national interests. The right to transfer an interest in copyright should not be contingent on such sophistication." Perhaps the most moderate comments came from the American Intellectual Property Law Association:

Such amendments to the Copyright Act are premature. The technological and other changes that have been proposed, including adoption of a guided remitter model, have the potential to significantly improve the incentives for copyright owners to record documents pertaining to copyright. These changes should be allowed to take effect and then be studied to determine if additional changes, possibly including legislation, are appropriate. ${ }^{407}$

\& Dashiell Renaud, The Future of United States Copyright Formalities: Why We Should Prioritize Recordation, and How We Should Do It, 28 BERKELEY TECH. L. J. 1459 (2013).

${ }^{398}$ See Daniel Gervais \& Dashiell Renaud, supra note 397, at 1491.

${ }^{399}$ See id.

${ }^{400}$ See Jane C. Ginsburg, supra note 397, at 1613.

${ }^{401}$ See id. at 1585-1586; Daniel Gervais \& Dashiell Renaud, supra note 397, at 1486-1487

${ }^{402}$ See Notice of Inquiry of Recordation Reengineering at 2699.

${ }^{403}$ NOI Comments of American Society of Authors, Composers, and Publishers and Broadcast Music, Inc., p. 9.

${ }^{404}$ See NOI Comments of American Society of Media Photographers, p. 3.

${ }^{405}$ NOI Comments of PACA, Digital Media Licensing Association, p. 4.

${ }^{406}$ See NOI Comments of Screen Actors Guild - American Federation of Television and Radio Artists, p. 4.

${ }^{407}$ NOI Comments of the American Intellectual Property Law Association, p. 3. 
These last comments make perfect sense. As Professor Jane Ginsburg, herself one of the commentators who has explored new recordation formalities, observed, "there is zero point in punishing people for not complying with a system that doesn't work. . . [W]hile [new] 'sticks' are interesting things to contemplate, they don't make sense without a working system." ${ }^{408}$ As noted above, the dramatic increase in recording fees in 2000-2003 very likely caused a substantial decrease in rates of recording. ${ }^{409}$ The difficulties experienced by remitters in a paperbased system with substantial delays also probably reduce recording. The first steps in encouraging recording should be to make recording easier, not to visit legal disabilities on those who do not pay high fees and overcome logistical difficulties imposed by the current recording system. It should be added that although there is some anecdotal evidence that some documents pertaining to copyright are not recorded, no one knows what percentage of documents are not recorded, or which types of documents are most often not recorded. And although we know that some incentives have probably had a substantial impact on overall recording rates, while others have not, little work has been done on what additional incentives would likely be most effective. Without knowing how much recording there is to be incentivized, at whom the incentives should be targeted, or which incentives would most likely be effective, the creation of new incentives would be shots in the dark.

\section{Amending the Copyright Act.}

Although this report concludes that the recommendations it makes regarding an electronic recordation system can be implemented under the current Copyright Act, it has also identified a number of instances in which the Act's language could be clarified and better adapted to a modern recording system. Those instances include the following:

- “Actual Signatures." Section 205(a) of the Copyright Act allows a document to be filed for recordation if it bears the "actual signature" of the person who executed it. The term "actual signature" could be construed more broadly than "handwritten signature on paper," but it is also the case that at the time the term was originally formulated in the early 1960s, and at the time that Congress passed $\S 205$ (a) as part of the Copyright Act in 1976, no documents pertaining to copyright were being executed by any other means then through handwritten signatures on paper. Thus, it would be useful to clarify the acceptability of electronic signatures on documents remitted for recordation.

- Certifications. Section 205(a) also allows a document to be filed for recordation "if it is accompanied by a sworn or official certification that it is a true copy of the original, signed document." 410 As noted above, ${ }^{411}$ this formulation does not exactly fit the technical reality of electronic filing of documents, a process that involves the transmission of the contents of a document and the making of a new copy of that

\footnotetext{
${ }^{408}$ Columbia Roundtable Transcript, p. 238 (comments of Professor Jane Ginsburg, Columbia Law School).

409 See supra p. 53.

41017 U.S.C. $\$ 205(a)$.

411 See supra p. 68.
} 
document on a Copyright Office computer. That process does not result in the Copyright Office receipt of any physical object - any "copy" - sent by the remitter. In addition, under certain circumstances, remitters may not be in a position to certify that an electronic document is a true copy of an original; they may only be able to certify that to the best of their knowledge it is. ${ }^{412}$ It may also be useful to require other certifications in connection with document recordation. ${ }^{413}$ Thus, the Copyright Act should ideally authorize the Copyright Office to require such certifications in conjunction with document recordation as it deems necessary to safeguard the integrity of the public repository and catalog of recorded documents.

- Remitter Provision of Cataloging Information and Constructive Notice. As noted above, ${ }^{414} \S 705$ (a) of the Copyright Act already clearly allows the Copyright Office to delegate some or all of the responsibility of indexing recorded documents to others, including remitters. However, $\S 205$ (c) of the Copyright Act still refers in passing to a time "after the document is indexed by the Register of Copyrights," 415 which may confusingly suggest to some that the Copyright Office must itself perform all of the tasks associated with indexing. Because $\S 205$ (c) concerns constructive notice, the reference to indexing by the Register may also cause some confusion about the effects of remitter provision of inaccurate indexing information on constructive notice. To eliminate this confusion, § 705(a) could be amended to state explicitly that the Copyright Office can require remitters to provide indexing information for remitted documents. At the same time, $\S 205$ (c) could be amended to indicate that, when a remitter provides indexing information for a remitted document, the document will give constructive notice with respect to any particular work referenced in the document only if, after that information is incorporated into the Copyright Office index, a reasonable search by title or registration number of the work will locate the document.

- Remitter Receipt of Labeled Document. As noted above, ${ }^{416} \S 205(\mathrm{~b})$ of the Copyright Act provides that, after recording a document, the Register shall "return it," along with a certificate of recordation. Copyright Office practice since 1870 has been to return the original remitted copy of the document to the remitter. In an electronic recording system, that is not possible; remitting a document involves transmission of electronic file contents rather than transportation of a physical copy, and "return" of the document similarly involves electronic transmission of data rather than physical transportation of a copy. Although, as explained above, ${ }^{417}$ "document" can be interpreted as intangible text rather than physical object, the Copyright Act could be amended to clarify, after recordation,

\footnotetext{
412 See supra p. 67.

413 See supra p. 68.

${ }^{414}$ See supra p. 92

41517 U.S.C. $\S$

${ }^{416}$ See supra p. 108.

${ }^{417}$ See id.
} 
the Register should send or transmit a labeled copy of the recorded document to the remitter, or inform the remitter how such a copy can be electronically retrieved.

\section{Additional Recommendations.}

There a number of recommendations that do not concern the principal features of an electronic recordation system, but represent important adjuncts. They concern information gathering and handling; registration numbers in recorded document records; provisions supporting interoperability and third-party enhanced services; a model for updating contact and "rights and permissions" information; and litigation notifications under Section 508 of the Copyright Act.

\section{Information Gathering and Handling.}

a. Data Collection in an Electronic Recordation System. Implementing an electronic recordation system provides an opportunity to reassess the types of information that should be gathered in conjunction with the submission of a document to be recorded. In the past, the labor involved with manual transcription of any information submitted has likely impeded consideration of other types of information that would be useful to have in conjunction with recorded documents, and backlogs have led to periodic "trim orders" under which transcription was further limited and Copyright Office Catalog records became thinner. As Microsoft pointed out in its comments to the Notice of Inquiry, "[e]nabling copyright owners to submit more robust data about their works would provide richer information to the public, thereby increasing precision and benefitting both creators and would-be users." ${ }^{418}$ Although the Office has to be careful not to overburden remitters with information requests, a few key pieces of information could be very valuable:

- Document Type. The Office currently does not ask remitters to specify what type of document they are remitting: an assignment, grant of a security interest, exclusive license, option, etc. If the remitted document has a title, that title is transcribed, and the title often gives some indication of the document type. However, some documents are not titled, and others have titles that do not give any indication of the document type, such as "Appendix A," or an ambiguous indication, such as "Copyright Agreement." It would be useful to gather such information by asking remitters to check boxes next to one or more provided terms, and specify a document type in an "other" text box if none of the provided terms fit. This information could help the Copyright Office understand who was recording documents and why, and to track changes in recording rates and spot potential problems that might become visible when, for example, there was a swift decline in the recording rate for a particular type of document. To be sure, some remitters may make mistakes in categorizing documents, and care would have to be

\footnotetext{
${ }^{418}$ NOI Comments of Microsoft Corporation, p.3.
} 
taken to ensure that searchers were not misled about the legal effect of documents by mistaken remitter-provided information. Perhaps the document type information could initially not be displayed in the basic public record, or displayed with a disclaimer that it is provided by the remitter and may be inaccurate.

- Type of Work Concerned. Similarly, it would be helpful to track which copyright industries were engaging in transactions in which types of works, and were recording the documents that executed those transactions. The Copyright Office Catalog currently contains very little information about the types of works involved in transactions represented by recorded documents. Occasionally, but very rarely, the title field for the work also contains a description of the type of work it is. In addition, about $45 \%$ of works in recorded documents have registration numbers, but those only classify works by registration class, which is very broad - both songs and motion pictures are works of the performing arts, and both novels and computer programs are textual works. Thus, it would be helpful to have a series of terms describing types of works that remitters could check.

b. Data Format Consistency and Parsing. The implementation of an electronic recordation system can also provide an occasion to review how data about recorded documents is stored in the Copyright Office Catalog. In order to facilitate machine reading and interpretation of data, which is essential to performing statistical studies and to enabling combination of that data with data available in other databases, that data should be stored and organized according to certain principles. Many fields in current Copyright Office Catalog records of recorded documents conform to these principles, but some of them do not. One example of a field the data in which fails to conform to multiple principles is field 269x, which stores execution and certification dates of documents.

- Consistent formatting of data. Data should be consistently formatted. There is a consistent format for a full execution date in field 269x: one or two numerals for the date, a three letter abbreviation for the month, and two numerals for the year. Thus, for example, the execution of a document on June 19, 2013 is represented as 19Jun13. However, many documents do not contain complete execution dates; they may only contain the month and the year, or the year. There is no standard format for incomplete dates, and recordation specialists have used literally dozens of format in reporting incomplete dates. Some examples include "_ _ _ / 13 "; "30Mar-“"; "1993"; “-1993"; "Mar93." Even though partial execution date information can be helpful - if you want to know how many documents were executed in 2013, or if you're searching for a document you know was executed in 2013, you don't actually need the date and month information - inconsistent formatting of partial dates can make it very difficult to retrieve partial-date records with a year-limited query.

- One Type of Information per Field. Databases are easiest to work with when each field contains one type of information. In many records, the 269x field contains not only dates, but explanatory text: "effective as of"; "nunc pro tunc"; "certification date"; and so on. That 
explanatory text should ideally be placed in a different field, or distinct fields should be created for recurring types of dates (in fact, 269y has now been created to hold certification dates).

- One Unit of Information per Field per Record. Databases are also easier to work with when each field in a particular record contains only one unit of the type of information it is supposed to contain - for example, a single date, rather than multiple dates. In the case of 269x, if a document was executed on more than one date, because it was signed by different parties on different dates, the dates are all entered in as a string in a single instance of the $269 x$ field. It would be better if a single instance of a 269x field contained only one date. Depending upon the structure of the database, multiple instances can be organized in different ways. In the case of the MARC record format currently used by the Copyright Office Catalog, each field and subfield is repeatable, so there can be many instances of 269x in a single MARC record, and each date should ideally be entered in its own instance of 269x. In the case of a relational database, a separate dates table could be constructed, linked to a documents table, and one record in the documents table could be linked to more than one record in the dates table.

- Enumerated Data When Possible. If it can be determined that the question to be answered with data in a particular field only has a small number of answers, then it is desirable to articulate those answers and structure the data field so that it only allows those answers as possible values. For example, as mentioned above, entries in the $269 x$ field include a variety of phrases explaining what a date means when it is not a straightforward date of execution: it may be a date on which the document takes effect that is different than the date of execution, or a date of certification. There are probably a limited number of different meanings a date can have when it is connected with the date of execution, but is different than that date. It would be best if those meanings can be enumerated, and the "date type" field can then be defined as an enumerated field with a limited number of possible entries.

Copyright Office staff members are aware of these principles, and over the past three decades, cataloging practices, though sometimes affected by serious budget constraints and conversions between systems, have improved a great deal. However, the principles are still far from perfectly implemented. When the Copyright Office transitioned to an electronic registration system, it was able to introduce many improvements in the formatting and structuring of Copyright Office Catalog data concerning registrations. It should take the same steps when transitioning to electronic recordation. ${ }^{419}$

\footnotetext{
${ }^{419}$ One commenter has proposed that the Copyright Office "adopt a robust but flexible abstract data model that allows the various entities it deals with (and the relationships between them) to be identified and described in a standard way." NOI Comments of Paul Jessop, Founder and Director, County Analytics, Ltd, p. 2. There is undoubtedly some merit to this proposal, but it should be recognized that there is a data model already implicit in the data structure of Copyright Office Catalog recordation records that has been refined over decades. That data model is incomplete, because the Catalog does not attempt to describe fully the contents of each document, and in particular, the details of the interest granted in the document. Although this report recommends gathering information about broad categories of interests granted by recorded documents, see supra p. 113, development of a standardized language that could exhaustively describe all details of every interest granted by a recorded copyright
} 
c. Change Logs. Changes made to records in the Copyright Office Catalog are currently not logged. If a remitter reports an error in a Copyright Office Catalog record to the Copyright Office, and the error is confirmed, one of the few people who are authorized to make changes directly in the database edits the database. After the edit is made, all trace of the pre-edit state of the record disappears. For a number of reasons, evidence of the existence of the error should be retained, along with information about the time and date that any change was made. First, understanding what information the Catalog displayed as of a certain date and time could be important to identifying the facts of which a party had constructive or actual knowledge at the time of a particular transaction; under the Copyright Act and the Bankruptcy Act, that could determine the outcome of a dispute over title to a work under copyright. Second, maintaining automatic change logs could deter any tampering with the database, and could aid detection of tampering were it to occur.

\section{Registration Numbers in Recorded Document Records.}

Of the approximately 8 million works identified in recorded documents cataloged in the Copyright Office Catalog as of March 2013, about 3.7 million works, or 46\%, are identified by registration number. Of course, the Copyright Office cannot require remitters to submit registration numbers for all recorded documents, because some transactions involve unregistered works, though the Office could consider requiring such registration numbers when the works have been registered. ${ }^{420}$ Even when a document does contain one or more registration numbers, however, it is currently very difficult to search for it by one of those numbers. First, a search on the Voyager Catalog web interface designated as a "registration number" search will not retrieve any recorded documents in which that number appears, because that search does not target the field in which registration numbers appear in recorded document records; rather, it only targets the fields in which registration numbers appear in registration records. A searcher must know that a "keyword" search is necessary to locate registration numbers in recorded document records, and that is not likely to be intuitively obvious. Second, registration numbers typically appear in recorded documents in the format in which they are issued on registration certificates, namely, with spaces and hyphens, such as "VA 1-134-857." They are transcribed into Catalog records in exactly the format in which they appear in the documents. By contrast, a "registration number" search on the Voyager Catalog web interface must use a 12-character string without hyphens or spaces, in which zeros are added between the letter prefix and the registration number as necessary to make the string exactly 12 characters long. Thus, for example, the registration

document would be a very tall order. Data modeling should thus begin with thorough description of the current implicit, incomplete data model; a determination should be made about the ways in which the model will remain incomplete, and then shortcomings of the model within its recognized limits should be assessed.

${ }^{420}$ See, e.g., UCLA Roundtable Transcript, p. 173 (comments of Bradley Russell, Sony Pictures Entertainment); $i d$. (comments of Mary McGuire, 20th Century Fox) (noting that not all documents that parties wish to record concern registered works). 
number that would appear as "VA 1-134-857" on a registration certificate would have to be entered as "VA0001134857" in a registration number search.

There are a number of unfortunate results of the search design and formatting issues with registration numbers in recorded document records. First, it is not possible to do a single search that will retrieve both registration records and recorded document records concerning a particular registered work. Second, searches for recorded documents by the registration numbers of works appearing in those documents are tricky: even if one knows that a "keyword" search is necessary, and one knows the registration number of a work, the search may fail to find relevant documents, because the formatting of registration numbers in recorded documents records has not been standardized, and any difference in formatting - an extra space, or a missing hyphen - will result in a failed search. This is particularly troubling because under the Copyright Act, registration numbers are supposed to play an important role in constructive notice. If a document "would be revealed by a reasonable search under the . . . registration number of the work," 205(c)(1), the public is deemed to have constructive notice of its contents. When many Copyright Catalog document records do include registration numbers, but they are tricky to find, it is uncertain whether a court would hold that they could have been found through a reasonable search. That uncertainty makes copyright transactions less stable.

Historically, one of the arguments for keeping registration numbers relatively obscure in recorded document records began from the fact that the Copyright Office did not have the resources to verify each registration number that appeared in a document remitted for recordation. If the registration numbers were not verified, the argument proceeded, they were not trustworthy and should not be too prominently displayed in the records. This report, however, is recommending a fundamental shift away from the view that no entry should be made in the Copyright Office Catalog unless it was made or checked by a Copyright Office employee. If a remitter is going to be responsible in the first instance for the information in a Catalog record of a recorded document, he or she should also be responsible for the registration numbers that form part of that record.

Remitters may continue to enter registration numbers in various formats, and it certainly doesn't help that the format that the Copyright Office uses in registration certificates is different than the format it uses in Catalog registration records. However, it is very easy to write a computer program that standardizes the format for registration numbers, either as they are entered, or after they are entered. Whether a registration number is entered as "VA 1-134-857"; "VA 1134857"; "VA 1,134,857"; "VA1134857"; or any number of other formats, as long as the alphabetical and numerical strings are correct, a computer program can easily convert whatever is entered to "VA0001134857." Assuming that the Copyright Office continues to use the 12digit format for representing registration numbers in registration records, this report recommends

${ }^{421} 17$ U.S.C. $\S 205(c)(1)$. 
ensuring that all registration numbers that are entered as part of recorded document records are converted to that format, and that the "registration number" search on the Voyager Catalog web interface be reprogrammed to target registration numbers in recorded document records as well as those in registration records. A computer program could also convert all 3.7 million registration numbers in existing recorded document records into the 12-character format. This report also recommends that the Office do just that - preserving the format as entered in one field, but converting the existing numbers into 12-character format, and entering the numbers in that format into another field that is also targeted by the "registration number" search. That step alone would make hundreds of thousands of document records visible that had previously been invisible to a registration number search. ${ }^{422}$

\section{Interoperability and Third-Party Enhanced Services.}

A number of commenters and roundtable participants remarked that the ability to combine information about works under copyright from different public and private databases, and to communicate between databases, could provide great utility and would likely become more and more important in the future. ${ }^{423}$ One of the benefits would be to provide easy, low-cost paths to licensing transactions from whatever identifying information was available about a work. Thus, for example, if all someone interested in using an image had was the image, without any information about the author or owner of copyright in that image, it would be helpful to have a database of images that included information about copyright ownership and licensing, such as the PLUS (Picture Licensing Universal System). ${ }^{424}$ However, such a private database might be lacking information that could be provided by copyright registration and document recordation databases; or the official databases might provide information that was more authoritative. ${ }^{425}$ In that case, linking from a private database to the Copyright Office databases could be very useful. ${ }^{426}$ In other cases, someone who was interested in a work might begin a search in the Copyright Office Catalog with a title or registration number; that Catalog might contain some

\footnotetext{
${ }^{422}$ Alternatively, a more sophisticated search program could find registration numbers regardless of the format in which they were stored in Copyright Catalog records.

${ }^{423}$ See UCLA Roundtable Transcript, pp. 195-96 (comments of John Cate, American Music Partners)

("Interoperability is extremely important with our own industry databases in music, for example, but also with the Copyright Office as ... the final backstop for that reconciliation process that goes on between authors, between titles, et cetera. I think that's going to become very, very important, more important than it is now.").

${ }^{424}$ See NOI Comments of the Graphic Artists Guild, p. 5.

${ }^{425}$ One roundtable participant expressed a need for current licensing information "at scale," such as a comprehensive global database of music publishing ownership information to associate with sound recordings, to facilitate "respectful distribution." See Stanford Roundtable Transcript, pp.95-96, 105-106 (comments of Kevin Montler, Google). It is unlikely that the Copyright Office will provide such a database, but it could provide an authoritative "second check" for large portions of such a database.

${ }^{426}$ See NOI Comments of the American Society of Media Photographers, p. 2 ("We would urge that the new system be designed to take advantage of all of the searching and linking possibilities, including image-recognition-based search technologies, that exist in a digital environment. Such a system could be integrated with both the Copyright Office's database of registrations and independent databases and registries.").
} 
important information about the work, but not a licensing contact. In that case, a link from a Catalog record to a database that contained licensing contacts would be helpful. ${ }^{427}$

The value of databases can be enhanced, not just by linking from one existing database to another existing database, but also by enabling third parties to aggregate information from multiple databases, and to provide enhanced services with respect to existing databases. For example, if the Copyright Office provided a public document repository in PDF format, but did not provide full-text searching of the documents in that repository, a third party might want to provide that full-text searching capability.

What can and should the Copyright Office do to enable interoperability between databases, and the provision of enhanced services by third parties? Complete consideration of this issue is beyond the scope of this report, but a number of comments may be in order. Aggregation of information stored in different databases is made possible at the most basic level by ensuring that the databases have one or more well-defined fields in common, so that information about a particular object, such as a copyrighted work, from one database can be matched to information about that object from another database. Thus, preparation for interoperability starts with the data principles articulated above. ${ }^{428}$ For example, data about a song in the Copyright Office Catalog might be matched with data in the ASCAP or BMI repertory databases by matching one or more fields, one of which might be the song title. However, the main "title" field in Copyright Office Catalog registration records, 245a, often contains not only the title proper, but also the names of the author or authors. That kind of mixing of two different types of data in a single field will make it difficult to facilitate the exchange of information between the Copyright Office Catalog and other databases.

Two issues related to interoperability and third-party services deserve separate consideration: standard identifiers and application programming interfaces.

a. Standard Identifiers. Many copyright industries use standard identifiers of various kinds to identify particular editions of works. The International Standard Book Number, or ISBN, is probably the oldest and best known of these. Copyright Office Catalog registration records currently accommodate three types of standard identifiers: ISBNs; ISSNs (International Standard Serial Numbers); and ISRCs (International Standard Recording Codes). However, there are a relatively small number of registration records that actually contain these standard identifiers. Of the approximately 16,700,000 registration records in the Copyright Office

\footnotetext{
${ }^{427}$ See Columbia Roundtable Transcript, pp. 199-200 (comments of Heather Reid, Copyright Clearance Center) ("[I]t is not just maintaining that date for the beauty of it . . It is to enable people to find out what is, in fact, copyrighted, and then, pointing people to licensing services that are already available . . . and ... having that standardized metadata, the standard numbers, is what is going to make that possible.").

${ }^{428}$ See p. 113, supra.
} 
Catalog as of March 2013, only 565,000 (3.38\%) contained ISBNs; 402,000 (2.41\%) contained ISSNs; and 5,510 (0.03\%) contained ISRCs.

Records of recorded documents in the Copyright Office Catalog do not accommodate any standard identifiers. Because many private databases use standard identifiers extensively to uniquely identify editions of works, accommodation of standard identifiers could be an important step to enabling interoperability. Ideally, both registration and recordation records would accommodate, not just ISBNs, ISSNs, and ISRCs, but a wide variety of standard identifiers. For example, the International Organization for Standardization (ISO), which has published standards defining ISBNs, ISSNs, and ISRCs, has also published standards defining International Standard Musical Work Codes (ISWCs), International Standard Music Numbers (ISMNs), International Standard Audiovisual Numbers (ISANs), and International Standard Text Codes (ISTCs). ${ }^{429}$ All of these can be and have been used to identify objects that include copyrightable content. Care needs to be taken, however, in understanding the relationship between the objects identified by standard identifiers and "works" in the copyright sense, because there is usually not a one-to-one relationship. For example, hardcover and paperback editions of a book may be the same work, and the edition identified by an ISBN may from a copyright perspective be a collective work that includes a principal literary work, cover art, other design work, and an introduction - not just the principal literary work.

Standard identifiers include not only identifiers for editions of works, but also identifiers for authors and distributors of works, such as International Standard Name Identifiers (ISNIs) ${ }^{430}$ one block of which are reserved for Open Researcher and Contributor IDs (ORCIDs), ${ }^{431}$ designed to uniquely identify scientific and other academic authors. These are not yet widely used in documents remitted for recordation, but they may begin to be used more frequently, and if they are, the Copyright Office Catalog should accommodate them. ${ }^{432}$

b. Application Programming Interfaces. In its broadest sense, the term "application programming interface" or "API" refers to any set of programming instructions and standards that enables one piece of software to communicate with and use functions of another piece of software. For example, an operating system like Microsoft Windows 7 or Apple OS X has a set of standards and instructions that can be incorporated into application programs like word processing or spreadsheet programs so that those programs can accept input from a keyboard, display output to a screen, and read from and write to memory - functions that are all controlled by the operating system. In a somewhat narrower sense, the term has been used to refer to

\footnotetext{
${ }^{429}$ See ISO Standards Catalogue, ISO/TC 46/SC 9 - Identification and description, http://www.iso.org/iso/home/store/catalogue tc/catalogue tc browse.htm?commid=48836 (last visited September 11, 2014).

${ }^{430}$ See http://www.isni.org/ (last visited July 28, 2014).

${ }^{431}$ See http://orcid.org (last visited July 28, 2014).

${ }^{432}$ See Stanford Report, supra n. 4, at 37 (suggesting that the Copyright Office consider promoting the use of International Standard Name Identifiers).
} 
programming instructions and standards that enable software to communicate over the Internet with other software that is running on an Internet-connected server, and to control various functions performed by that software. Thus, for example, Google Maps has an API that enables other websites to embed maps hosted by Google on their web pages, and to manipulate those maps in various ways, and have users manipulate the maps, while remaining on the other websites. $^{433}$

A number of commenters and roundtable participants have suggested that the Copyright Office provide an API for the Copyright Office Catalog. Microsoft Corporation, for example, commented that the Copyright Office "should also enable access via standard application programming interfaces (APIs) that third parties could use to design and develop all manner of services, both commercial and non-commercial, using the data." 434 Some APIs can be very complicated, because the functions performed by the software to be controlled by the API are very complicated. In the case of the Copyright Office Catalog, however, by far the most important function at issue, and probably the only one for which the Copyright Office would need to develop an API in the near future, is retrieval of data from the Catalog. ${ }^{435}$ In other words, the Office would need to enable the Catalog to be searched, and to return search results, over the Internet, using a standard query language. While that may be no small task, especially given the idiosyncrasies of the MARC data format in which Catalog records are now stored, it is still helpful to understand that the API in question would only need to handle read-only database queries.

\footnotetext{
${ }^{433}$ See https://developers.google.com/maps/ (last visited July 28, 2014). For a list of the most popular Internetbased application programming interfaces, see Programmable Web, http://www.programmableweb.com/category/all/apis?order=field_popularity (last visited July 28, 2014).

${ }^{434}$ NOI Comments of Microsoft Corporation, p. 2; see also Columbia Roundtable Transcript, p. 189 (comments of Maurice A. Russell, Harry Fox Agency) ("Often, we are dealing with very, very high volumes of new releases on digital services. .. . So, an API would be really helpful."); id. at 190 (comments of Victor S. Perlman, American Society of Media Photographers) (an application programming interface would also be good for photographic works, "particularly if you could integrate seamlessly with a registry like the PLUS registry ...."); UCLA Roundtable Transcript, p. 201 (comments of Lawrence Liu, Universal Studios) (providing an application programming interface "sounds great").

${ }^{435}$ Both Microsoft and the Copyright Principles Project have discussed the possibility of having accredited third parties accept registration applications and documents for recording, which would require an application programming interface that could write to the Copyright Office Catalog database, and enable the addition of documents to the document repository, as well as read from the database. See NOI Comments of Microsoft Corporation, p. 2 ("' $[\mathrm{T}]$ he Office should explore an 'API-first' approach for the receipt of information, such as information relating to transfers, from third-party services."); Pamela Samuelson \& Members of the Copyright Principles Project, The Copyright Principles Project: Directions for Reform, 25 BERKELEY TECH. L. J. 1175, 12031204 (2010) ("The Copyright Office should transition away from being the sole registry for copyrighted works and toward certifying the operation of registries operated by third parties, both public and private... The model is similar to the domain name registration system, where multiple private parties provide services and access to the database of domain names."). The number of registrations processed every year, and possible additional registrations in a lower-cost system, might be sufficient to attract interest and investment from third-party providers. It is less clear whether the vastly smaller number of documents processed every year would also be sufficient to attract third-party providers.
} 
Creating and publishing an API that could allow others to develop software that could retrieve data from the Copyright Office Catalog over the Internet could be tremendously valuable. As Microsoft suggested in its comments, it could enable others to create a wide variety of applications that would incorporate copyright registration and recorded document data, and that could aggregate that data with data from other sources. Historically, the Copyright Office has been a small department of the Library of Congress, and its operations have not been independent and nimble enough to develop new services quickly. The great advantage of having the Catalog accessible through an API is that Copyright Office resources and approval are not needed to build new services that would incorporate Catalog data. Others can do that using the API. Thus, making Catalog data available through an API could usher in a new era of widespread use and prominence of that data. ${ }^{436}$

\section{Section 508 Litigation Notifications.}

Section 508 of the Copyright Act requires federal courts to send to the Copyright Office notifications of actions filed under that Act, including the title, author, and registration number of each work involved, and the names and addresses of the parties. ${ }^{437}$ It also requires the courts to send notifications of final judgments in those actions, together with copies of those judgments. ${ }^{438}$ Those notifications are to be made "part of the public records of the Copyright Office." $" 439$ Nearly identical provisions appear in the Patent Act for patent litigation, ${ }^{440}$ and in the Lanham Act for trademark litigation. ${ }^{441}$ The Administrative Office of the United States Courts has created paper forms for the courts to use in reporting filings and determinations for copyrights to the Copyright Office, ${ }^{442}$ and for patents and trademarks to the Patent and Trademark Office, ${ }^{443}$ and courts use those forms to make their reports. The Patent and Trademark Office receives patent and trademark litigation notices and makes them part of the Internet-accessible files of the patents and trademarks to which they pertain.

If properly handled, streamlined $\S 508$ notifications could provide the missing link between the two largest databases in the United States concerning works under copyright: the Copyright Office's registration database, and the litigation database of all lower federal courts,

\footnotetext{
${ }^{436}$ One alternative to providing an API that would place more of the development burden on third-party developers would be bulk downloads of data, provided with very frequent updates. The Patent and Trademark Office provides a number of bulk data downloads, some of them updated on a daily basis. For a list of USPTO bulk data products with download links, see http://www.uspto.gov/products/catalog/2014USPTOProductMatrix.xlsx (last visited August 13, 2014).

${ }^{437}$ See 17 U.S.C. $\$ 508(a)$.

${ }^{438}$ See 17 U.S.C. $\$ 508($ b).

43917 U.S.C. $\$ 508(\mathrm{c})$.

${ }^{440}$ See 33 U.S.C. $\$ 290$.

${ }^{441}$ See 15 U.S.C. $\$ 1116(\mathrm{c})$.

${ }^{442}$ See Form AO121, Report on the Filing or Determination of an Action or Appeal Regarding a Copyright, available at http://www.uscourts.gov/uscourts/FormsAndFees/Forms/AO121.pdf (last visited July 29. 2014).

${ }^{443}$ See Form AO120, Report on the Filing or Determination of an Action Regarding a Patent or Trademark, available at http://www.uscourts.gov/uscourts/FormsAndFees/Forms/AO120.pdf (last visited July 29, 2014).
} 
PACER. Although the documents for all copyright infringement lawsuits docketed in PACER somewhere contain the titles of every work at issue in that lawsuit, and registration or preregistration numbers for almost every work, ${ }^{444}$ PACER itself cannot be searched by title of work, or by registration number, and it does not offer full-text search of the documents it contains. As Figure 9 below shows, even PACER's “Advance Search" interface only allows searching by case number, caption, party name, or dates of filing or closure. The search results can be narrowed to copyright cases by selecting "Copyright" in the "Nature of Suit" window, but "Copyright" is only a limiter - it must be used in conjunction with other search terms. Nor do other databases add what PACER lacks. Westlaw and LEXIS do have full-text searching, but their pleadings databases are far from complete. Bloomberg Law apparently has a more complete pleadings database, but its full-text search will only pick up registration numbers if they are entered in exactly the format that they occur in the pleadings, which can be variable.

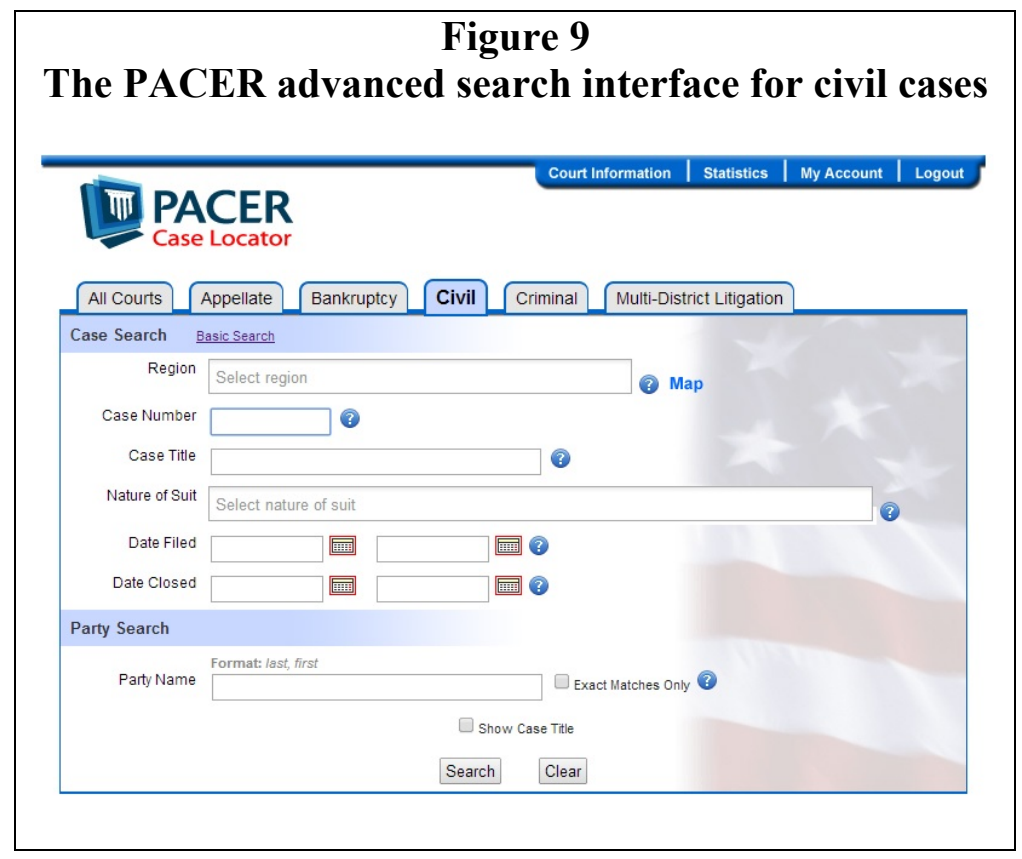

\footnotetext{
${ }^{444}$ Section 411(a) of the Copyright Act generally requires registration or preregistration as a condition of instituting a copyright infringement lawsuit. See 17 U.S.C. § 411(a). Infringement lawsuit filings may lack a registration or preregistration number in a number of circumstances: (1) the work or works in question may be foreign works, to which the $\S 411$ (a) requirement does not apply, see id.; (2) the Copyright Office may have refused registration, see id. ("where the deposit, application, and fee required for registration have been delivered to the Copyright Office in proper form and registration has been refused, the applicant is entitled to institute a civil action for infringement if notice thereof, with a copy of the complaint, is served on the Register of Copyrights"); (3) in "application" jurisdictions, courts may allow infringement lawsuits to proceed when a registration application has been filed but the Office has not yet granted or refused registration. See, e.g., Cosmetic Ideas, Inc. v. IAC/Interactivecorp, 606 F.3d 612, 621 (9th Cir. 2010) ("receipt by the Copyright Office of a complete application satisfies the registration requirement of $\S 411$ (a)"). In addition, some copyright lawsuits may be declaratory judgment actions that require no registration. See, e.g., Sportsmans Warehouse, Inc. v. Fair, 576 F. Supp. 2d 1175, 1183 (D. Colo. 2008). It is difficult to know exactly how many lawsuits proceed without registrations or preregistrations; it would be much easier to calculate that number if there were a complete catalog of $\S 508$ notifications, as this report recommends.
} 
In responding to a comment critical of the proposal to dispose of $\S 508$ notifications, the National Archives and Records Administration contended that the $\S 508$ notifications only duplicated what was available on PACER and subscription services such as Westlaw and Lexis/Nexis. ${ }^{445}$ Because none of those databases is searchable by work title or registration number, however, that contention is not valid.

Copyright catalog entries for Section 508 notifications could add valuable information about the state of the title of a registered work: They could make parties who are interested in the work aware of current or past litigation involving the work, and therefore aware either that there is some uncertainty about the ownership or scope of copyright in the work, or that an uncertainty has been resolved through the final judgment of a federal court. They could also be very useful to large-scale empirical research concerning trends in copyright litigation. By linking information in $\S 508$ notifications to information in the copyright registrations that the notifications reference, one could answer questions about litigation rates, rates of success, average pendency of litigation, and other litigation characteristics for particular types of works of authorship - motion pictures, songs, sound recordings, computer programs, and so forth. Although the Copyright Catalog $\S 508$ entries could be useful even while the Copyright Catalog and the PACER databases remain completely separate, the matching of registration numbers and work titles to docket numbers could also provide the basis at some future date for providing direct links from one database to the other.

Unfortunately, the $\S 508$ notifications are currently serving no purpose at all. Section 508 notifications were only entered into the Copyright Office Catalog between 1978 and mid-1980. Between mid-1980 and 1986, § 508 notifications were assigned serial numbers, and indexed on paper index cards by the plaintiff's name. ${ }^{446}$ From 1981 through 1985, and again from 1988 through 1992, they were captured on microfilm, arranged on each roll alphabetically by the plaintiff's name. $^{447}$ However, these efforts all ended before the federal courts first went online with PACER in $2001,{ }^{448}$ and they were thus too early to be truly useful. In 2007, the Copyright Office submitted a request for records disposition authority to the National Archives and Records Administration (NARA). NARA published a Federal Register notice regarding a proposed records schedule in May $2007^{449}$ and then approved the request in November $2007 .{ }^{450}$ Under the

\footnotetext{
${ }^{445}$ See Letter of July 17, 2007 from Larry Baume, Supervisor, Life Cycle Management Division, National Archives and Records Administration to Professor Michael Churgin, University of Texas School of Law.

${ }^{446}$ See Library of Congress, Copyright Office, Notice of Change in Procedures Regarding 17 U.S.C. 508 Filings, 45 Fed. Reg. 41548 (June 19, 1980).

${ }^{447}$ See Library of Congress, Copyright Office, Change in Procedure Regarding Filing of Notifications (17 U.S.C. 508 Filings), 51 Fed. Reg. 29973 (Aug. 21, 1986); E-Mail from George Thuronyi to Robert Brauneis, August 4, 2014. (The e-mail also indicates that there are 17 rolls of microfilm of 508 notifications in the Copyright Office inventory that are undated.)

${ }^{448}$ See Wikipedia, PACER (law), http://en.wikipedia.org/wiki/PACER (law) (last visited August 23, 2014).

${ }^{449}$ See National Archives and Records Administration, Records Schedules; Availability and Request for Comments, 72 Fed. Reg. 27593, 27594 (May 16, 2007) ("20. Library of Congress, Copyright Office .... Notices of judicial
} 
approved request, the Copyright Office destroys all $\S 508$ notifications three years after they have been received. No use of the $\S 508$ notifications is currently made at the Copyright Office, and they are not indexed or cataloged in any way, so searching through them is too costly and time-consuming to be practical. Thus, either section 508 should be repealed, or the notifications should be made useful by incorporating them into the Copyright Office Catalog and the document repository.

This report recommends integration of the $\S 508$ reporting process into the electronic recordation system. If $\S 508$ notices were entered into an electronic catalog, they could form the basis of an index of litigation searchable by title and registration number of the copyrighted work or works involved, linking work titles and registration numbers to docket numbers. Such integration should be able to realize the potential benefits of combining litigation information with registration information at relatively low marginal cost. It would also keep pace with and improve upon what the Patent and Trademark Office does with its parallel notifications of patent and trademark litigation.

If an electronic recordation system is created, federal courts could submit $\S 508$ notifications online through the same interface as those who remitted documents; once the court staff member indicated that he or she was submitting a $\S 508$ notification, the appropriate set of text boxes would appear for such statements, and the information would be added to the Copyright Office Catalog. This would require less labor than the courts currently expend in filling out section 508 notifications, and would not require paper, envelopes, or postage; it also would not require any labor on the part of Copyright Office staff to transcribe information from paper-based $\S 508$ notifications. It has been rumored that not all clerks of federal courts are equally assiduous in filing $\S 508$ notifications, which might result in an incomplete database. If filing were made much easier, however, and the Copyright Office explained how the notifications were useful and reminded courts of their statutory obligations, it is likely that compliance would become virtually universal.

The key to making $\S 508$ notifications useful would be to have them populate a set of fields that would enable people to find litigation about particular works under copyright by title or registration number, and then go search PACER or other legal databases for further information about that litigation. Ideally, the information would be stored according to rules and principles that could later enable direct communication between databases, or aggregation of information from multiple databases. ${ }^{451}$ Thus, for example, when $\S 508$ notifications were cataloged 1978-1980, a typical Catalog entry for a $\S 508$ notification would contain a 500a "notes" field that would read as follows: "Notification (under 17 U.S.C. 508) of filing (docket

actions and decisions on copyright cases, including Form AO121"). Renee Coe of the Copyright Office drafted several proposals to automate filing of Section 508 notifications, but none of them were ever implemented.

${ }^{450}$ The request was approved as National Archives and Records Administration Job No. N1-297-07-1.

${ }^{451}$ See pp. 113, 118 supra. 
no. S78-0072(N) filed 20Mar78 in U.S. District Court, Southern District of Mississippi, Southern Division) Order of dismissal and stipulation of settlement attached." "452 That entry mixes five different types of information in a single field: (1) a document type; (2) a docket number; (3) a date; (4) information about the date, namely, that it is a filing date; (5) the name of a court; and (6) information about an attachment, namely, that it is an order of dismissal and stipulation of a settlement. Ideally, each of those items of data should be stored in its own separate field. In addition, the data should ideally be formatted in the same way that the Administrative Office of the United States Courts formats it in its PACER database, so that data format issues do not stand in the way of any future communication between or aggregation of those databases.

Lastly, as the National Archives and Records Administration noted in its response to a commenter, ${ }^{453}$ the court filings that are attached to the $\S 508$ notifications, such as complaints or final judgments, are the least important aspect of the notifications, since those filings are available on PACER. In fact, $\S 508$ (a) does not require any document to be attached to a notification of the filing of a complaint; documents are only required by $\S 508(\mathrm{~b})$, which provides that a clerk of court shall send a copy of any final order or judgment and any accompanying written opinion along with the notification of that order or judgment. See 17 U.S.C. $\S \S 508(\mathrm{a}), 508(\mathrm{~b})$. The Copyright Office should consider promulgating a regulation that would relieve the clerks of courts of their $\S 508$ (b) obligation to send documents to the Copyright Office as long as those documents were available in PACER or some other publicly available repository. That would properly focus the $\S 508$ duties of the courts on the provision of important information that is not available elsewhere.

\section{Updating Contact and "Rights and Permissions" Information: A New Model.}

When a party registers a claim of copyright or records a document, its contact information as of the time of registration or recordation - potentially including a mailing address, e-mail address, and telephone number - becomes part of Copyright Office records. Registrants also have the option to provide information about whom to contact to license the registered work, commonly called "rights and permissions" information. Ideally, such rights and permissions information could include licensing terms and links to automated licensing platforms, thus further streamlining licensing transactions.

The current term of copyright is very long, and even if title to a work under copyright does not change, the contact information of the owner of copyright and the rights and permissions information (for ease of reference, this section will refer to both as "contact information") may change. Obsolete contact information raises the cost of engaging in copyright

\footnotetext{
${ }^{452}$ See "Love lifted me \& 20 other titles; musical compositions," Document No. V1694P401 (recorded November $30,1978)$.

${ }^{453}$ See n. 445 supra.
} 
transactions - one must spend more resources looking for the owner or agent - and in serious cases contributes to the "orphan works" problem, when diligent searches for the owner and agent fail. $^{454}$

Unfortunately, the current mechanisms for updating contact information are awkward and cumbersome. As an FAQ page on the Copyright Office website explains, ${ }^{455}$ copyright owners have two options. First, they can record a document announcing the change in contact information and listing all of the works that are affected by the change. Second, if a claim of copyright in the works has been registered, they can file a supplementary registration form, Form CA. As a conceptual matter, neither of these methods fits a change-of-contact-information scenario particularly well. A recorded document typically memorializes a transaction that has affected the title to a work under copyright, whereas a change of contact information leaves the title of the works untouched. A registration is connected with the creation of a new work, and a supplementary registration is typically connected with the correction of errors on the original registration, whereas a change of address involves no new work and no error. More importantly, however, these methods are both ridiculously expensive. The current basic fee for recording a document is $\$ 105$, plus $\$ 35$ per ten additional titles. ${ }^{456}$ Thus, if a company that owned 1000 works under copyright (whether photographs, songs, motion pictures, or any other types of works) moved its headquarters from New York to Los Angeles, or from Manhattan to Brooklyn, or even three blocks south in Manhattan, it would have to pay $\$ 3605$ to record a document to announce to the public through the Copyright Office that it had moved. The current fee for filing a supplementary registration, Form CA, is $\$ 130 .^{457}$ Thus, if the 1000 works owned by a company were individually registered, that company would have to pay $\$ 130,000$ to notify the public of its change of address through the Copyright Office. Those high costs virtually guarantee that contact information will rarely be updated at the Copyright Office. As a result, as works and transactions get older, the percentage of them for which the contact information stored in Copyright Office records is no longer correct will become larger and larger.

As part of its mission to facilitate transactions in works under copyright, the Copyright Office should make it much easier for owners of copyright interests to publicize their updated contact information through the Office, and in connection with existing registrations and recorded documents. Anyone who has an eCO user account should be able to state that he or she has responsibility for maintaining current contact information (including rights and permissions information) for an individual or a company, and should be able to fill out a simple online form with new contact information as of a certain date. Any Copyright Office Catalog record with the old contact information should be updated with a link to the new contact information. The date

\footnotetext{
${ }^{454}$ See, e.g., Stanford Report, supra n. 4, at 15-19 (describing the orphan works problem as a symptom of insufficient copyright ownership information).

${ }^{455}$ See Which Form Should I Use?, http://www.copyright.gov/help/faq/faq-forms.html (last visited July 28, 2014).

${ }^{456} \mathrm{See}$ http://www.copyright.gov/docs/fees.html (last visited July 28, 2014).

${ }^{457}$ See id.
} 
of each amendment should be preserved, as should the old information, both to aid in determining what contact information was publicly available as of a given date, and to deter abuses of the ability to amend contact information. ${ }^{458}$ Because that information greatly assists the market for interests in copyright, and because it helps the Copyright Office maintain its role as a key information provider in that market, the fee for entering a change of address should be nominal, or zero. One commenter suggested the creation of a similar database of author contact information that would draw upon, and link to and from, the Library of Congress Name Authority File. $^{459}$

Obviously, there are risks of fraud; criminals may try to submit false contact information and then accept licensing fees or assignment payments for works that they do not own. However, they would have to create or gain access to password-protected eCO accounts in order to do so, and there are also standard techniques available to combat such fraud, such as sending a notice that contact information has been changed to the old postal and e-mail addresses, and telling the recipients to contact the Copyright Office if they believe that the change was made in error. A low-cost or free mechanism for updating contact and rights and permissions information would both increase the availability of current information of those crucial types, and increase the use and popularity of eCO accounts.

\section{Conclusion.}

Document recordation at the Copyright Office has not kept pace with business practices, nor has it kept pace with advances in technology that could make the recording process more efficient and less costly, while at the same helping to build a better document repository and catalog. Implementing an electronic recordation system that operates on the principle of guided remitter responsibility would represent a giant step forward in copyright document recordation. Such a system has the promise of substantially lowering costs, which in turn would result in lower fees and more documents remitted for recordation. Those documents could be made much more conveniently available to the public on the Internet. The catalog of documents could also be better developed and made available in a way that would promote third-party development of services that build on the information it provides. Though many of the steps proposed in this report are incremental, their combined impact could dramatically improve the availability of information about works under copyright, and thus better facilitate the use of and a market in those works.

\footnotetext{
${ }^{458}$ For recommendations concerning change $\log$ s or audit trails more generally, see supra p. 116.

459 See NOI Comments of Science Fiction and Fantasy Writers of America, Inc., pp. 2-4. For the Name Authority File, see http://id.loc.gov/authorities/names.html (last visited August 13, 2014).
} 


\section{Appendix: An Overview of the Proposed Recordation Process}

This report includes many recommendations about how an electronic recordation system might be structured, including recommended language for certifications and other mechanisms that occur at various points in the recordation process. However, the report is not arranged in the same order as the sequence of the proposed process, and it therefore can be difficult to envision exactly what the proposed process would look like when all of the separate elements are combined. This Appendix presents an outline that views the proposed recordation process from a step-by-step perspective, incorporating the report's recommendations.

1. Account Creation: The remitter creates a recordation account, and the Office potentially verifies some information to check the remitter's identity. The remitter creates a username, password, and "challenge question" for her account. ${ }^{460}$

2. Account Sign-In: The remitter must be signed into her account to remit documents and complete certifications. ${ }^{461}$

3. Cataloging Information: The remitter provides cataloging information by filling out an online form and going through the guided remitter process. During this time, she is cautioned that all cataloging information that she provides must be found in the document; she cannot use the "electronic cover sheet" to add details that are missing from the remitted document. ${ }^{462}$

4. Signing Certifications: The remitter begins to complete a series of certifications. To sign the certifications, the remitter checks a box next to the text of the certification, and then types her name. ${ }^{463}$

5. "True Copy" Certification: The remitter completes a certification that her document is a "true copy" (under the current statutory language) because the document lacks an "actual signature."

a. Proposed language for certification: "I swear, under penalty of perjury, that to the best of my knowledge, the document that I am transmitting to the Copyright Office has not been edited or altered in any way since it has been signed." 464

\footnotetext{
${ }^{460}$ For in-depth discussion of this particular proposal, see p. 70, supra.

461 See p. 71, supra.

${ }^{462}$ See p. 89, supra.

${ }^{463}$ See p. 71, supra.

${ }^{464}$ See p. 68, supra.
} 
6. "Perjury" Certification: The remitter certifies that she is not making any false statements or including any false signatures.

a. Proposed language for certification: "I hereby acknowledge that if I submit a document for recordation that I know contains any materially false statement or forged signatures, or if I knowingly submit false information about the document, I could be subject to federal criminal prosecution under 18 U.S.C. $§ 1001 . " 465$

7. Uploading the Document and the "Eligibility" Certification: The remitter uploads the document file to the Copyright Office server. The document is displayed in the remitter's browser window and the remitter has opportunity to review it. She is then asked to sign a certification that it meets the eligibility requirements.

a. Proposed language for certification: "I hereby state that I have had an opportunity to review this document as it has been uploaded to the Copyright Office, and that it meets the following requirements:

- All text in the document is clearly legible.

- The document is complete; it is not missing any appendices or schedules mentioned in the text, and if it is redacted, the redactions are only of the types allowed and are initialed.

- The document is signed, and the signatures are identifiable as such.

- The document actually or potentially concerns or affects an interest in one or more copyrighted works." 466

8. "Redaction" Certification: During eligibility certification, the remitter is asked to check a box if the document is redacted. If remitter checks yes, she is taken to another screen that details redaction requirements and is asked to certify that those requirements are met. Completing this certification will return the remitter to the eligibility certification screen. ${ }^{467}$

9. Review Screen: After the certifications are completed, remitter is presented with a review screen, including all of the cataloging information she has supplied, as well as a copy of the document that she has uploaded. ${ }^{468}$

\footnotetext{
${ }^{465}$ See p. 68, supra.

${ }^{466}$ See p. 86, supra.

${ }^{467}$ See p. 86, supra. For a discussion of the considerations involved in crafting policy with regard to redaction, see $\mathrm{p}$. 76, supra.

${ }^{468}$ See p. 90 , supra.
} 
10. Review Screen Email: The remitter is presented with the option of having the review screen contents sent to her by email. This allows the remitter to circulate the review screen contents to other parties and double-check the entries before final submission. ${ }^{469}$

11. Final Submission, Payment and Receipt Confirmation: Once the remitter is ready to make final submission of the document and the accompanying information, the website presents the remitter with an amount due, calculated according to the current fee schedule, taking into account the number of titles and/or registration numbers that the remitter represented were referenced by the remitted document. The website guides the remitter to payment choices, including payment from a deposit account and payment via credit card. The remitter chooses a payment option, enters any necessary payment information, and clicks "submit and pay." Once the payment is approved, the document and cataloging information are placed in queue, ready for processing and addition to repository and catalog. The remitter is sent an email to confirm that the document, cataloging information, and payment have been received. ${ }^{470}$

12. Certificate of Recordation and Recorded Document: Once the Copyright Office has processed a remitted document, it sends to the remitter a copy of the remitted document, labeled on each page with the recorded document number and the page number, and a recordation certificate, in electronic form - probably as Portable Document Format files attached to an e-mail. ${ }^{471}$

a. Link to Office Record: Preferably within the same email, the Copyright Office sends the remitter a link to the Copyright Office record as it is available online, and recommends that the remitter check to see that the record, and all connected records regarding works specifically referenced in the document, are accurate. If the Copyright Office workflow makes it challenging to send this link in the same email as the certificate, it could be sent in a separate e-mail. ${ }^{472}$

13. Requesting Corrections: Even after final submission, the remitter has the ability to request correction of any errors that she made which resulted in catalog entries that did not reflect the contents of the recorded document, perhaps using on online form for this purpose. $^{473}$

\footnotetext{
${ }^{469}$ See p. 90 , supra.

${ }^{470}$ See p. 24, supra. The remitter may be directed to an external website, such as pay.gov, to make certain forms of payment, and that website may send additional communications to the remitter.

${ }_{471}^{4}$ See p. 107, supra.

${ }^{472}$ See p. 100, supra.

${ }^{473}$ See p. 90, supra.
} 
14. Updating Contact Information. At any time, the remitter could update contact information with respect to an existing document record through her user account. The old contact information would be preserved, and the date and time of the change would be noted. ${ }^{474}$

${ }^{474}$ See p. 126, supra. 
